RAFAEL MIKIO NAKANISHI

\title{
COMPARAÇÃO DE DADOS EXPERIMENTAIS E DE SIMULAÇÃO NUMÉRICA DE SINAIS DE ULTRASSOM.
}

São Paulo 


\section{COMPARAÇÃO DE DADOS EXPERIMENTAIS E DE SIMULAÇÃO NUMÉRICA DE SINAIS DE ULTRASSOM.}

Dissertação apresentada à Escola Politécnica da Universidade de São Paulo para obtenção do título de Mestre em Ciências

São Paulo 


\title{
COMPARAÇÃO DE DADOS EXPERIMENTAIS E DE SIMULAÇÃO NUMÉRICA DE SINAIS DE ULTRASSOM.
}

\author{
Dissertação apresentada à Escola Politéc- \\ nica da Universidade de São Paulo para ob- \\ tenção do título de Mestre em Ciências \\ Área de Concentração: Engenharia \\ Mecânica \\ Orientador: Prof. Dr. Raúl González Lima
}


Autorizo a reprodução e divulgação total ou parcial deste trabalho, por qualquer meio convencional ou eletrônico, para fins de estudo e pesquisa, desde que citada a fonte.

Este exemplar foi revisado e corrigido em relação à versão original, sob responsabilidade única do autor e com a anuência de seu orientador.

São Paulo, de de

Assinatura do autor:

Assinatura do orientador:

\section{Catalogação-na-publicação}

\section{Nakanishi, Rafael Mikio}

Comparação de dados experimentais e de simulação numérica de sinais de ultrassom / R. M. Nakanishi -- versão corr. -- São Paulo, 2019.

$101 \mathrm{p}$.

Dissertação (Mestrado) - Escola Politécnica da Universidade de São Paulo. Departamento de Engenharia Mecânica.

1.Tomografia por ultrassom 2.Transdutores de ultrassom 3.Método dos elementos finitos I.Universidade de São Paulo. Escola Politécnica.

Departamento de Engenharia Mecânica II.t. 


\section{Agradecimentos}

Primeiramente, agradeço ao meu orientador Raúl González Lima pelos seus valiosos ensinamentos e sua inspiradora dedicação como professor.

Agradeço à Carolina Eimi Kajiyama pelo amor, suporte e incentivo que sempre foi dado quando eu necessitei. Também agradeço à minha família pelo apoio, carinho e compreensão durante esta jornada.

Agradeço aos colegas do Laboratório de Engenharia Ambiental e Biomédica (LAB) pelo companheirismo. Um obrigado especial ao Talles Batista Rattis Santos que me ajudou na solução dos mais diversos problemas.

Agradeço ao Laboratório de Ultrassom da Escola Politécnica pelo auxílio no desenvolvimento desde trabalho, em especial ao professor Pai Chi Nan e seus alunos José Hilton Nascimento Neto e Nilton Barbosa da Rosa Júnior.

Por fim, agradeço ao Conselho Nacional de Desenvolvimento Científico e Tecnológico $(\mathrm{CNPq})$ pelo apoio financeiro deste trabalho. 


\section{Resumo}

Tomografia por ultrassom é uma técnica de imageamento onde uma propriedade do domínio (como velocidade de propagação do som) é estimada a partir da excitação e medição de sinais de ultrassom (como pressão acústica) na fronteira do domínio. Uma atual aplicação médica desta técnica é a detecção de câncer de mama, e uma futura aplicação é o monitoramento da atividade pulmonar em tempo real. Neste trabalho foram projetados, fabricados e testados transdutores de ultrassom de cerâmica monoelemento de frequências de $500 \mathrm{kHz}$ e $150 \mathrm{kHz}$ e foi utilizado o método de elementos finitos para solução da equação de propagação da onda acústica no tempo. Os dados experimentais foram coletados e comparados com a resposta obtida pela etapa computacional. O erro máximo encontrado da diferença entre os resultados experimentais e numéricos no eixo central foi de aproximadamente $6 \%$.

Palavras-chave: Tomografia por Ultrassom, Transdutores, Método dos Elementos Finitos. 


\begin{abstract}
Ultrasound tomography is an imaging technique where a material property of the domain (as propagation speed of sound) is estimated from the excitation and measurement of ultrasound signals (such as acoustic pressure) on the boundary of the domain. A current medical application of this technique is the detection of breast cancer, and one future application is the monitoring of lung activity in real time. In this work monoelement ceramic ultrasonic transducers were designed, built and tested for frequencies of $500 \mathrm{kHz}$ and $150 \mathrm{kHz}$ and the finite element method was used to solve the acoustic wave equation in the time domain. The experimental data were collected and compared to the numerical results. The maximum error of the difference between experimental and numerical results on the central axis was approximately $6 \%$.
\end{abstract}

keywords: Ultrasound Tomography, Transducers, Finite Element Method. 


\section{Sumário}

1 Introdução 9

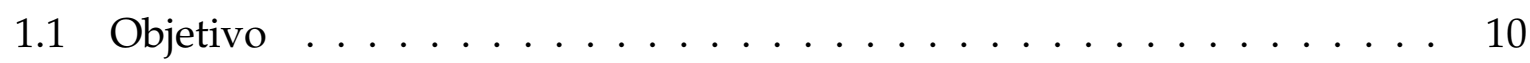

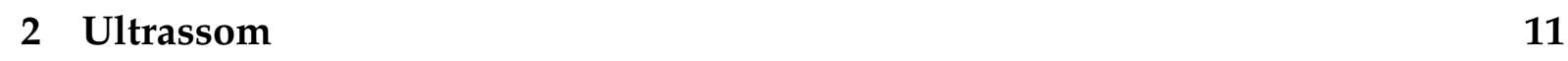

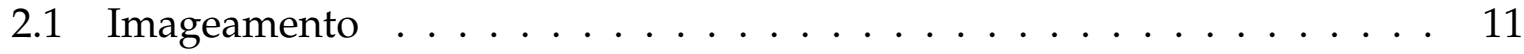

2.2 Transdutores de ultrassom . . . . . . . . . . . . . . . . . . . . . . 12

2.2 .1 Fabricação dos transdutores . . . . . . . . . . . . . . . 13

2.3 Modelo computacional . . . . . . . . . . . . . . . . . 14

2.4 Otimização do custo computacional . . . . . . . . . . . . . . 14

$\begin{array}{lll}3 & \text { Metodologia } & 16\end{array}$

3.1 Ensaio experimental $\ldots \ldots \ldots \ldots \ldots \ldots$

3.1.1 Fabricação dos transdutores . . . . . . . . . . . . . . . 16

3.1 .2 Testes experimentais . . . . . . . . . . . . . . . . 18

3.2 Modelo computacional . . . . . . . . . . . . . . . . . . 21

3.2.1 Equação de propagação da onda . . . . . . . . . . . . . 22

3.2.2 Método dos Elementos Finitos . . . . . . . . . . . . . 22

3.2 .3 Integrador numérico de diferenças centrais . . . . . . . . . . . 27

3.2 .4 Método de truncamento modal . . . . . . . . . . . . . . . . 28

3.2 .5 Testes computacionais . . . . . . . . . . . . . . . . . 29

3.3 Comparação . . . . . . . . . . . . . . . . . . . . . . 31

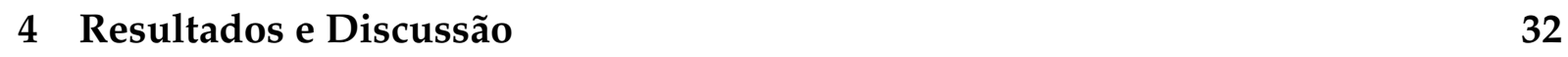

4.1 Testes dos transdutores . . . . . . . . . . . . . . . . . . . . 32

4.2 Teste do modelo computacional . . . . . . . . . . . . . . . . . 48

4.3 Comparação . . . . . . . . . . . . . . . . . . . . . . . 90 
\begin{tabular}{lll}
5 Conclusões & 93 \\
\hline
\end{tabular}

5.1 Próximos Passos . . . . . . . . . . . . . . . . . . . . . . . . . 94

\begin{tabular}{ll}
\hline A Rotina ARPACK & 95
\end{tabular}

\begin{tabular}{ll}
\hline Referências Bibliográficas & 99
\end{tabular} 


\section{Capítulo 1}

\section{Introdução}

Ultrassom é definido como uma onda mecânica cuja frequência é superior à máxima frequência audível em seres humanos (aproximadamente $20 \mathrm{kHz}$ ) e possui diversas aplicações na indústria e na medicina. Uma das aplicações mais recentes do uso do ultrassom na medicina é a tomografia por ultrassom [1]. Nesta aplicação é gerada uma imagem da seção transversal de um domínio de interesse a partir da excitação e da coleta de sinais de ultrassom por meio de sua fronteira.

Para excitação e medição de ondas de ultrassom utilizam-se transdutores. Estes dispositivos convertem energia elétrica em vibração mecânica e vice-versa, sendo utilizados tanto como atuadores quanto como sensores [2].

O ultrassom segue a equação da onda, onde a solução desta equação diferencial parcial pode ser calculada a partir do método dos elementos finitos. Neste método, o domínio é subdividido em elementos cuja a solução analítica é conhecida [3]. Conhecendo as propriedades do meio e as condições de contorno, é possível calcular a distribuição da pressão no interior do domínio.

Assim como a Tomografia de Impedância Elétrica [4], a tomografia por ultrassom é um problema inverso, não linear e mal-posto. Segundo Kaipio e Somersalo [5], problemas mal-postos são sensíveis à erros de modelagem, afetando significativamente a qualidade da imagem estimada. Ambas as técnicas são consideradas de baixo custo, possuem alta resolução temporal, não utilizam radiação ionizante e são portáteis. 


\subsection{Objetivo}

O objetivo deste trabalho é comparar dados experimentais de ultrassom com dados de simulação numérica obtidos pelo modelo de elementos finitos. Neste trabalho são desenvolvidos e testados transdutores de ultrassom para a parte experimental, e implementada a solução da equação de propagação de ondas acústicas utilizando o método dos elementos finitos. 


\section{Capítulo 2}

\section{Ultrassom}

Ultrassom é uma onda mecânica cuja frequência é superior a $20 \mathrm{kHz}$ (máxima frequência audível do ser humano) e possui diversas aplicações médicas. Na área médica, geralmente o ultrassom é utilizado para imageamento, entretanto existem algumas aplicações onde o ultrassom é usado no tratamento de patologias [6]. Devivo à sua alta resolução temporal, esta técnica poderia ser utilizada para monitoramento do sistema cardiopulmonar em tempo real.

\subsection{Imageamento}

Em aplicações clínicas, existem diferentes modalidades de imageamento utilizando ultrassom. Os modos mais comuns são modo $\mathrm{A}$, modo $\mathrm{B}$, modo $\mathrm{M}$ e doppler. O modo A (Amplitude) é o gráfico unidimensional da amplitude do sinal de reflexão da onda de ultrassom em função do tempo, enquanto o modo B (Brilho) é, basicamente, um conjunto bidimensional de gráficos de modo A. Já o modo $\mathrm{M}$ (Movimento), é formado pelo modo A em função do tempo, permitindo observar dinamicamente uma região unidimensional. Por fim, com o uso do efeito doppler em ultrassom é possível verificar o sentido e a velocidade de um fluxo devido à diferença na frequência observada 1 .

Um problema enfrentado no uso clínico do ultrassom está relacionado à dificuldade de penetração do ultrassom no corpo humano. Regiões ósseas (em especial o crânio) e pulmonares dificultam a propagação da onda de ultrassom e, consequentemente, diminuem a qualidade da imagem. Outra limitação é o possível baixo contraste

\footnotetext{
${ }^{1}$ Um descrição mais detalhada de cada um dos modos e suas aplicações clínicas pode ser encontrada em [7]
} 
na imagem, uma vez que tecidos moles podem apresentar pequenas diferenças de impedância acústica ${ }^{2}$.

Um outra forma de obter imagens utilizando sinais de ultrassom é através da tomografia por ultrassom. Nesta modalidade, um conjunto de vários transdutores é colocado ao redor do domínio de interesse. Um transdutor excita o domínio enquanto os outros medem a resposta do sistema, e então repete-se o processo para cada transdutor. Com este conjunto de dados, estima-se o mapa da distribuição de uma propriedade de interesse do meio. Atualmente esta técnica pode ser utilizada para detecção de câncer de mama [1], e uma possível aplicação seria o monitoramento em tempo real da função cardiopulmonar.

\subsection{Transdutores de ultrassom}

Transdutores de ultrassom são dispositivos que convertem energia elétrica em vibração mecânica e vice-versa. Existem diversas tecnologias para construção de transdutores, como transdutores capacitivos [9], indutivos [10] ou que utilizam cerâmicas piezoelétricas, sendo este último o mais comum.

Os transdutores de cerâmica piezoelétrica podem ser do tipo array ou monoelemento [2]. Transdutores monoelemento são aqueles que possuem apenas uma cerâmica piezoelétrica enquanto os transdutores do tipo array são aqueles que possuem uma fileira de cerâmicas piezoelétricas que podem ser excitadas independentemente, possibilitando efeitos como mudança da direção e/ou focalização do eixo acústico. Outro tipo de contrução de transdutor é o tipo Tonpilz [11], geralmente utilizado para aplicações de alta potência.

Os transdutores de baixa potência geralmente são utilizados para imageamento e podem tanto emitir quanto receber ondas acústicas, enquanto transdutores de alta potência têm como aplicações destruição de pedras nos rins e a desnaturação de proteínas por meio de aquecimento [6]. Geralmente a frequência de excitação/medição destes transdutores está na faixa dos $\mathrm{MHz}$, no entanto, para aplicações cardiopulmonares, frequências na ordem de centenas de $\mathrm{kHz}$ podem ser utilizadas. Como a atenuação da onda acústica está relacionada com a frequência, a utilização de frequências menores

\footnotetext{
${ }^{2}$ Impedância acústica específica $(Z)$ é uma propriedade de um determinado meio definido por $Z=$ $\rho c$, onde $\rho$ e $c$ são a densidade e a velocidade de propagação do som no meio respectivamente [8]
} 
pode ser necessária para que o sinal atravesse o domínio.

\subsubsection{Fabricação dos transdutores}

A figura 2.1 mostra o modelo típico da estrutura de um transdutor monoelemento utilizando material piezoelétrico. $\mathrm{O}$ transdutor geralmente é composto por uma cerâmica piezoelétrica reponsável pela vibração do sistema. Atrás da cerâmica existe uma camada de retaguarda (backing) e entre a cerâmica e o domínio existe uma camada de compatibilização acústica (matching).

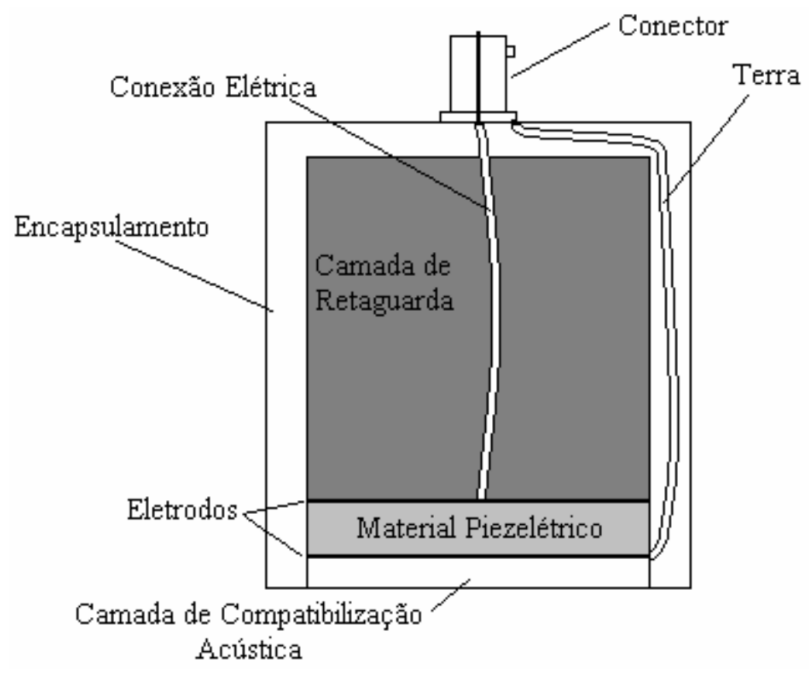

Figura 2.1: Modelo típico da estrutura de um transdutor de ultrassom monoelemento, extraído de [12].

O material cerâmico piezoelétrico, quando excitado, gera duas frentes de onda em sentidos opostos. Uma destas penetra no meio, enquanto a outra avança em sentido contrário. O backing tem como objetivo o amortecimento da frente de onda cujo sentido é o oposto ao desejado, pois esta onda pode interferir no formato e amplitude do sinal aplicado no domínio. Para o backing procura-se utilizar uma camada com o mesmo valor de impedância acústica da cerâmica, para não ocorrer reflexão da onda. E o seu comprimento de ser suficiente para obter a atenuação desejada [13].

O matching tem como objetivo a máxima transmissão da onda de ultrassom da cerâmica para o meio [14]. Para isto, o seu valor de impedância acústica $\left(Z_{\text {match }}\right)$ é calculado por $Z_{\text {match }}=\sqrt{Z_{\text {cer }} Z_{\text {meio }}}$, onde $Z_{\text {cer }}$ e $Z_{\text {meio }}$ são as impedâncias acústicas da cerâmica 
e do meio, respectivamente. A espessura da camada no material de matching deve ser igual a um quarto do comprimento de onda $(\lambda / 4)[8] .3$.

\subsection{Modelo computacional}

A partir do modelo fluídico elástico e da $2^{\mathrm{a}}$ Lei de Newton, é possível deduzir a equação de propagação da onda acústica [8]. Esta equação pode ser resolvida analiticamente para domínios simples. Para domínios mais complexos, soluções numéricas são adotadas como o método dos elementos finitos.

O método dos elementos finitos é um procedimento numérico utilizado para solução de equações diferenciais parciais [3]. Este método é utilizado quando a solução analítica não é trivial. Através do método dos elementos finitos, o sistema de interesse é discretizado em pequenas partes, onde a solução analítica é conhecida. Recombinando todos os elementos é possível encontrar a solução global do sistema.

Quando a excitação é contínua, esta equação pode ser resolvida no domínio da frequência. Esta forma simplificada é a equação de Helmholtz [15]. Além disso, é possível resolver o problema no domínio do tempo, utilizando um método de integração temporal, como o método de diferenças centrais [16].

Por fim, o método dos elementos finitos também possibilita simular formas de excitação mais complexas. Podem ser simulados os efeitos de um transdutor em array ou os modos de vibrar de um transdutor Tonpilz (como mostrado em [11, Fig. 2]). Isto é obtido modificando-se geometria, forma de onda e/ou início da excitação na superfície modelada do transdutor.

\subsection{Otimização do custo computacional}

Como o passo de simulação numérica é necessário para tomografia por ultrassom, é desejado que o método seja computacionalmente eficiente e com baixo consumo de memória $R A M$. Um forma de reduzir o custo computacional é a diminuição da malha de elementos finitos. Esta diminuição pode ser obtida a partir do uso de elementos

\footnotetext{
${ }^{3} \mathrm{O}$ valor do comprimento de onda pode ser calculado a partir de $c=\lambda f$, onde $c$ é a velocidade do som do meio e $f$ é a frequência da onda [8]
} 
infinitos, imposição de condições de contorno analíticas, uso de uma camada de atenuação ( Perfectly Matching Layer), entre outros [15].

O Perfectly Matching Layer (PML) é uma técnica onde o domínio considerado é reduzido para uma região de interesse, com uma camada atenuadora em sua volta, simulando um grande domínio sem reflexões [17]. Existe um compromisso no valor de atenuação desta camada, pois se o valor for muito baixo a onda não é completamente atenuada, mas se o valor for muito alto, ocorre reflexão da onda e interfere na resposta da região de interesse.

Outro tipo de redução da dimensão do problema que pode ser utilizado é o método de truncamento modal [18]. Neste método, são calculados os modos de vibrar mais importantes do sistema e feita uma superposição modal. Os termos menos importantes são desprezados, e assim, a dimensão do sistema diminui. 


\section{Capítulo 3}

\section{Metodologia}

Este trabalho abordou o problema em duas partes. A primeira está relacionada com os ensaios experimentais realizados, na qual transdutores de ultrassom foram fabricados e testados. Enquanto a segunda parte está relacionada ao desenvolvimento do modelo computacional, onde a equação de propagação de onda foi simulada a partir da modelagem do problema através do método dos elementos finitos. Por fim, os resultados foram comparados.

\subsection{Ensaio experimental}

O ensaio experimental tem como objetivo coletar dados de pressão de ondas de ultrassom. Nesta etapa foram desenvolvidos os transdutores e realizados os testes experimentais.

\subsubsection{Fabricação dos transdutores}

Para este ensaio, os transdutores fabricados foram do tipo monoelemento cerâmico. A fabricação foi necessária devido à dificuldade de encontrar transdutores comerciais na faixa de frequência desejada e ao seu elevado custo. A frequência escolhida para a fabricação dos primeiros transdutores foi de $500 \mathrm{kHz}$. Este valor foi escolhido para avaliação do processo de fabricação por meio da comparação com transdutores de referência.

Para maior penetração da onda em tecido pulmonar, frequências menores são desejadas pois possuem menor atenuação. Após a avaliação do processo de fabricação 
dos transdutores de $500 \mathrm{kHz}$, transdutores com frequência de $150 \mathrm{kHz}$ foram fabricados pelo Laboratório de Ultrassom da Escola Politécnica da Univerdade de São Paulo. A fabricação do transdutor de $500 \mathrm{kHz}$ seguiu a construção de um transdutor cerâmico monoelemento típico, como mostrado na figura 2.1 .

Para a fabricação do backing foi utilizada uma mistura de resina epóxi com tungstênio. A proporção de tungstênio e sua atenuação foram retirados de [13] (figura 3.1). Salienta-se que a resina e a frequência do transdutor escolhidos para este trabalho diferem de [13], entretanto estes valores foram utilizados como uma estimativa inicial.

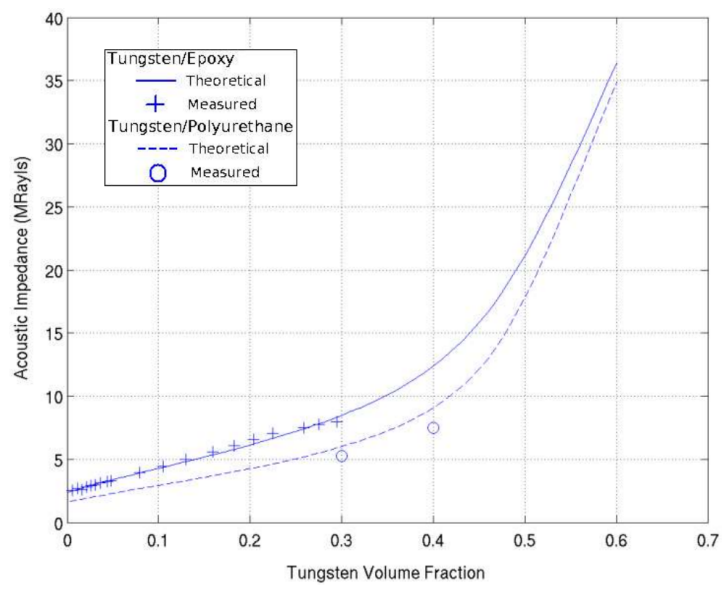

(a) Impedância acústica da mistura

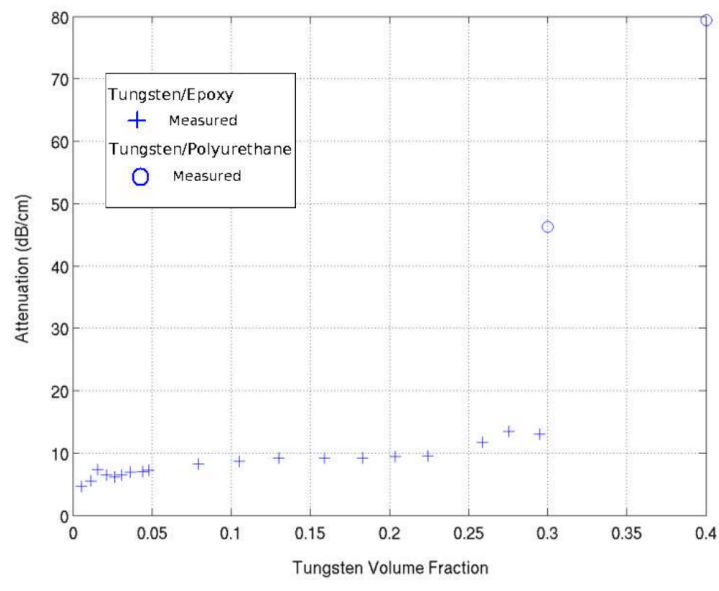

(b) Atenuação da mistura

Figura 3.1: Propriedades acústicas da mistura de resina epóxi e tungstênio (extraído de [13]).

O backing projetado deve possuir impedância acústica de 23 MRayls (mesmo valor da cerâmica), que corresponde a um valor de fração de volume de tungstênio de aproximadamente $50 \%$ (figura 3.1(a) . Com base nesta fração de volume, e extrapolando o gráfico apresentado em 3.1(b), a atenuação da mistura é considerada $10 \mathrm{~dB} / \mathrm{cm}$. Para uma atenuação de onda de $60 \mathrm{~dB}$, é necessário um comprimento de backing de $6 \mathrm{~cm}$. Considerando que o caminho percorrido na propagação e após a reflexão é igual, o comprimento escolhido é de $3 \mathrm{~cm}$.

O matching foi feito utilizando uma mistura de resina epóxi com alumina. Os valores de impedância acústica e velocidade do som da mistura são apresentados nos gráficos da figura 3.2, extraídos de [19]. Da mesma forma que o backing, estes valores foram obtidos para outra resina e outra frequência, mas podem ser utilizados como estimativa inicial. 

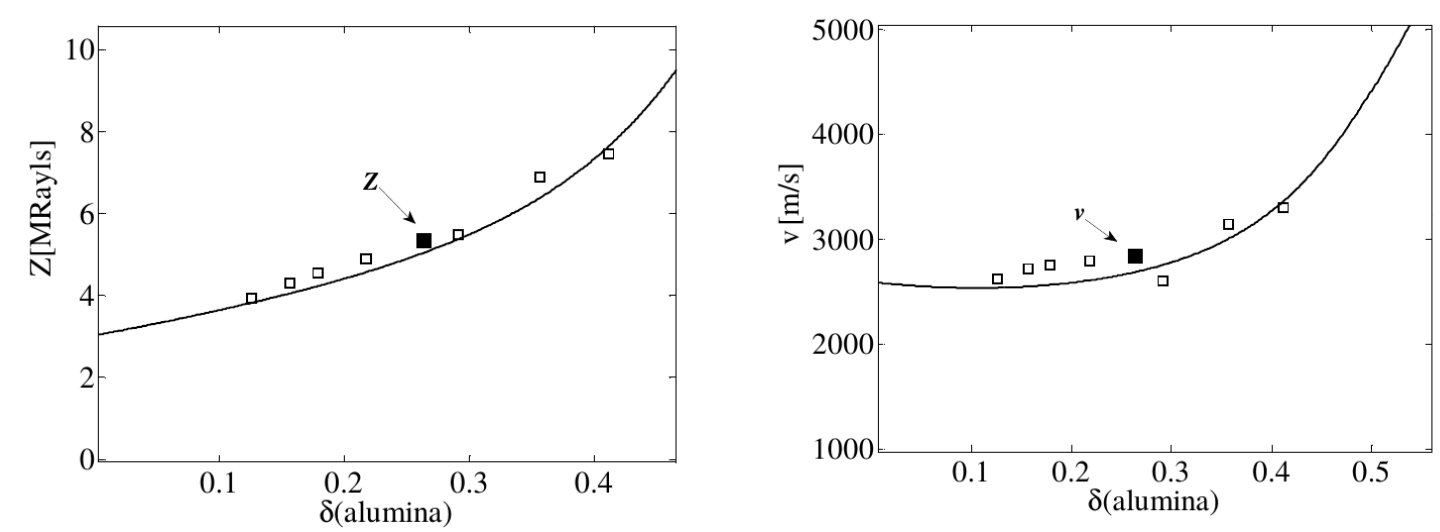

(a) Impedância acústica da mistura por fração de (b) Velocidade do som da mistura por fração de volume de alumina $(\delta)$ volume de alumina $(\delta)$

Figura 3.2: Propriedades acústicas da mistura de resina epóxi e alumina, adaptado de [19].

Considerando que o meio de interesse possui impedância acústica próxima da água (1,5 MRayls), a impedância acústica do matching deverá ser $Z_{\text {match }}=\sqrt{23 \times 1,5} \approx 5,8$ MRayls. Utilizando o grafico da figura 3.2, a fração de volume de alumina deve ser de aproximadamente 30\%, para o valor de impedância acústica calculada. Para este valor de fração de volume, a velocidade do som na camada é de, aproximadamente, $2800 \mathrm{~m} / \mathrm{s}$. Portanto, a espessura do matching é de $\lambda / 4=c /(4 \times f)=2800 /(4 \times 500000)=$ $0,0014 m=1,4 m m$.

Para o encapsulamento foi desenvolvido um modelo para impressão 3D. Este modelo é mostrado na figura 3.3 . O encapsulamento foi projetado de modo que a espessura do backing e do matching fossem respeitadas. Para os testes experimentais devem ser fabricados dois transdutores similares utilizando os parâmetros apresentados.

$\mathrm{O}$ transdutor de referência de $500 \mathrm{kHz}$ e os transdutores de $150 \mathrm{kHz}$ utilizados neste trabalho foram projetados, contruídos e cedidos pelo Laboratório de Ultrassom da Escola Politécnica da Univerdade de São Paulo.

\subsubsection{Testes experimentais}

Para os testes experimentais foi utilizada uma bancada cujo esquema pode ser visto na figura 3.4 . Esta bancada possui uma cuba retangular preenchida com água onde os transdutores serão submersos. Os transdutores foram conectados a um pulsador/re- 


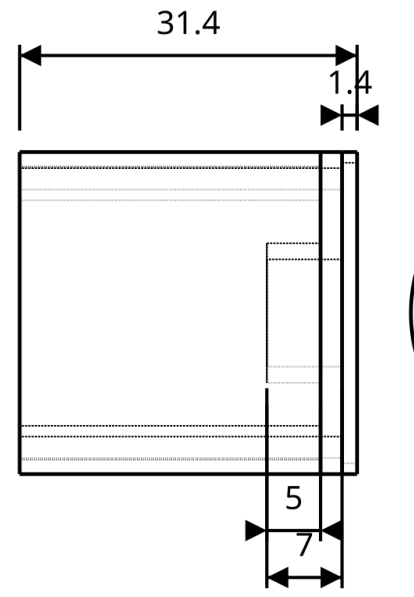

(a) Vista lateral

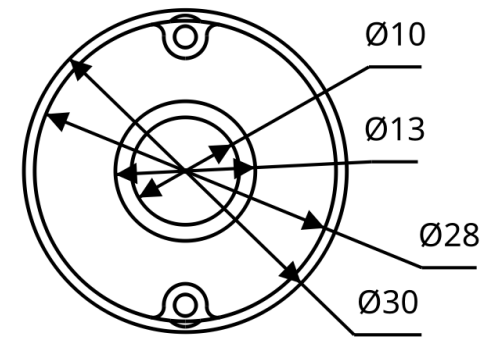

(b) Vista superior

Figura 3.3: Desenho do encapsulamento do transdutor de $500 \mathrm{kHz}$ (medidas em $\mathrm{mm}$ ). Fonte: autor.

ceptor "Panametrics Model 5077PR' ${ }^{1}$. Os sinais recebidos foram transmitidos para um osciloscópio ${ }^{1]}$ (cuja frequência de amostragem está na faixa dos $\mathrm{GHz}$ ) e foram coletados para processamento posterior.

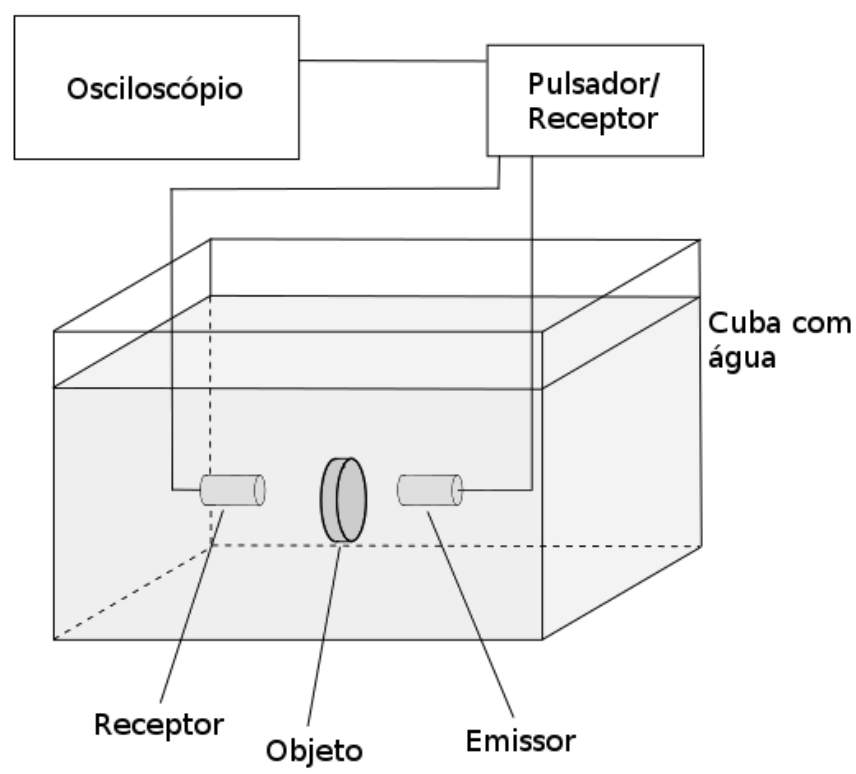

Figura 3.4: Esquema da bancada experimental utilizada. Fonte: autor.

Este pulsador/receptor aciona o transdutor com um pulso de tensão quadrado em

\footnotetext{
${ }^{1}$ Equipamento cedido pelo Laboratório de Ultrassom da Escola Politécnica da Univerdade de São Paulo.
} 
uma frequência suficientemente baixa para o sistema estabilizar entre dois pulsos consecutivos. A largura deste pulso é ajustada conforme a frequência do transdutor [20]. Além disso, é possível ajustar o valor da amplitude deste pulso que aciona o transdutor (100V, 200V, 300V ou 400V). Como receptor, este equipamento possui um filtro passa-banda que é ajustado para a faixa de $1 \mathrm{kHz}$ até $10 \mathrm{MHz}$.

A distância entre os transdutores foi controlada através de um sistema de movimentação por motores de passo. Desta forma a variação de distância possui melhor precisão e repetibilidade, quando comparada ao posicionamento manual.

O primeiro teste realizado foi a compararação da onda emitida pelo transdutor de $500 \mathrm{kHz}$ fabricado com a resposta do transdutor de referência. Os transdutores foram colocados na mesma posição para emitir a onda e um hidrofone ${ }^{2}$ foi utilizado como receptor. O objeto não foi utilizado neste teste. Tanto os valores de amplitude quanto de frequência foram analisados.

São propostos testes que verificam a velocidade de propagação da onda tanto no meio (água) quanto no objeto inserido (latão). Uma vez que estas propriedades são conhecidas, os valores estimados através dos transdutores podem ser avaliados. Neste teste ambos transdutores fabricados foram utilizados para emitir e receber os dados. Inicialmente foi calculada a velocidade do som da água $\left(c_{\text {água }}\right)$. Este cálculo foi feito utilizando a seguinte equação:

$$
c_{\text {água }}=\frac{\Delta x}{\Delta t},
$$

onde $\Delta x$ é a variação de distância entre duas posições de coleta de dados e $\Delta t$ é a variação no tempo de trajeto da onda. Utilizou-se a variação da distância pois uma variação controlada pelo sistema de movimentação é mais precisa do que uma posição absoluta.

Em seguida, o objeto é inserido entre os transdutores e sua velocidade do som $\left(c_{o b j}\right)$ foi calculada. Neste teste foram feitas duas aquisições de dados. Primeiramente, foi fixada uma distância entre os transdutores $\left(d_{a ́ g u a}\right)$ e o tempo de propagação da onda é coletado sem o objeto $\left(t_{\text {água }}\right)$. Esta distância foi calculada utilizando a relação $d_{\text {água }}=$ $c_{\text {água }} . t_{\text {água }}$ uma vez que a velocidade do som na água já foi previamente calculada.

\footnotetext{
${ }^{2} \mathrm{O}$ hidrofone foi projetado, contruído e cedido pelo Laboratório de Ultrassom da Escola Politécnica da Univerdade de São Paulo.
} 
Em seguida o objeto foi colocado entre os trasdutores sem alterar a distância entre eles e o novo tempo de propagação é coletado $\left(t_{\text {prop }}\right)$. O cálculo da velocidade do som no objeto foi dada pela seguinte equação:

$$
c_{o b j}=\frac{d_{o b j}}{t_{\text {prop }}-\frac{d_{\text {agua }}-d_{o b j}}{c_{\text {agua }}}},
$$

onde $d_{o b j}$ é a espessura conhecida do objeto.

Por fim foi feita uma varredura do valor de pressão no eixo que passa pelo centro do transdutor (eixo acústico). No início do teste os dois transdutores são posicionados com as faces (que contém o matching) em contato e, utilizando os motores de passo, são deslocados em $1 \mathrm{~cm}$ até existir uma distância de $15 \mathrm{~cm}$ entre eles. $O$ sinal da pressão ao longo do tempo é adquirido para cada distância. Neste teste são realizadas três coletas de dados, duas onde cada um dos trasdutores fabricados emite e o transdutor de referência recebe e uma onde um transdutor fabricado emite e o outro fabricado recebe.

No caso dos transdutores de $150 \mathrm{kHz}$, como transdutores de referência para esta frequência não estavam disponíveis, foi feito apenas experimentos onde um dos transdutores fabricados emitia o sinal e o outro recebia a resposta. Foram feitos os experimentos para medição da velocidade do som e o teste de varredura (com deslocamentos de $0,5 \mathrm{~cm}$ ). O experimento utilizando o objeto de latão não foi realizado.

\subsection{Modelo computacional}

A física da propagação da onda de ultrassom pode ser descrita a partir da equação de onda e pode ser resolvida através do método dos elementos finitos. A resposta no tempo será obtida através de um integrador de diferenças centrais. Nesta seção são descritos o equacionamento do modelo utilizando o método dos elementos finitos, o integrador de diferenças centrais no tempo, a técnica de truncamento modal e os testes computacionais realizados. 


\subsubsection{Equação de propagação da onda}

A partir do modelo fluídico elástico e da $2^{\mathrm{a}}$ Lei de Newton, é possível deduzir a equação de propagação da onda [8]. Assumindo um meio líquido, sem atenuação e sem fontes externas, a equação da onda é descrita em 3.3 .

$$
\nabla^{2} p(x, t)=\frac{1}{c^{2}} \frac{\partial^{2} p(x, t)}{\partial t^{2}}
$$

onde $p(x, t)$ é a pressão do fluido descrito em todo o espaço e tempo, $c$ é a velocidade

do som do meio, o operador $\nabla^{2}$ é o laplaciano e $\frac{\partial^{2} p(x, t)}{\partial t^{2}}$ é a derivada segunda da pressão no tempo.

Existem diversos modelos de atenuação da onda acústica [8], mas é adotado o modelo proporcional à derivada da pressão. Adicionando-se a componente de atenuação e fonte externa, a equação pode ser reescrita como

$$
-\frac{1}{c^{2}} \frac{\partial^{2} p(x, t)}{\partial t^{2}}-\alpha \frac{\partial p(x, t)}{\partial t}+\nabla^{2} p(x, t)=-f(x, t)
$$

onde $\alpha$ é o coeficiente de atenuação no tempo (cuja unidade é $s / m^{2}$ ) e $f(x, t)$ é a fonte externa descrita em todo espaço e tempo.

\subsubsection{Método dos Elementos Finitos}

A partir da equação de onda com atenuação e fonte externa 3.4

$$
-\frac{1}{c^{2}} \frac{\partial^{2} p}{\partial t^{2}}-\alpha \frac{\partial p}{\partial t}+\nabla^{2} p=-f
$$

pode-se utilizar a formulação de resíduos ponderados para obter sua forma fraca [15]. Multiplicando a equação 3.4 por uma ponderação $\tilde{p}$ e integrando em todo o domínio $(V)$ é obtida a seguinte equação:

$$
\int_{V} \tilde{p}\left(-\frac{1}{c^{2}} \frac{\partial^{2} p}{\partial t^{2}}-\alpha \frac{\partial p}{\partial t}+\nabla^{2} p+f\right) d V=0 .
$$

Rearranjando-se os termos a equação 3.5 fica: 


$$
-\int_{V}\left(\frac{1}{c^{2}} \tilde{p} \frac{\partial^{2} p}{\partial t^{2}}\right) d V-\int_{V}\left(\alpha \tilde{p} \frac{\partial p}{\partial t}\right) d V+\int_{V}\left(\tilde{p} \nabla^{2} p\right) d V+\int_{V}(\tilde{p} f) d V=0
$$

Utilizando a regra do produto no terceiro termo da equação 3.6

$$
-\int_{V}\left(\frac{1}{c^{2}} \tilde{p} \frac{\partial^{2} p}{\partial t^{2}}\right) d V-\int_{V}\left(\alpha \tilde{p} \frac{\partial p}{\partial t}\right) d V+\int_{V}(\vec{\nabla} \cdot(\tilde{p} \vec{\nabla} p)) d V-\int_{V}(\vec{\nabla} \tilde{p} \vec{\nabla} p) d V+\int_{V}(\tilde{p} f) d V=0 .
$$

Aplicando o Teorema do Divergente no terceiro termo da equação 3.7 e rearranjando os termos:

$$
\int_{V}\left(\frac{1}{c^{2}} \tilde{p} \frac{\partial^{2} p}{\partial t^{2}}\right) d V+\int_{V}\left(\alpha \tilde{p} \frac{\partial p}{\partial t}\right) d V+\int_{V}(\vec{\nabla} \tilde{p} \vec{\nabla} p) d V=\int_{\Omega}\left(\tilde{p} \frac{\partial p}{\partial n}\right) d \Omega+\int_{V}(\tilde{p} f) d V
$$

onde $\Omega$ é a superfície do domínio $V$ e $n$ é o vetor normal desta superfície.

Neste trabalho, serão utilizados elementos tetraédricos, que são os mais simples para o caso tridimensional e garantem convergência para solução verdadeira [15]. Desta forma, a aproximação 3.9 é feita:

$$
p^{e}=a^{e}+b^{e} x+c^{e} y+d^{e} z=\left[\begin{array}{llll}
1 & x & y & z
\end{array}\right]\left[\begin{array}{l}
a^{e} \\
b^{e} \\
c^{e} \\
d^{e}
\end{array}\right]
$$

onde $p^{e}$ é a pressão interna no elemento $e$.

Os coeficientes $a^{e}, b^{e}, c^{e}$ e $d^{e}$ podem ser encontrados utilizando-se as coordenadas dos vértices do tetraedro e seus respectivos valores de potencial (pressão), como mostrado na equação 3.10 . 


$$
\begin{gathered}
{\left[\begin{array}{llll}
1 & x_{1} & y_{1} & z_{1} \\
1 & x_{2} & y_{2} & z_{2} \\
1 & x_{3} & y_{3} & z_{3} \\
1 & x_{4} & y_{4} & z_{4}
\end{array}\right]\left[\begin{array}{l}
a^{e} \\
b^{e} \\
c^{e} \\
d^{e}
\end{array}\right]=\left[\begin{array}{l}
p_{1}^{e} \\
p_{2}^{e} \\
p_{3}^{e} \\
p_{4}^{e}
\end{array}\right]} \\
{\left[\begin{array}{l}
a^{e} \\
b^{e} \\
c^{e} \\
d^{e}
\end{array}\right]=\left[\begin{array}{llll}
1 & x_{1} & y_{1} & z_{1} \\
1 & x_{2} & y_{2} & z_{2} \\
1 & x_{3} & y_{3} & z_{3} \\
1 & x_{4} & y_{4} & z_{4}
\end{array}\right]^{-1}\left[\begin{array}{l}
p_{1}^{e} \\
p_{2}^{e} \\
p_{3}^{e} \\
p_{4}^{e}
\end{array}\right],}
\end{gathered}
$$

onde $p_{k}^{e}$ é o potencial de cada vértice $k=1,2,3,4$ do tetraedro $e$ e $\left(x_{k}^{e}, y_{k}^{e}, z_{k}^{e}\right)$ é a coordenada de cada vértice $k$.

A matriz inversa da equação 3.10 pode ser escrita na forma 3.11 .

$$
\left[\begin{array}{cccc}
1 & x_{1} & y_{1} & z_{1} \\
1 & x_{2} & y_{2} & z_{2} \\
1 & x_{3} & y_{3} & z_{3} \\
1 & x_{4} & y_{4} & z_{4}
\end{array}\right]^{-1}=\left[\begin{array}{cccc}
\alpha_{1} & \alpha_{2} & \alpha_{3} & \alpha_{4} \\
\beta_{1} & \beta_{2} & \beta_{3} & \beta_{4} \\
\gamma_{1} & \gamma_{2} & \gamma_{3} & \gamma_{4} \\
\delta_{1} & \delta_{2} & \delta_{3} & \delta_{4}
\end{array}\right]
$$

Usando as equações 3.10 e 3.11 na equação 3.9 é obtida a equação 3.12

$$
p^{e}=\left[\begin{array}{llll}
1 & x & y & z
\end{array}\right]\left[\begin{array}{cccc}
\alpha_{1} & \alpha_{2} & \alpha_{3} & \alpha_{4} \\
\beta_{1} & \beta_{2} & \beta_{3} & \beta_{4} \\
\gamma_{1} & \gamma_{2} & \gamma_{3} & \gamma_{4} \\
\delta_{1} & \delta_{2} & \delta_{3} & \delta_{4}
\end{array}\right]\left[\begin{array}{c}
p_{1}^{e} \\
p_{2}^{e} \\
p_{3}^{e} \\
p_{4}^{e}
\end{array}\right] .
$$

Definindo as funções de forma $N_{k}$ a partir da relação 3.13 ;

$$
N_{k}=\alpha_{k}+\beta_{k} x+\gamma_{k} y+\delta_{k} z, \quad k=1,2,3,4
$$

a relação 3.12 pode ser reescrita como equação 3.14 


$$
p^{e}=\left[\begin{array}{llll}
N_{1} & N_{2} & N_{3} & N_{4}
\end{array}\right]\left[\begin{array}{c}
p_{1}^{e} \\
p_{2}^{e} \\
p_{3}^{e} \\
p_{4}^{e}
\end{array}\right]=N p_{\sim}^{e}
$$

onde $N$ é o vetor com as funções de forma e $p_{\sim}^{e}$ é o vetor com o valor da pressão nos nós do elemento $e$.

Como as funções de forma $N$ só dependem do espaço, as derivadas parciais em função do tempo podem ser escritas como mostram as equações $3.15 \mathrm{e} 3.16$

$$
\begin{gathered}
\frac{\partial p^{e}}{\partial t}=N \frac{\partial p^{e}}{\partial t}, \\
\frac{\partial^{2} p^{e}}{\partial t^{2}}=N \frac{\partial^{2} p_{\sim}^{e}}{\partial t^{2}} .
\end{gathered}
$$

O termo $\nabla p^{e}$ pode ser calculado como mostra a equação 3.17

$$
\nabla p^{e}=\left[\begin{array}{c}
\frac{\partial p^{e}}{\partial x} \\
\frac{\partial p^{e}}{\partial y} \\
\frac{\partial p^{e}}{\partial z}
\end{array}\right]=\left[\begin{array}{cccc}
\frac{\partial N_{1}}{\partial x} & \frac{\partial N_{2}}{\partial x} & \frac{\partial N_{3}}{\partial x} & \frac{\partial N_{4}}{\partial x} \\
\frac{\partial N_{1}}{\partial y} & \frac{\partial N_{2}}{\partial y} & \frac{\partial N_{3}}{\partial y} & \frac{\partial N_{4}}{\partial y} \\
\frac{\partial N_{1}}{\partial z} & \frac{\partial N_{2}}{\partial z} & \frac{\partial N_{3}}{\partial z} & \frac{\partial N_{4}}{\partial z}
\end{array}\right]\left[\begin{array}{c}
p_{1}^{e} \\
p_{2}^{e} \\
p_{3}^{e} \\
p_{4}^{e}
\end{array}\right]=B p_{\sim}^{e}
$$

onde a matriz $B$ é mostrada na equação 3.18 .

$$
B=\left[\begin{array}{cccc}
\beta_{1} & \beta_{2} & \beta_{3} & \beta_{4} \\
\gamma_{1} & \gamma_{2} & \gamma_{3} & \gamma_{4} \\
\delta_{1} & \delta_{2} & \delta_{3} & \delta_{4}
\end{array}\right]
$$

Utilizando a mesma interpolação para os pesos $\tilde{p}$, pode-se escrever os termos 3.19 , 3.20 e 3.21:

$$
\begin{gathered}
\int_{V^{e}}\left(\frac{1}{c^{2}} \tilde{p} \frac{\partial^{2} p}{\partial t^{2}}\right) d V=\left(\tilde{p}_{\sim}^{e}\right)^{T} \int_{V^{e}}\left(\frac{1}{c^{2}} N^{T} N\right) d V \frac{\partial^{2} p_{\sim}^{e}}{\partial t^{2}}=\left(\tilde{p}_{\sim}^{e}\right)^{T} M^{e} \ddot{p}_{\sim}^{e} \\
\int_{V^{e}}\left(\alpha \tilde{p} \frac{\partial p}{\partial t}\right) d V=\left(\tilde{p}_{\sim}^{e}\right)^{T} \int_{V^{e}}\left(\alpha N^{T} N\right) d V \frac{\partial p_{\sim}^{e}}{\partial t}=\left(\tilde{p}_{\sim}^{e}\right)^{T} C^{e} \dot{p}_{\sim}^{e}
\end{gathered}
$$




$$
\int_{V^{e}}(\vec{\nabla} \tilde{p} \vec{\nabla} p) d V=\left(\tilde{\tilde{p}}_{\sim}^{e}\right)^{T} \int_{V^{e}}\left(B^{T} B\right) d V p_{\sim}^{e}=\left(\tilde{p}_{\sim}^{e}\right)^{T} K^{e} p_{\sim}^{e}
$$

Supondo que o termo $c$ e o termo $\alpha$ são constantes dentro de um elemento, as matrizes locais $M^{e}$ e $C^{e}$ podem ser escritas como $3.22 \mathrm{e} 3.23$.

$$
\begin{aligned}
& M^{e}=\frac{1}{c^{2}} \int_{V^{e}}\left(N^{T} N\right) d V \\
& C^{e}=\alpha \int_{V^{e}}\left(N^{T} N\right) d V
\end{aligned}
$$

Para elementos tetraédridos lineares, as integrais das funções de forma são definidas como mostrado na Tabela 3.4 de [21] e pode ser escrita como 3.25 .

$$
\int_{V^{e}}\left(N^{T} N\right) d V=V^{e}\left[\begin{array}{cccc}
\frac{1}{10} & \frac{1}{20} & \frac{1}{20} & \frac{1}{20} \\
\frac{1}{20} & \frac{1}{10} & \frac{1}{20} & \frac{1}{20} \\
\frac{1}{20} & \frac{1}{20} & \frac{1}{10} & \frac{1}{20} \\
\frac{1}{20} & \frac{1}{20} & \frac{1}{20} & \frac{1}{10}
\end{array}\right]
$$

onde $V^{e}$ é o volume do elemento tetraédrico.

Como os termos da matriz $B$ são constantes, a integral de $B^{T} B$ no volume do elemento pode ser escrita como:

$$
\int_{V^{e}}\left(B^{T} B\right) d V=V^{e}\left[\begin{array}{cccc}
\beta_{1}^{2}+\gamma_{1}^{2}+\delta_{1}^{2} & \beta_{1} \beta_{2}+\gamma_{1} \gamma_{2}+\delta_{1} \delta_{2} & \beta_{1} \beta_{3}+\gamma_{1} \gamma_{3}+\delta_{1} \delta_{3} & \beta_{1} \beta_{4}+\gamma_{1} \gamma_{4}+\delta_{1} \delta_{4} \\
& \beta_{2}^{2}+\gamma_{2}^{2}+\delta_{2}^{2} & \beta_{2} \beta_{3}+\gamma_{2} \gamma_{3}+\delta_{2} \delta_{3} & \beta_{2} \beta_{4}+\gamma_{2} \gamma_{4}+\delta_{2} \delta_{4} \\
& & \beta_{3}^{2}+\gamma_{3}^{2}+\delta_{3}^{2} & \beta_{3} \beta_{4}+\gamma_{3} \gamma_{4}+\delta_{3} \delta_{4} \\
& & & \beta_{4}^{2}+\gamma_{4}^{2}+\delta_{4}^{2}
\end{array}\right]
$$

onde $V^{e}$ é o volume do elemento tetraédrico.

É possível interpolar com as mesmas funções de forma e somar os termos de fonte e excitação como mostra a equação 3.26

$$
\int_{\Omega}\left(\tilde{p} \frac{\partial p}{\partial n}\right) d \Omega+\int_{V}(\tilde{p} f) d V=(\underline{\tilde{p}})^{T} F
$$

Integrando-se em todos os elementos as equações $3.19,3.20$ e 3.21 e igualando-se à 
equação 3.26 é obtida a equação 3.27

$$
(\underbrace{\tilde{p}}_{\sim})^{T} M \underset{\sim}{\ddot{p}}+(\underbrace{\tilde{p}})^{T} C \underset{\sim}{\dot{p}}+(\underbrace{\tilde{p}}_{\sim})^{T} K \underset{\sim}{p}=\left(\sim^{\tilde{p}}\right)^{T} F
$$

Sendo os pesos $\tilde{p}$ arbitrários, a equação 3.27 pode ser simplificada e reescrita como a equação do método dos elementos finitos final 3.28

$$
M \underset{\sim}{\ddot{p}}+C \underset{\sim}{\dot{p}}+K \underset{\sim}{p}=F
$$

Modificando a notação, pode-se escrever a equação 3.29 . A nomenclatura das matrizes utilizadas é a mesma da equação de movimento, frequentemente resolvida por elementos finitos.

$$
M \ddot{p}+C \dot{p}+K p=F .
$$

A excitação imposta neste trabalho será apenas pressão (condição de contorno de Dirichlet). Esse tipo de excitação foi utilizado pois a relação direta com a saída facilita a comparação com os dados experimentais.

Para obter a resposta ao longo do tempo, este método utiliza um integrador numérico de diferenças centrais no domínio do tempo.

\subsubsection{Integrador numérico de diferenças centrais}

Neste método, o tempo é discretizado em intervalos regulares $h$, obtendo-se uma resposta $p[k]$ para cada amostra de tempo $k$. Este integrador é condicionalmente estável se o intervalo de integração for menor que um valor crítico [16].

Assim, é possível fazer as aproximações $3.30 \mathrm{e} 3.31$.

$$
\begin{gathered}
\dot{p}(t) \approx \frac{p[k+1]-p[k-1]}{2 h} \\
\ddot{p}(t) \approx \frac{p[k+1]-2 p[k]+p[k-1]}{h^{2}} .
\end{gathered}
$$

Usando as equações $3.30 \mathrm{e} 3.31$, a equação 3.29 pode ser reescrita como 3.32 


$$
M\left(\frac{p[k+1]-2 p[k]+p[k-1]}{h^{2}}\right)+C\left(\frac{p[k+1]-p[k-1]}{2 h}\right)+K p[k]=F
$$

Rearanjando os termos, pode-se escrever a equação 3.33 .

$$
\left(\frac{1}{h^{2}} M+\frac{1}{2 h} C\right) p[k+1]=F-\left(K-\frac{2}{h^{2}} M\right) p[k]-\left(\frac{1}{h^{2}} M-\frac{1}{2 h} C\right) p[k-1]
$$

A equação 3.33 pode ser considerada um sistema linear $A x=b$, onde:

$$
\begin{aligned}
x & =p[k+1] \\
A & =\left(\frac{1}{h^{2}} M+\frac{1}{2 h} C\right) \\
b & =\left(F-\left(K-\frac{2}{h^{2}} M\right) p[k]-\left(\frac{1}{h^{2}} M-\frac{1}{2 h} C\right) p[k-1]\right) .
\end{aligned}
$$

A solução de 3.34 encontra a pressão no próximo tempo discreto $p[k+1]$ e pode ser utilizada repetidamente para encontrar a resposta em todo o tempo de simulação.

\subsubsection{Método de truncamento modal}

O método de superposição modal é um método onde são calculados os modos de vibrar do sistema desejado e a resposta é dada por uma ponderação destes modos [18]. Neste trabalho será realizado um truncamento modal, onde apenas alguns dos modos serão calculados e levados em consideração para compor a resposta. Estes modos de vibrar são autovetores, as matrizes $M, C$ e $K$ da equação 3.29 são projetadas neste conjunto de vetores e a nova equação é resolvida [15].

Para calcular os autovetores, um modelo sem atenuação e sem fontes externas é usado. A equação 3.35 descreve este modelo.

$$
M \ddot{p}+K p=0
$$

A solução de 3.35 é dada por 3.36 .

$$
\lambda_{i} M v_{i}=K v_{i}
$$


onde $v_{i}$ é um autovetor associado com um autovalor $\lambda_{i}$.

Sendo $V$ a matriz contendo todos os autovetores $v_{i}$, a pressão $p$ pode ser escrita como $p=V \phi$, onde $\phi$ é uma coordenada modal. Então o conjunto de equações 3.37 pode ser escrito:

$$
\begin{aligned}
p & =V \phi \\
\dot{p} & =V \dot{\phi} \\
\ddot{p} & =V \ddot{\phi} .
\end{aligned}
$$

Usando $3.37 \mathrm{em} 3.29$.

$$
\begin{aligned}
M \ddot{p}+C \dot{p}+K p & =F \\
M V \ddot{\phi}+C V \dot{\phi}+K V \phi & =F \\
V^{T} M V \ddot{\phi}+V^{T} C V \dot{\phi}+V^{T} K V \phi & =V^{T} F \\
M_{m} \ddot{\phi}+C_{m} \dot{\phi}+K_{m} \phi & =F_{m}
\end{aligned}
$$

A última equação de 3.38 pode ser resolvida usando o mesmo integrador de diferenças finitas da seção 3.2 .3 . Vale observar que apenas a matriz $C_{m}$ não é diagonal.

\subsubsection{Testes computacionais}

Nesta seção serão descritos os testes computacionais realizados.

\section{Testes com malhas cilíndricas}

Os primeiros testes estão relacionados com parâmetros do método dos elementos finitos. Estes testes serão realizados em malhas de formato cilíndrico, onde a dimensão de propagação da onda é muito maior que as outras. Desta forma, a onda de resposta se assemelha com uma onda plana e as avaliações são simplificadas.

O primeiro teste verifica o efeito da discretização da onda no espaço (número de nós da malha de elementos finitos que descrevem um comprimento de onda) e é avaliado de duas formas. A primeira é a partir da variação da frequência de excitação para uma mesma malha e a segunda é a variação do refinamento da malha (número de nós utilizados para descrever um mesmo volume no espaço tridimensional) para uma frequência de excitação fixa. 
O próximo conjunto de testes procura avaliar os parâmetros físicos adotados no problema. Os parâmetros avaliados são a velocidade do som, reflexão da onda e atenuação do meio.

Para avaliar a propagação do som no meio é proposto a comparação do valor imposto de velocidade do som no meio com resultado da simulação. O cálculo da velocidade do som numérica $\left(c_{n}^{\text {meio }}\right)$ a partir da simulação é feito através da equação 3.39 .

$$
c_{n}^{\text {meio }}=\frac{\Delta x_{n}}{\Delta t_{n}}
$$

onde $\Delta x_{n}$ é a distância percorrida pela onda entre dois instantes de tempo e $\Delta t_{n}$ é o tempo de propagação da onda simulada.

Além disso, um objeto com velocidade do som diferente é inserido no meio e sua velocidade do som $\left(c_{n}^{o b j}\right)$ também é comparada com o valor imposto. A velocidade do som no objeto, a partir da simulação, é calculada a partir da equação 3.40 .

$$
c_{n}^{o b j}=\frac{d_{n}^{o b j}}{t_{n}^{t o t}-\frac{d_{n}^{t o t}-d_{n}^{o b j}}{c_{n}^{\text {meio }}}},
$$

onde $d_{n}^{o b j}$ é a espessura do objeto, $t_{n}^{\text {tot }}$ é o tempo total de propagação da onda, $d_{n}^{\text {tot }}$ é a distância total percorrida pela onda e $c_{n}^{\text {meio }}$ é a velocidade do som no meio calculada no teste anterior.

A reflexão da onda será avaliada a partir dos mesmos dados do teste anterior. Com a inserção do objeto, uma diferença de impedâncias acústicas é criada e a onda sofre efeitos de reflexão ao atravessar o objeto. Neste caso, quando onda transmitida atinge perpendicularmente o objeto, a amplitude da onda transmitida deve seguir a equação 3.41 [8].

$$
T=\frac{2 Z_{2}}{Z_{1}+Z_{2}}
$$

onde $T$ é a razão entre onda transmitida e refletida, $Z_{1}$ é a impedância acústica do meio da onda incidente e $Z_{2}$ é a impedância acústica do meio da onda transmitida.

Para verificar o comportamento da atenuação no espaço o valor de amplitude máximo é avaliado. Neste teste é verificado se a atenução proposta pelo modelo corresponde à atenuação esperada. 


\section{Testes com malhas semi-esféricas}

Para avaliar o comportamento da propagação da onda em um espaço tridimensional, uma malha em formato semi-esférico será utilizada. É esperado que a resposta deste teste possua um comportamento próximo de uma onda esférica e, neste caso, a atenuação decorrente do aumento do raio da esfera pode ser avaliada.

Outro teste realizado é a avaliação da resposta para uma mudança no foco do transdutor. Essa mudança é feita modificando apenas o tempo de acionamento de diferentes regiões do transdutor.

\section{Testes de otimização do método}

Dois métodos para redução do custo computacional são testados. O primeiro é o teste da implementação de um Perfectly Matching Layer (PML). Neste teste, uma malha cilíndrica com uma camada atenuadora é simulada visando obter a mesma resposta de uma malha esférica.

O segundo é o teste da implementação de um método de truncamento modal. Com uma malha cilíndrica serão feitos testes comparando o desempenho computacional do integrador por diferenças finitas no tempo com o método de truncamento modal. Serão analisados os parâmetros de erro em amplitude e erro em posição, além do tempo de execução e consumo de memória.

\subsection{Comparação}

Nesta etapa são comparados os resultados obtidos nos testes experimentais e computacionais.

Para realizar a comparação entre os dados experimentais e a saída do método dos elementos finitos, o experimento foi simulado. Para cada posição onde foi colocado o transdutor no ensaio experimental, foi calculada a média da resposta no tempo. Esta média foi calculada em uma região cuja área é a mesma do transdutor utilizado como sensor.

A partir destes resultados no tempo, foi determinado o valor máximo da resposta para aquela posição e estes valores foram colocados em um gráfico. Desta forma, a simulação tenta reproduzir o experimento realizado. 


\section{Capítulo 4}

\section{Resultados e Discussão}

\subsection{Testes dos transdutores}

Um dos transdutores de $500 \mathrm{kHz}$ fabricados pode ser visto na figura 4.1 A fabricação procurou seguir os cálculos da seção 3.1.1. entretanto a proporção de $50 \%$ de tungstênio não foi possível de se atingir na prática pois a viscosidade da mistura era elevada. O valor de fração de volume de tungstênio utilizado foi de $30 \%$.

Além disso, os valores das propriedades dos materiais utilizados na fabricação foram obtidas para uma resina e frequência diferentes. Para obter os valores exatos, ensaios de caracterização do material devem ser feitos. Entretanto, pela ausência de transdutores com a frequência desejada, tais testes não foram realizados. 


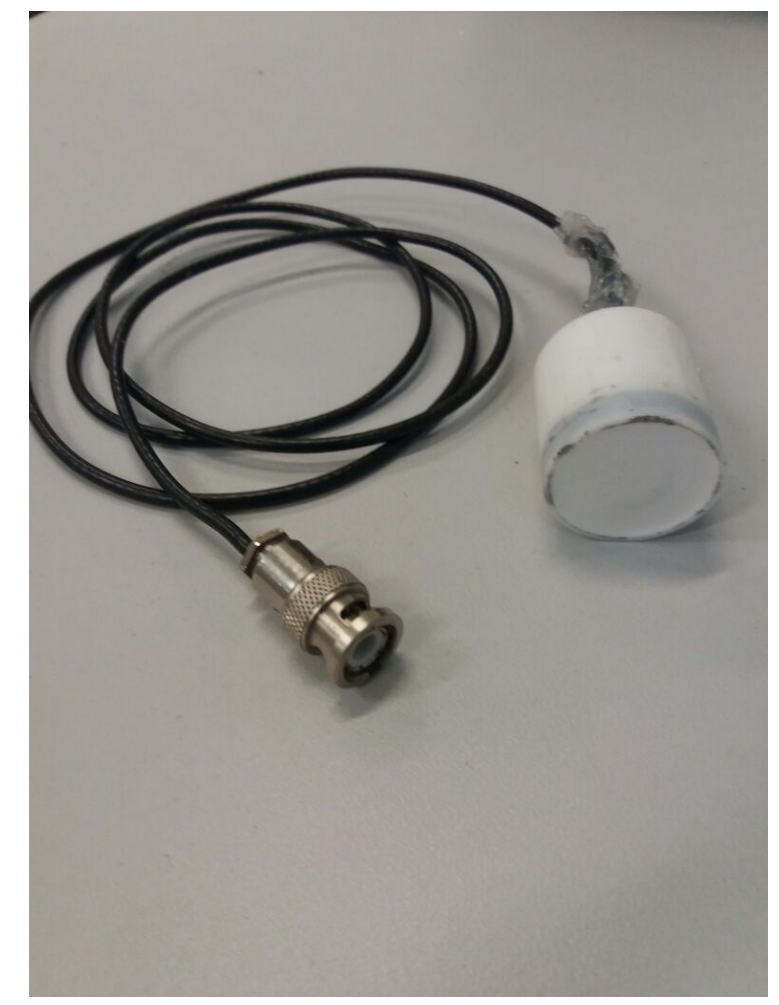

Figura 4.1: Transdutor fabricado.

Um dos transdutores de $150 \mathrm{kHz}$ cedido pelo Laboratório de Ultrassom da Escola Politécnica da Universidade de São Paulo pode ser visto no figura 4.2 .

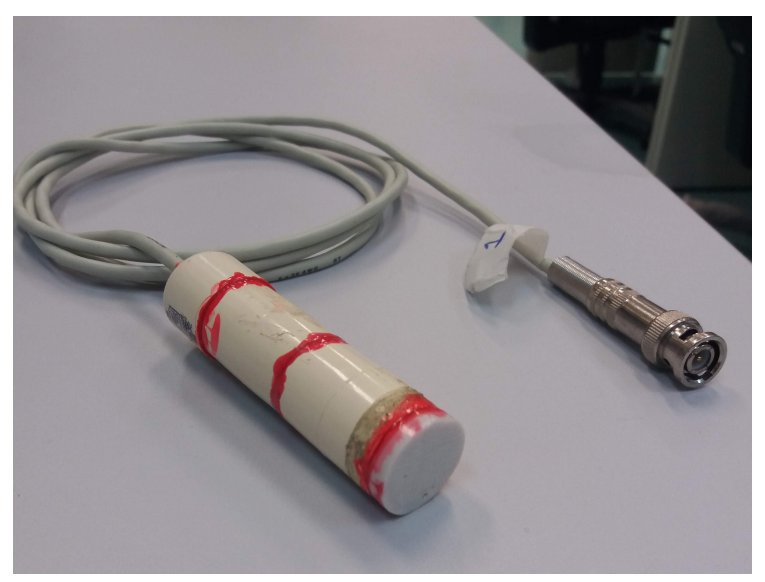

Figura 4.2: Transdutor de 150kHz.

A cuba e o sistema de movimentação pode ser visto na figura 4.3 , o pulsador/receptor na figura 4.4 e o osciloscópio na figura 4.5 . 


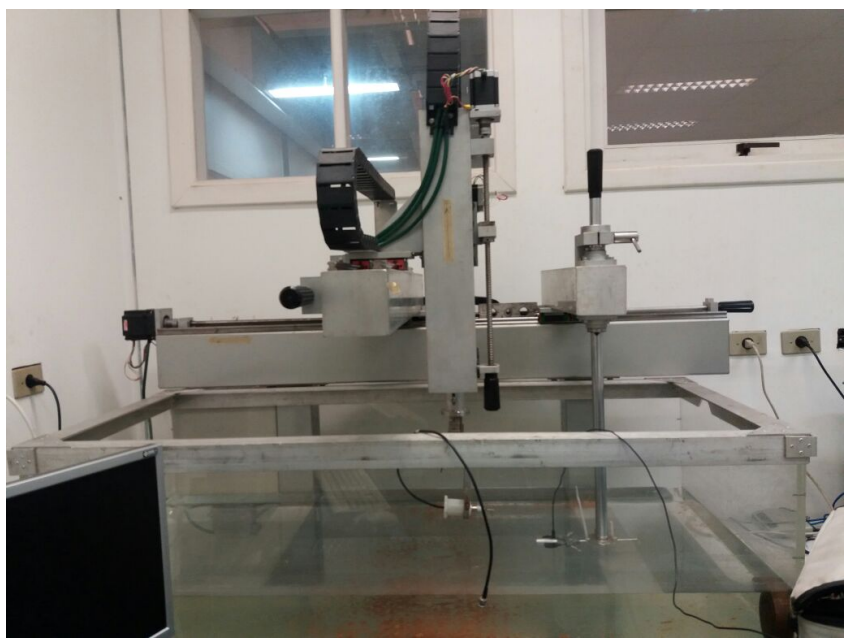

Figura 4.3: Cuba preenchida de água com sistema de movimentação utilizado

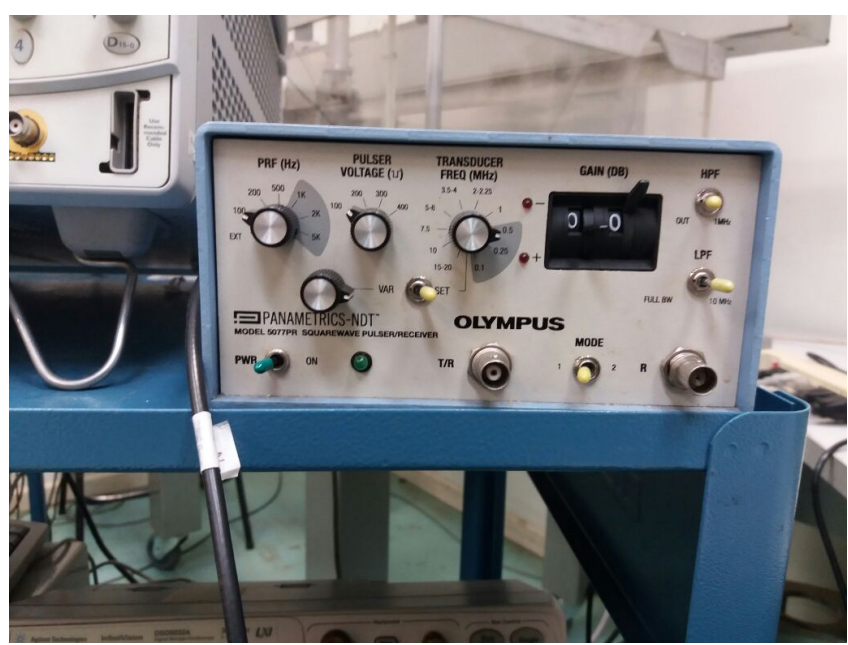

Figura 4.4: Pulsador/receptor utilizado 


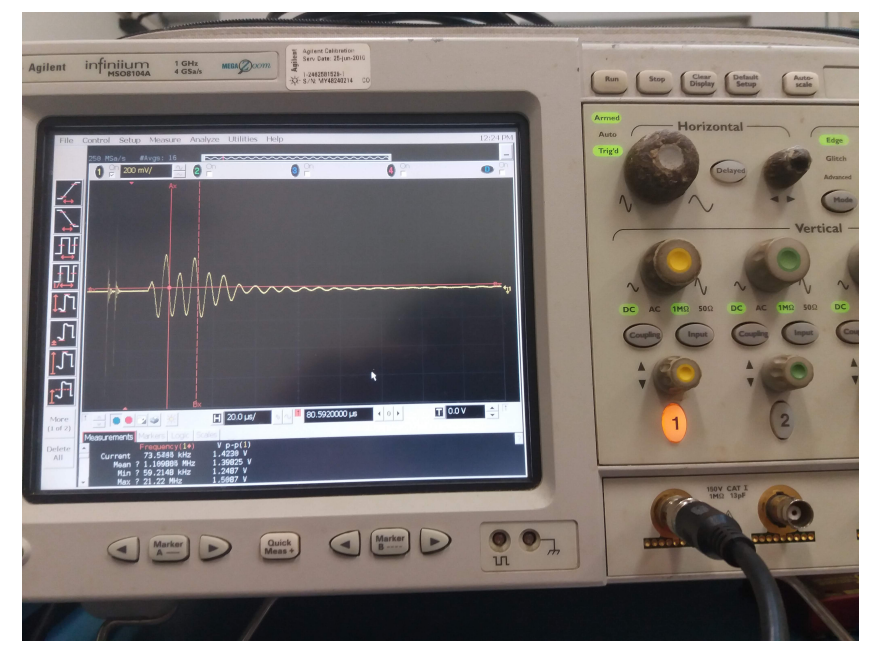

Figura 4.5: Osciloscópio utilizado

A imagem 4.6 mostra o objeto utilizado entre os dois transdutores. O material deste objeto é latão cuja velocidade do som está na ordem de 3500 a 4700m/s [8] e sua espessura é de $34,15 \mathrm{~mm}$.

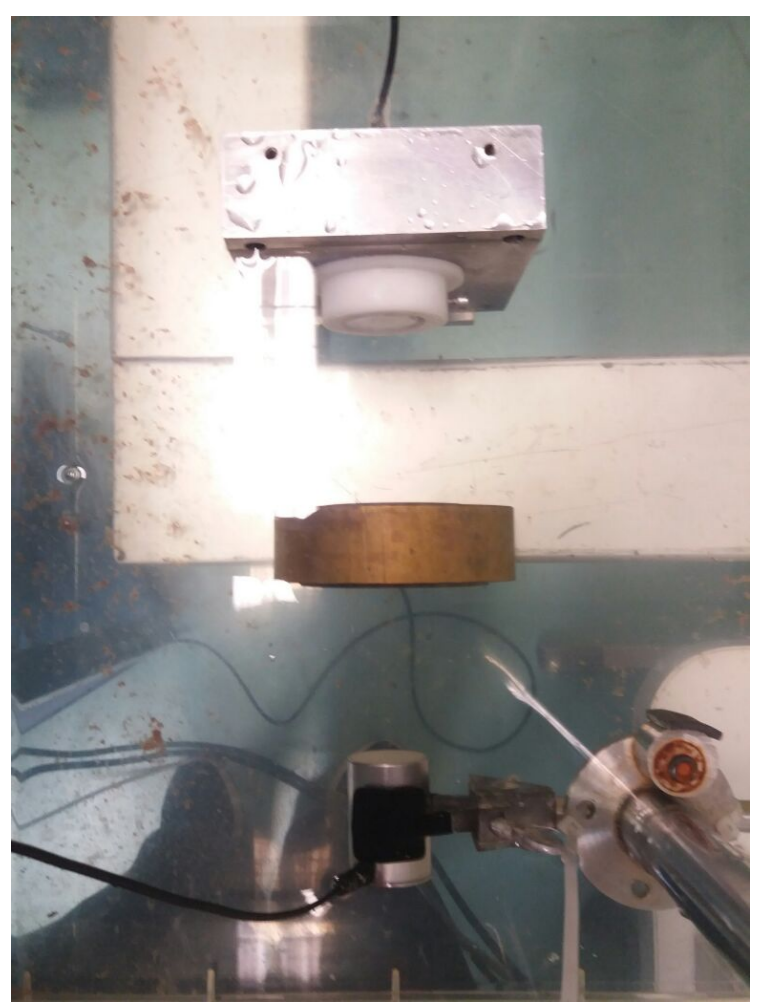

Figura 4.6: Objeto utilizado para testes

As imagens 4.7 e 4.8 ilustram o distanciamento dos transdutores de $500 \mathrm{kHz}$. A 
imagem 4.9 ilustra o distanciamento dos transdutores de $150 \mathrm{kHz}$. O posicionamento inicial (faces em contato) foi feita manualmente e, portanto, pode ocorrer erros de concentricidade.

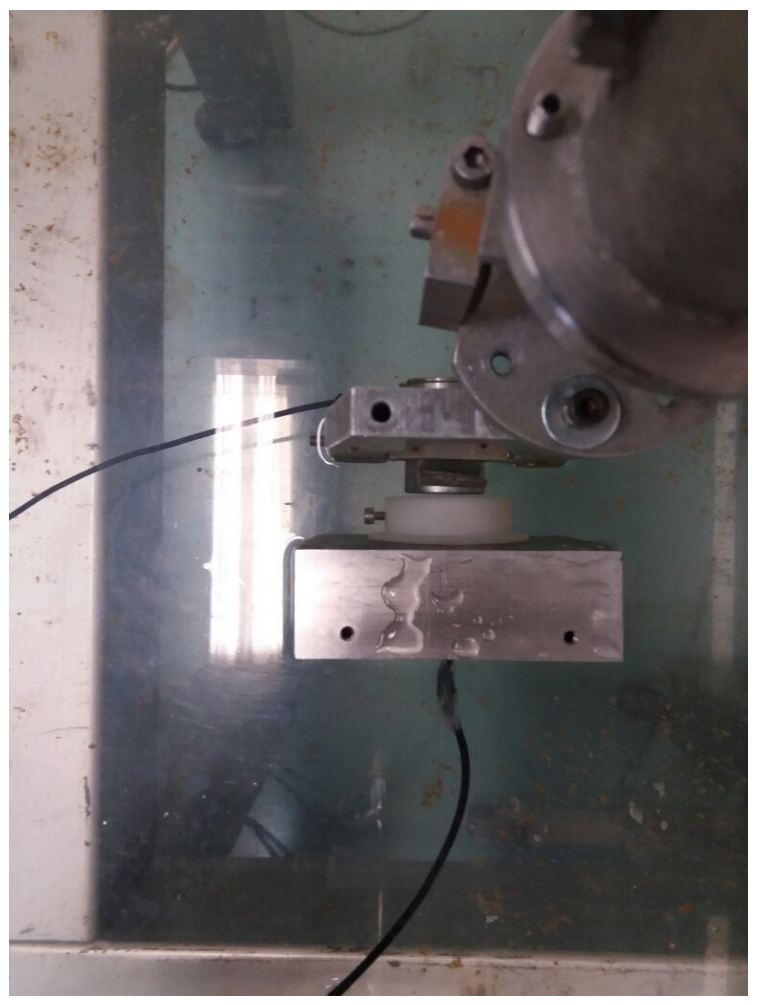

Figura 4.7: Transdutores de 500kHz com distância nula 


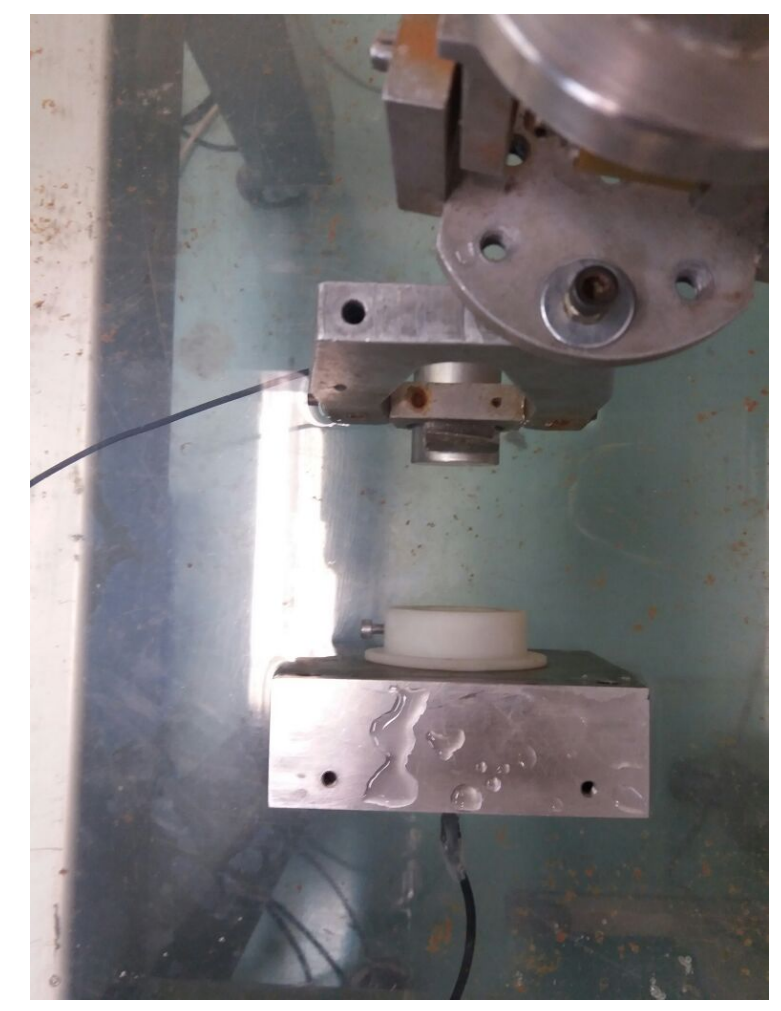

Figura 4.8: Transdutores de $500 \mathrm{kHz}$ com distância definida

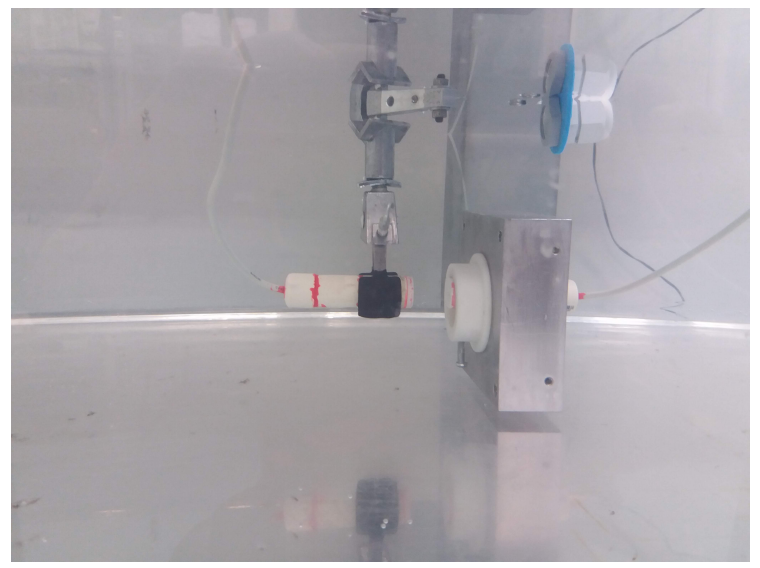

Figura 4.9: Transdutores de $150 \mathrm{kHz}$ com distância definida

Para todos os experimentos, os gráficos de pressão apresentados foram normalizados pelo valor máximo obtido para a configuração experimental específica. Isso foi feito, pois o objetivo é uma análise qualitativa inicial com foco na forma de onda. Além disso, as respostas são obtidas a partir de uma média de 16 amostras temporais. Entretanto, os experimentos não foram repetidos diversas vezes. A temperatura da água da 
cuba não foi medida para os experimentos com transdutores de $500 \mathrm{kHz}$, porém para os experimentos com os transdutores de $150 \mathrm{kHz}$ a temperatura estava em, aproximadamente, $21^{\circ} \mathrm{C}$.

Para o teste de amplitude e frequência do sinal de ultrassom do transdutor de $500 \mathrm{kHz}$, foi feita uma coleta com o hidrofone. Os gráficos das amplitudes dos sinais obtidos podem ser vistos na figura 4.10 e a sua transformada de Fourier na figura 4.11 .

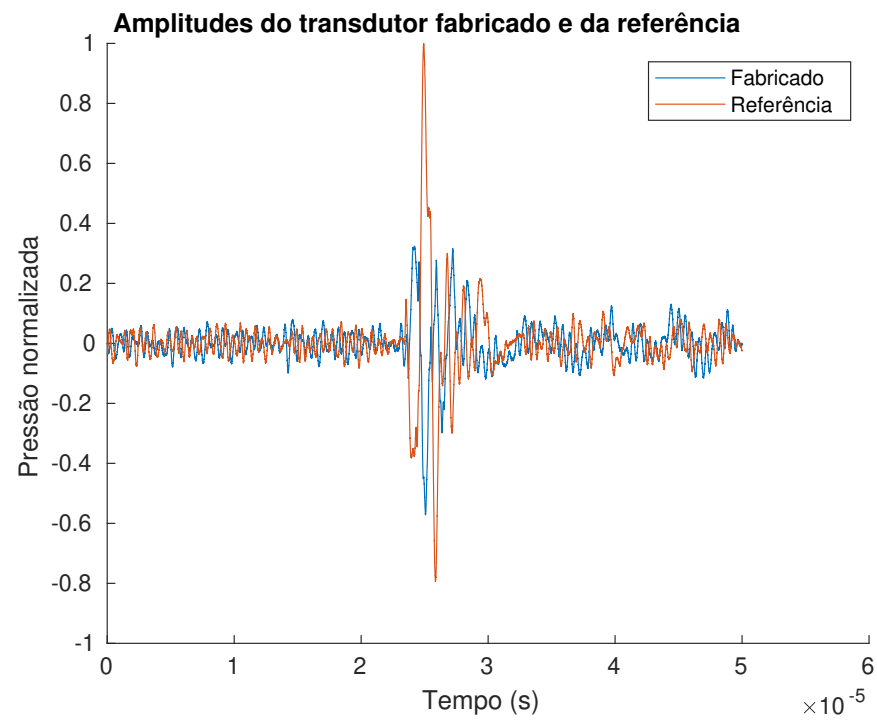

Figura 4.10: Comparação de amplitudes entre um transdutorde $500 \mathrm{kHz}$ fabricado e a referência 


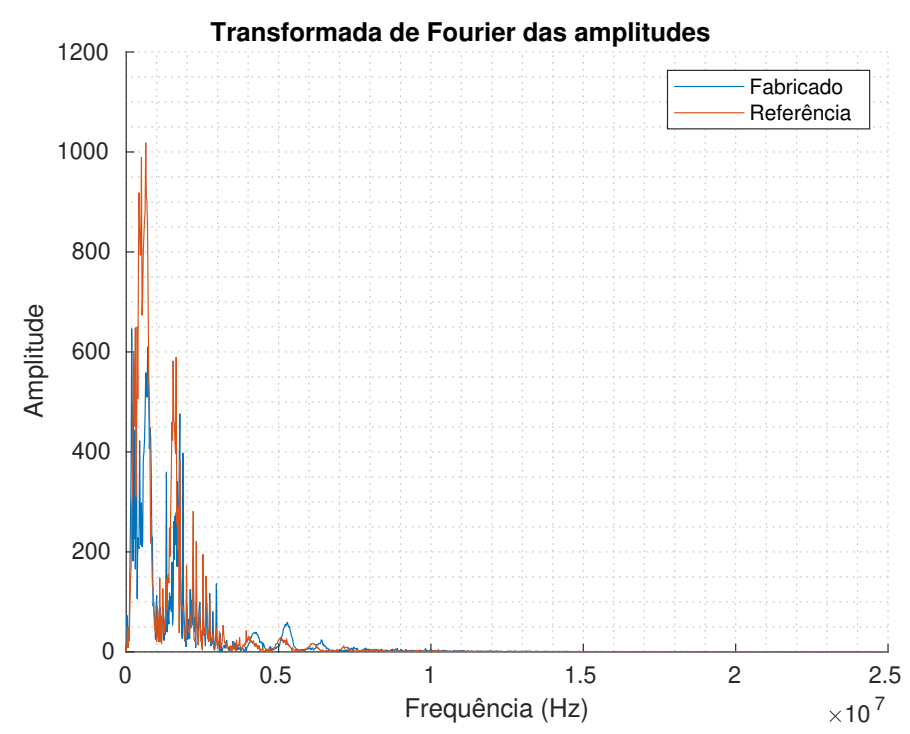

(a) Espectro com altas frequências

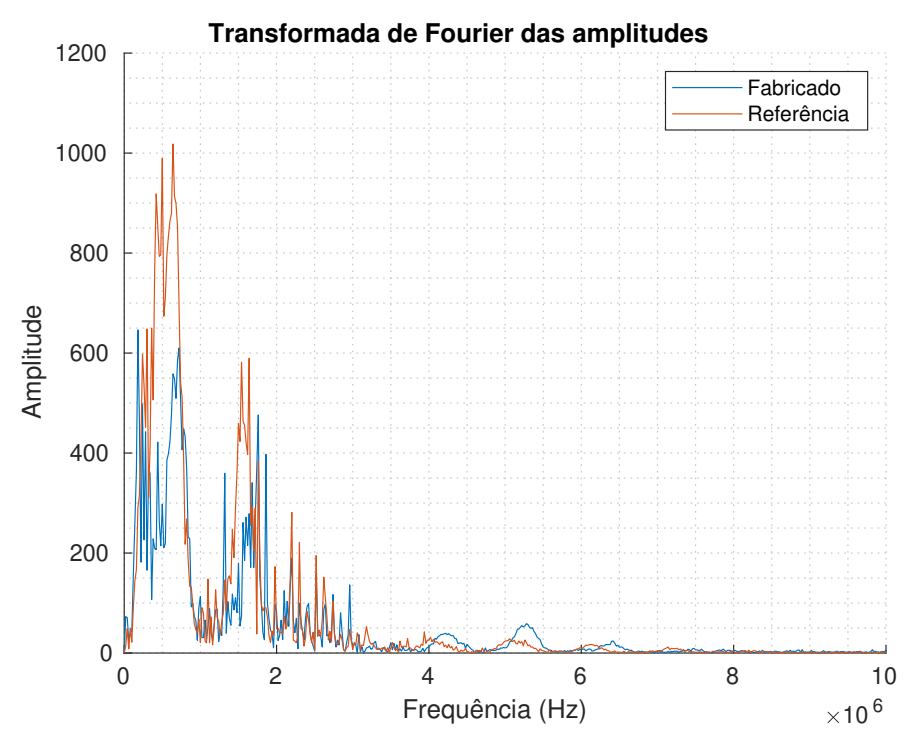

(b) Detalhe do espectro

Figura 4.11: Comparação da transformada de Fourier das amplitudes do transdutor fabricado de $500 \mathrm{kHz}$ e da referência

Como pode ser visto pela figura 4.10, a amplitude do transdutor fabricado está menor do que a da referência. O valor do máximo da referência é, aproximadamente, o dobro do fabricado. Entretanto, para este teste, foi utilizado um valor de tensão quatro vezes maior para acionar o transdutor fabricado. Assim, esta diferença aumenta para 8 vezes, aproximadamente. A frequência de ambos os transdutores estão próximas uma da outra e na faixa do valor esperado de $500 \mathrm{kHz}$, como pode ser visto na figura 4.11 . 
No caso dos transdutores de ultrassom de $150 \mathrm{kHz}$, como não havia transdutores de referência disponíveis, o teste de amplitude e frequência foi feito comparando a diferença do sinal emitido/medido de cada transdutor. A figura 4.12 mostra a comparação da amplitude dos sinais e a figura 4.13 mostra as respectivas transformada de Fourier.

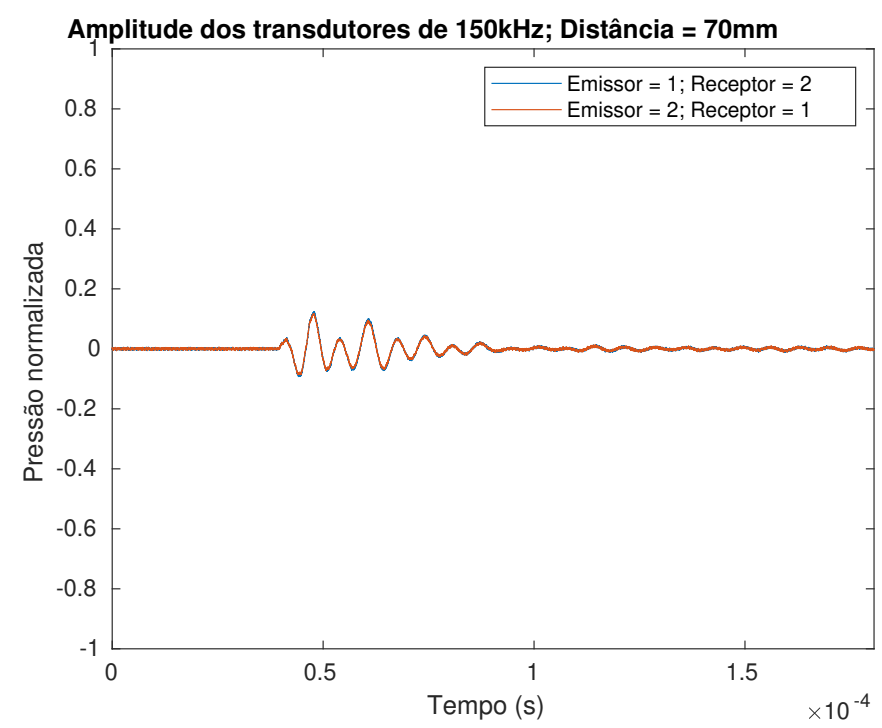

Figura 4.12: Comparação de amplitudes entre transdutores de 150kHz 


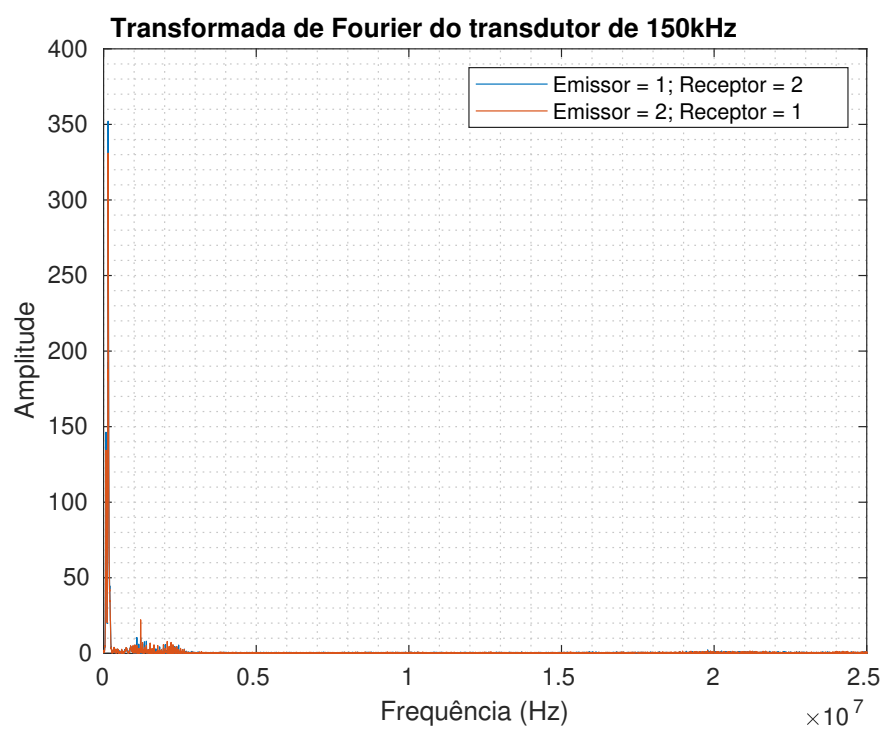

(a) Espectro com altas frequências

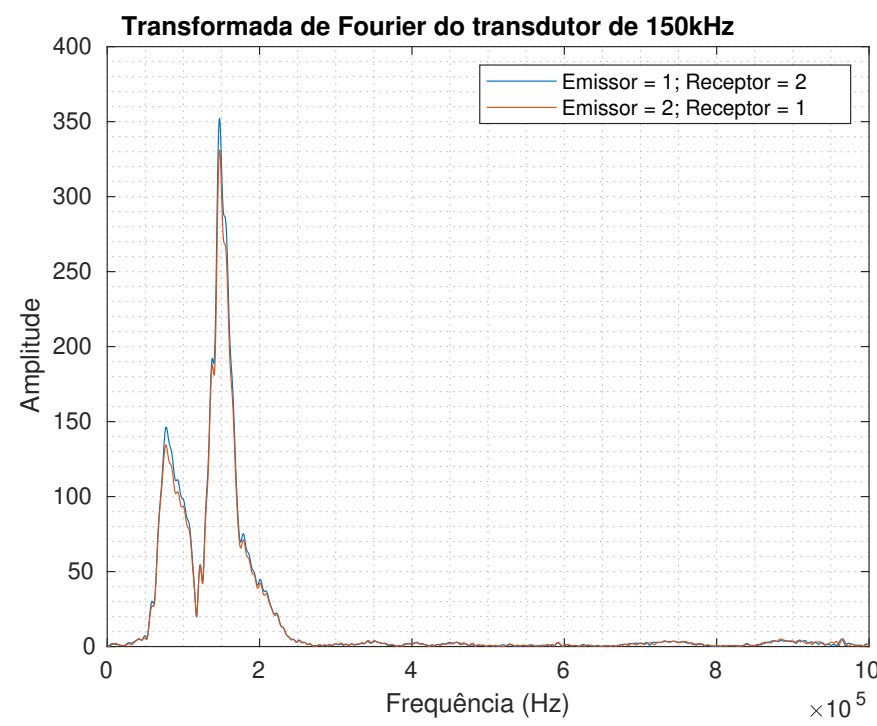

(b) Detalhe do espectro

Figura 4.13: Comparação da transformada de Fourier entre transdutores de $150 \mathrm{kHz}$

Como pode ser visto pela figura 4.12 , a diferença entre amplitudes dos transdutores é menor que 1,5\% para esta distância. A frequência de ambos os transdutores estão próximas uma da outra e próximas do valor esperado de $150 \mathrm{kHz}$, como pode ser visto na figura 4.13

Para o cálculo da velocidade do som do meio, a partir dos transdutores de $500 \mathrm{kHz}$, o gráficos da figura 4.14 foi utilizado. 


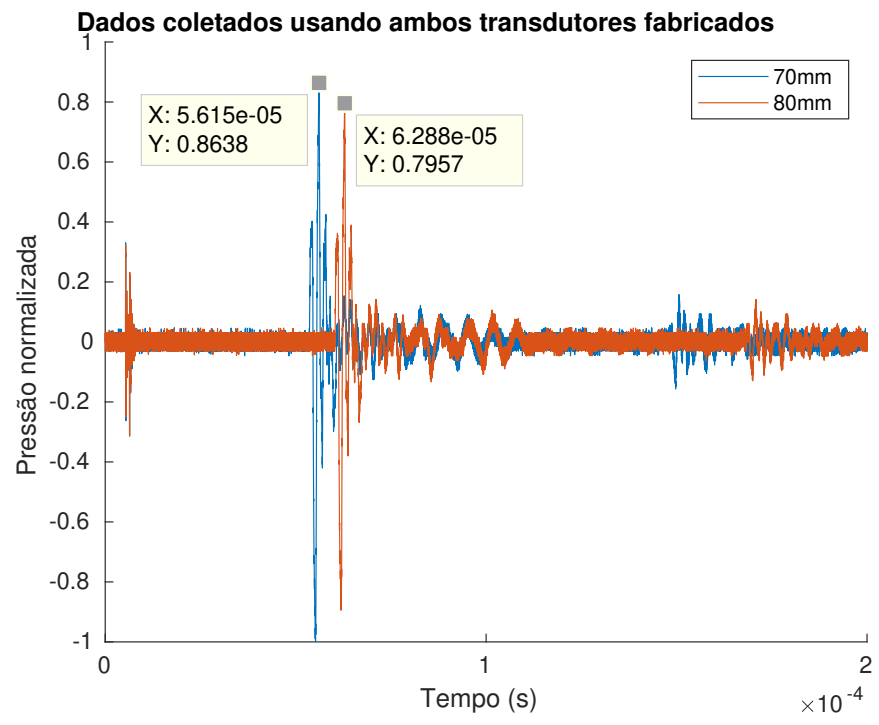

Figura 4.14: Dados coletados para duas distâncias entre transdutores de $500 \mathrm{kHz}$

A velocidade do som da água calculada é $c_{\text {água }}=10 \mathrm{~mm} /(62,88 \mu \mathrm{s}-56,15 \mu \mathrm{s}) \approx$ $1485,9 \mathrm{~m} / \mathrm{s}$, valor próximo ao esperado $(1500 \mathrm{~m} / \mathrm{s})$.

Os dados utilizados para o cálculo da velocidade do som do objeto são mostrados na figura 4.15 .

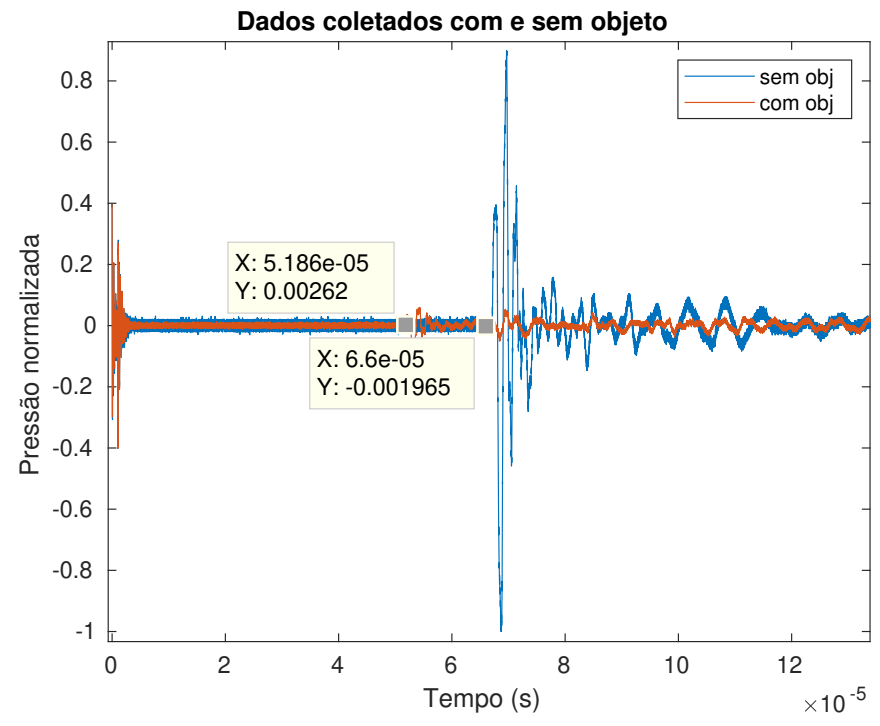

Figura 4.15: Dados coletados com e sem objeto entre transdutores de $500 \mathrm{kHz}$

Utilizando as equações apresentadas na seção 3.1 .2 e o gráfico 4.15, é possível calcular a distância entre os transdutores e a velocidade do som no objeto. A dis- 
tância calculada foi $d_{\text {água }}=0,0981 \mathrm{~m}$ e a velocidade do som do objeto calculada foi $c_{o b j}=3861,8 \mathrm{~m} / \mathrm{s}$, valor próximo ao esperado (na faixa entre 3500 e $4700 \mathrm{~m} / \mathrm{s}$ ).

Para o transdutor de $150 \mathrm{kHz}$, apenas o teste da velocidade do som do meio foi realizado. A figura 4.16 mostra os valores utilizados para o cálculo da velocidade.

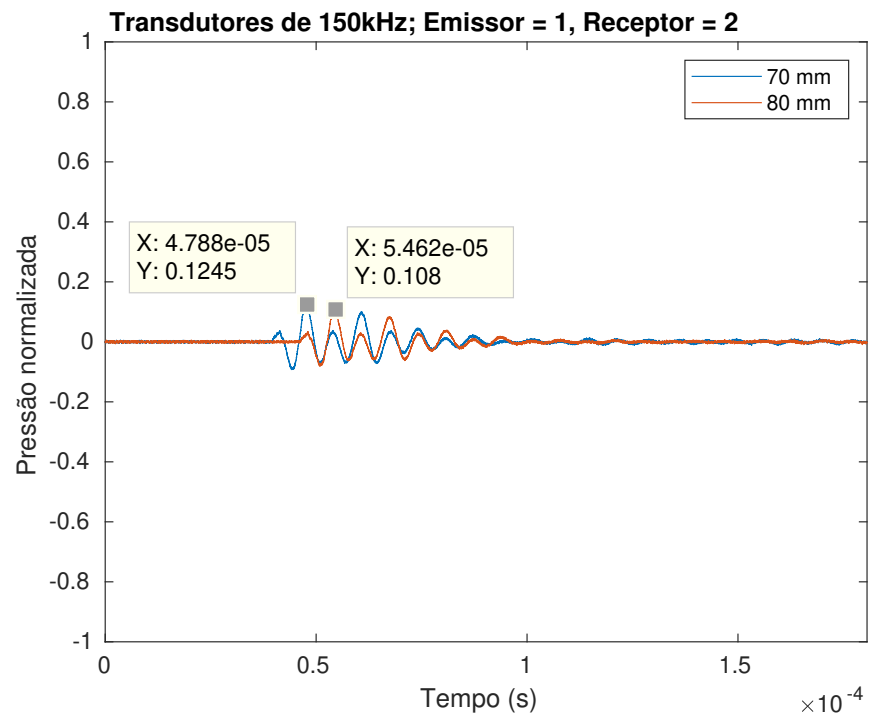

Figura 4.16: Dados coletados para duas distâncias entre transdutores de $150 \mathrm{kHz}$

A velocidade do som da água calculada é $c_{a ́ g u a}=10 \mathrm{~mm} /(54,62 \mu \mathrm{s}-47,88 \mu \mathrm{s}) \approx$ $1483,7 \mathrm{~m} / \mathrm{s}$, valor próximo ao esperado $(1500 \mathrm{~m} / \mathrm{s})$ e próximo ao valor obtido utilizando os transdutores de $500 \mathrm{kHz}$.

Para o teste dos valores máximos em função da distância dos transdutores de $500 \mathrm{kHz}$, a figura 4.17 mostra o sinal emitido por um transdutor fabricado e coletado pelo transdutor referência, a figura 4.18 mostra o sinal emitido pelo outro transdutor fabricado e coletado pelo transdutor de referência e a figura 4.19 mostra o sinal emitido e coletado por ambos transdutores fabricados. No caso onde ambos os transdutores utilizados foram os fabricados, a amplitude do pulso que acionou o transdutor foi de $200 \mathrm{~V}$, valor duas vezes maior do que nos outros casos. 


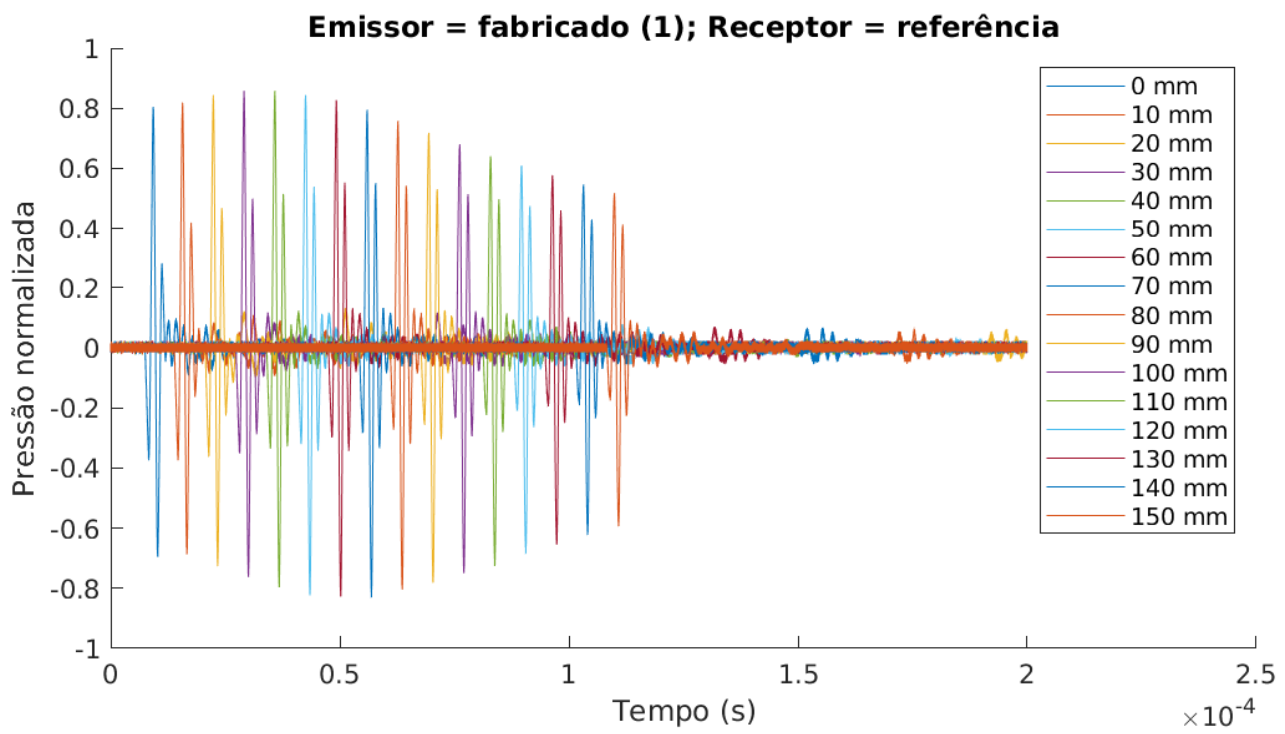

Figura 4.17: Sinal emitido por um transdutor fabricado (1) e recebido pelo transdutor de referência em diferentes posições.

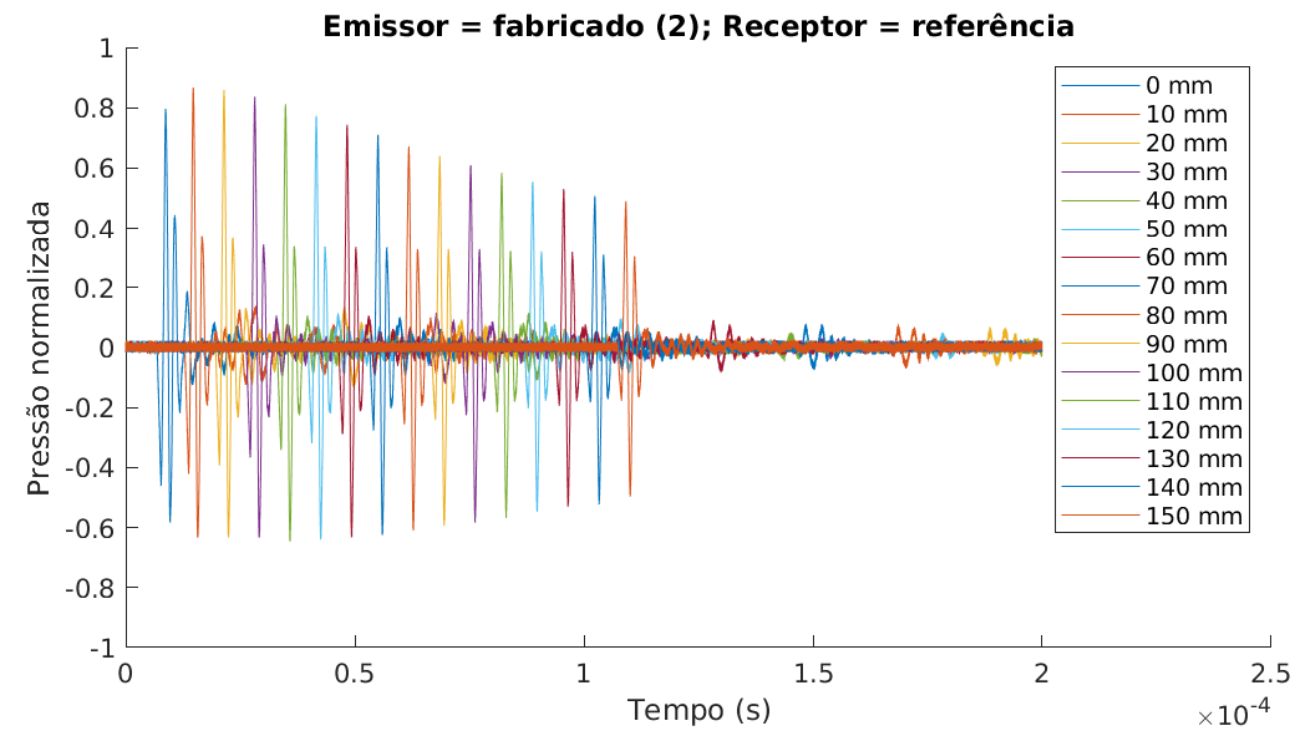

Figura 4.18: Sinal emitido por um transdutor fabricado (2) e recebido pelo transdutor de referência em diferentes posições. 


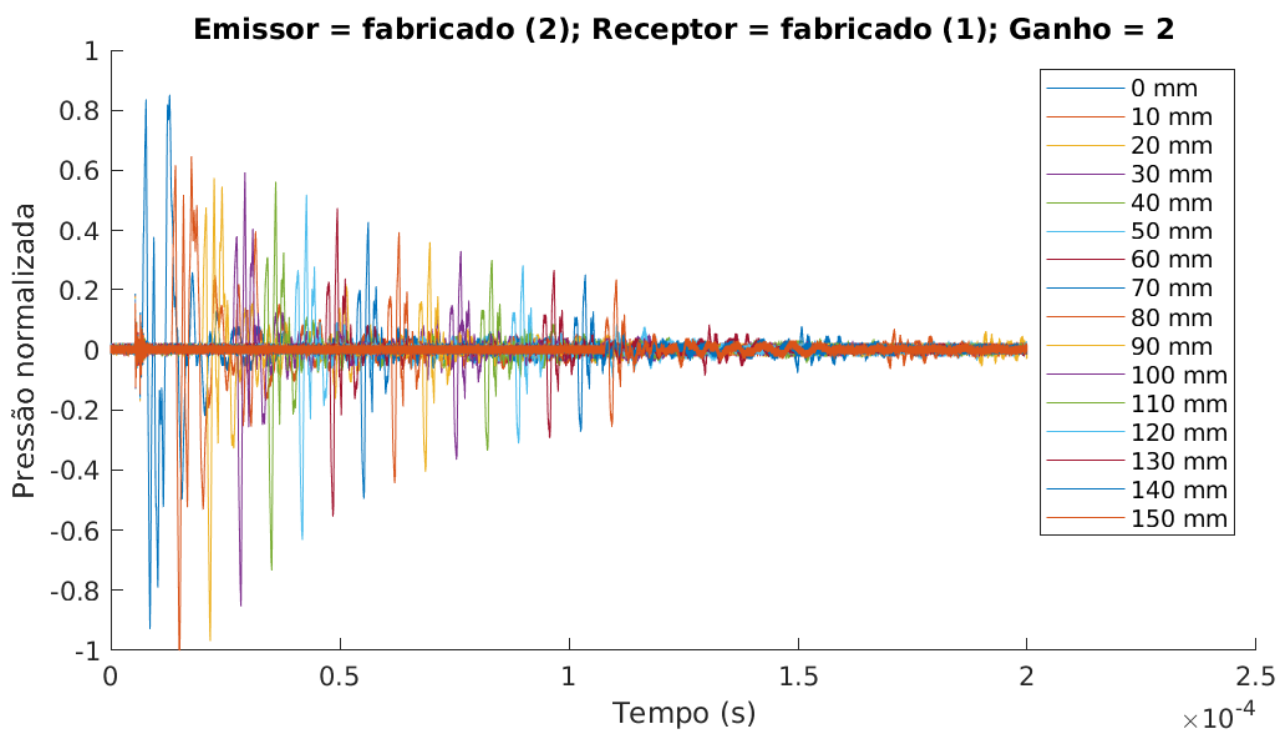

Figura 4.19: Sinal emitido por um transdutor fabricado (2) e recebido pelo outro transdutor fabricado (1) em diferentes posições.

A figura 4.20 mostra os valores máximos de amplitude do sinal no tempo para cada uma das distâncias utilizadas. Novamente, no caso onde ambos os transdutores utilizados foram os fabricados, a amplitude do pulso que acionou o transdutor foi de $200 \mathrm{~V}$, valor duas vezes maior do que no outros casos. 


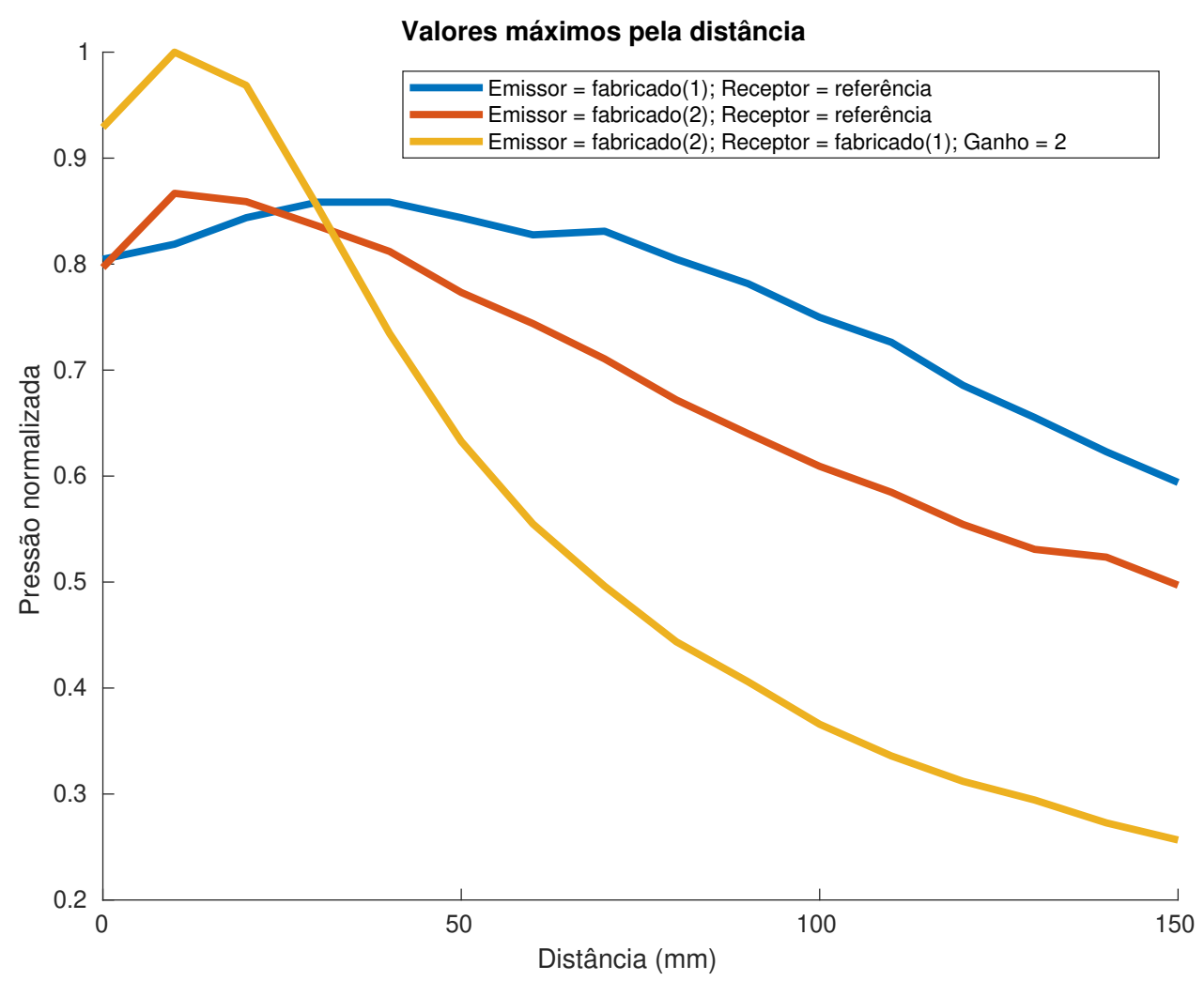

Figura 4.20: Valores máximos de amplitude pela distância dos transdutores de 500kHz.

É possível observar através das figuras 4.17, 4.18, 4.19 e 4.20 que, com o aumento da distância entre transdutores, a amplitude da onda sofre um aumento inicial seguido de uma queda. Pode-se notar que a amplitude do sinal é menor quando utiliza-se ambos transdutores fabricados. Possivelmente, este efeito é devido à uma fabricação inadequada do matching. Além disso a onda também possui mais ruído. Neste caso, é possível que o backing não esteja atenuando a onda indesejada o suficiente ou que esteja ocorrendo reflexões no backing antes de atenuar.

Como a fabricação é manual, o matching e o backing possui erros como proporções erradas devido à imprecisão na medida dos componentes, presença de bolhas na mistura e comprimento da camada imprecisa (efeito indesejado principalmente no matching). Outro fator que pode contribuir para os erros encontrados é a possível utilização de valores incorretos para as frações de volume de alumina e de tungstênio.

A figura 4.20 mostra que a mudança do receptor muda o comportamento da onda, sugerindo que o transdutor como receptor influencia no resultado. Uma das diferen- 
ças que poderiam explicar este comportamento é a diferença do foco do transdutor utilizado como receptor.

Para os transdutores de $150 \mathrm{kHz}$, foi feita apenas a comparação entre a emissão/ recepção de cada um dos transdutores. A figura 4.21 mostra o sinal emitido por um transdutor (1) e coletado pelo outro (2). A figura 4.22 mostra a situação inversa. Nestes casos, a amplitude do pulso de excitação utilizado foi de 100V.

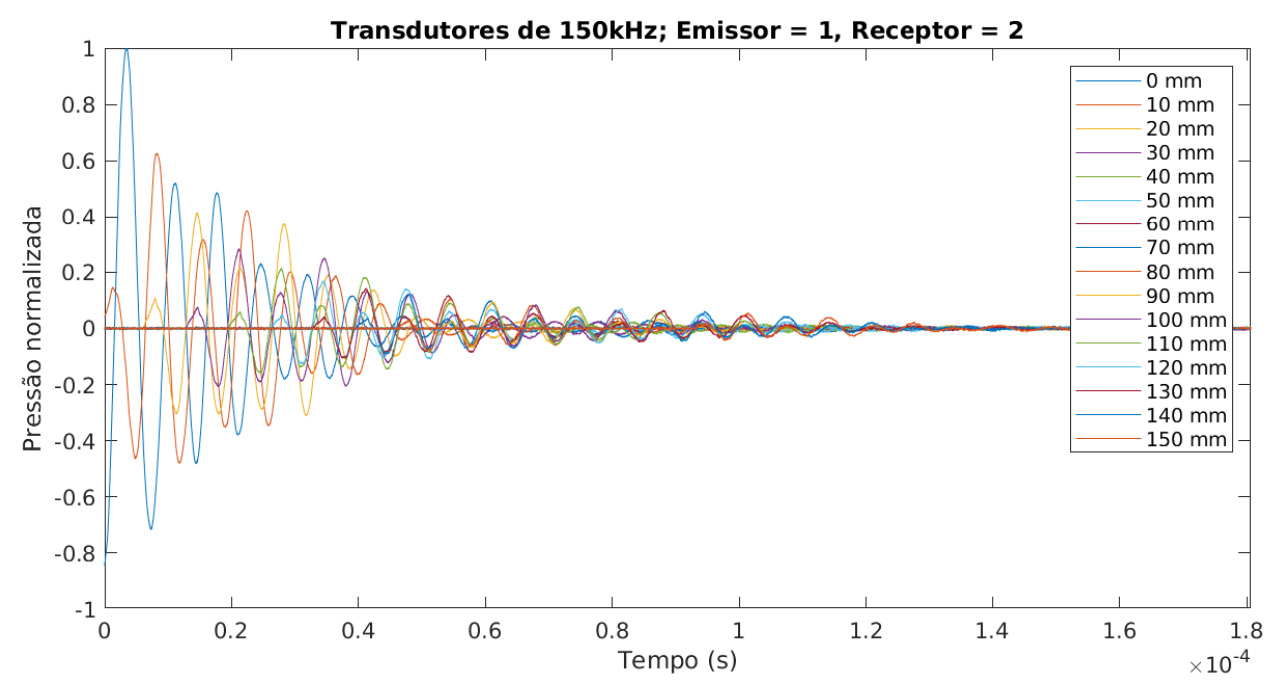

Figura 4.21: Sinal emitido por um transdutor de $150 \mathrm{kHz}$ (1) e recebido pelo outro (2).

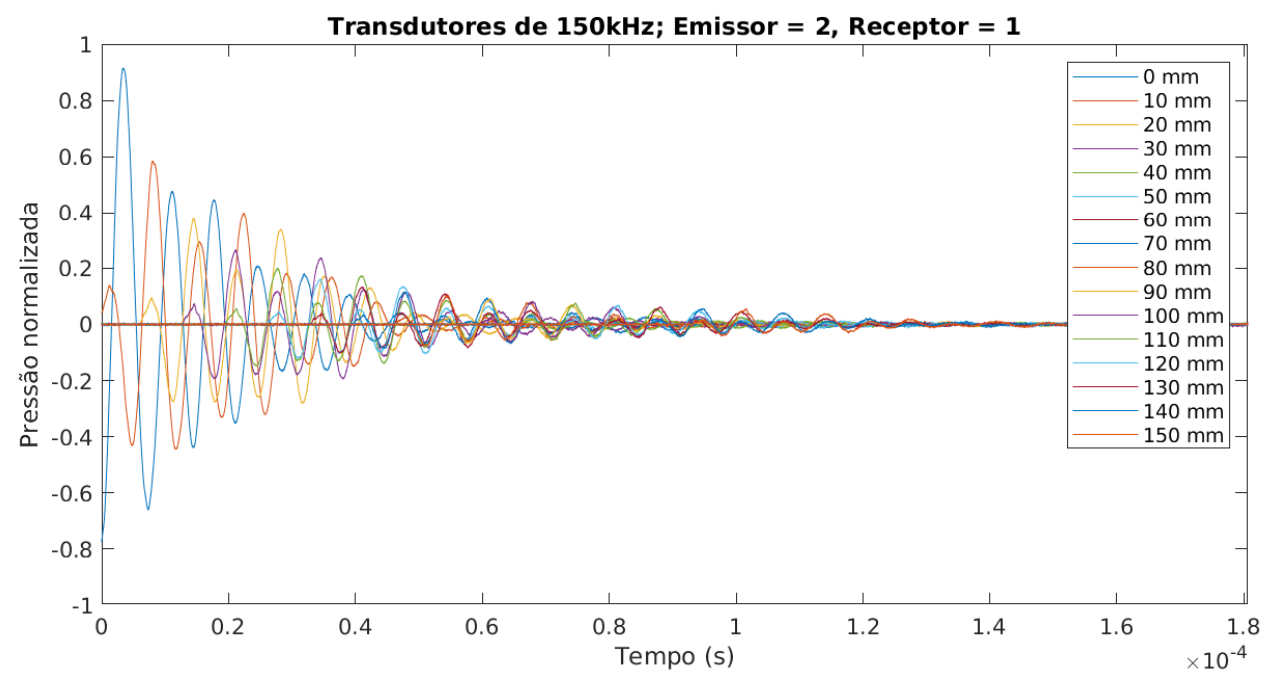

Figura 4.22: Sinal emitido por um transdutor de $150 \mathrm{kHz}$ (2) e recebido pelo outro (1).

A figura 4.23 mostra os valores máximos de amplitude do sinal no tempo para cada 
uma das distâncias utilizadas para os transdutores de 150kHz.

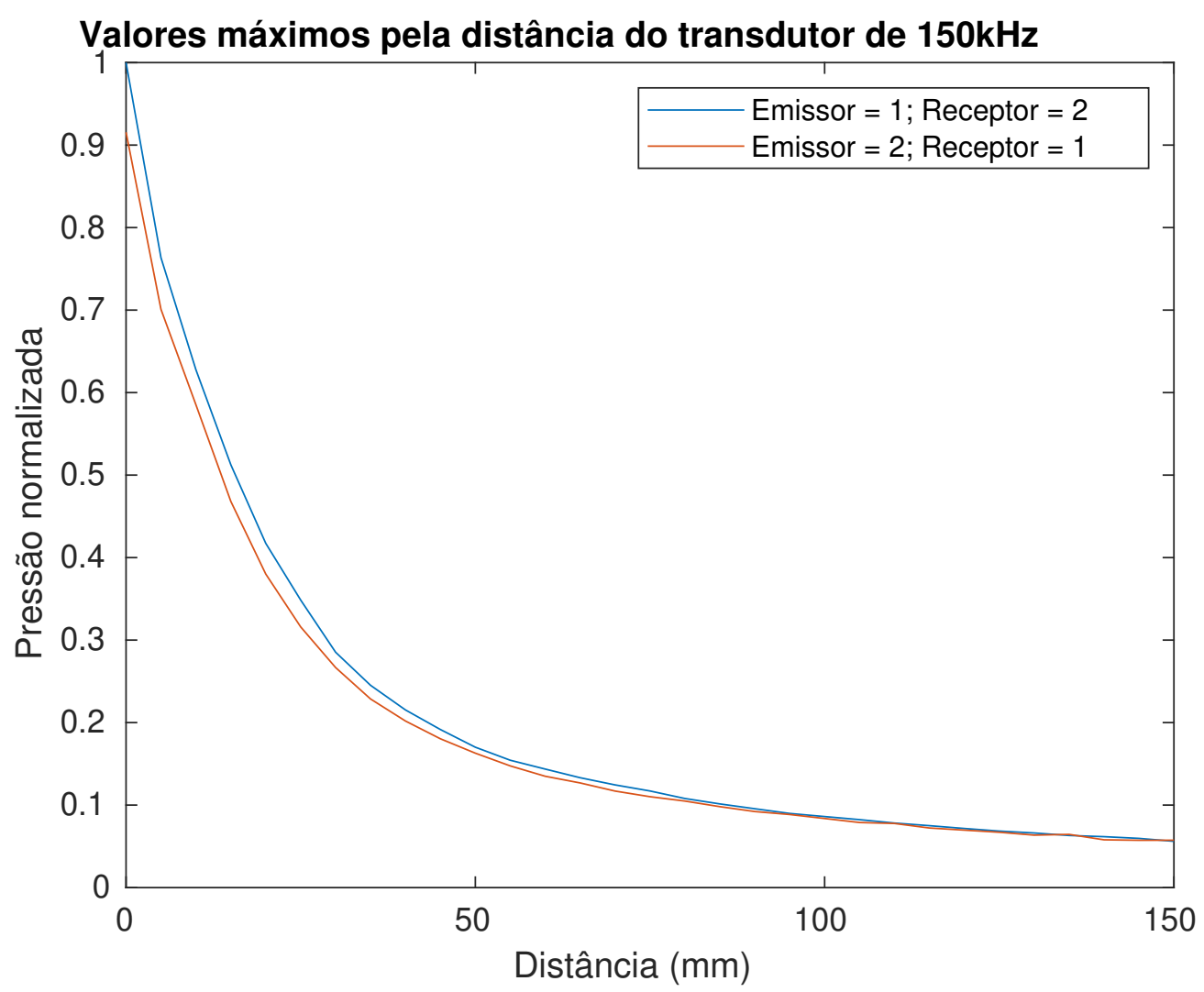

Figura 4.23: Valores máximos de amplitude pela distância dos transdutores de $150 \mathrm{kHz}$.

Diferentemente dos transdutores de $500 \mathrm{kHz}$, pela figura 4.23 , o comportamento apresentado pela amplitude é apenas decrescente. Além disso, as curvas possuem uma diferença inicial de quase $10 \%$ que diminui com o aumento da distância. Este dado $($ Emissor $=1$; Receptor $=2)$ foi utilizado na comparação com a simulação numérica.

\subsection{Teste do modelo computacional}

Para os testes computacionais a saída é o valor da pressão em todos os nós da malha de elementos finitos. Um exemplo de malha pode ser visto na figura 4.24 . 


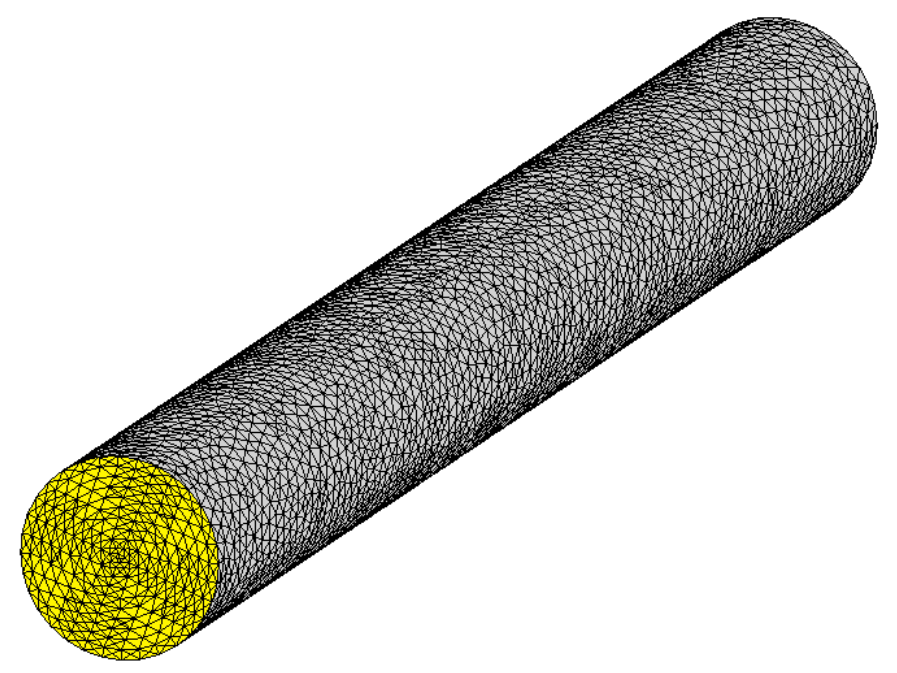

Figura 4.24: Exemplo de malha utilizada

Neste caso, uma escala de cores pode ser utilizada para representar a saída obtida, como mostrado na figura 4.25. Porém, para melhor interpretação dos resultados obtidos, foi gerado o gráfico da pressão no centro desta malha, como é mostrado na figura 4.26 . 


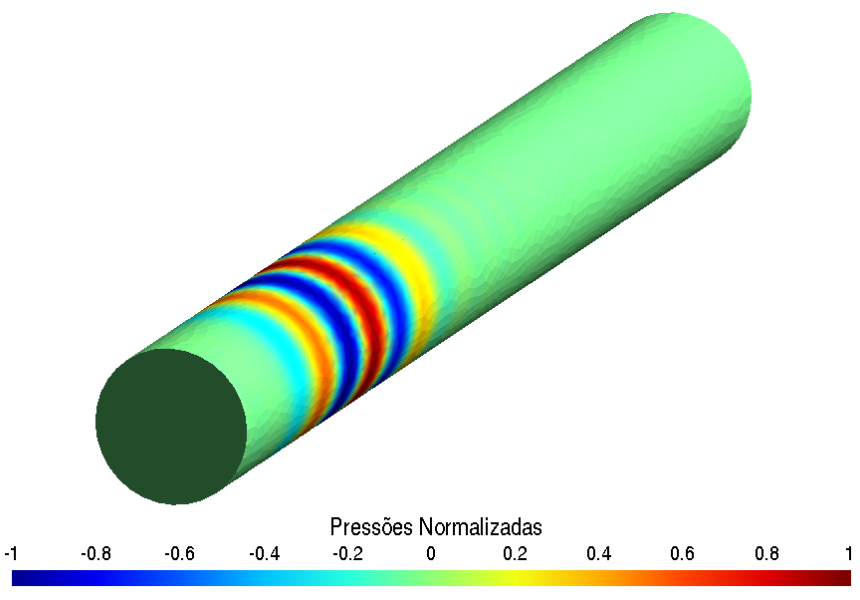

(a) Resultado em $25 \mu s$.

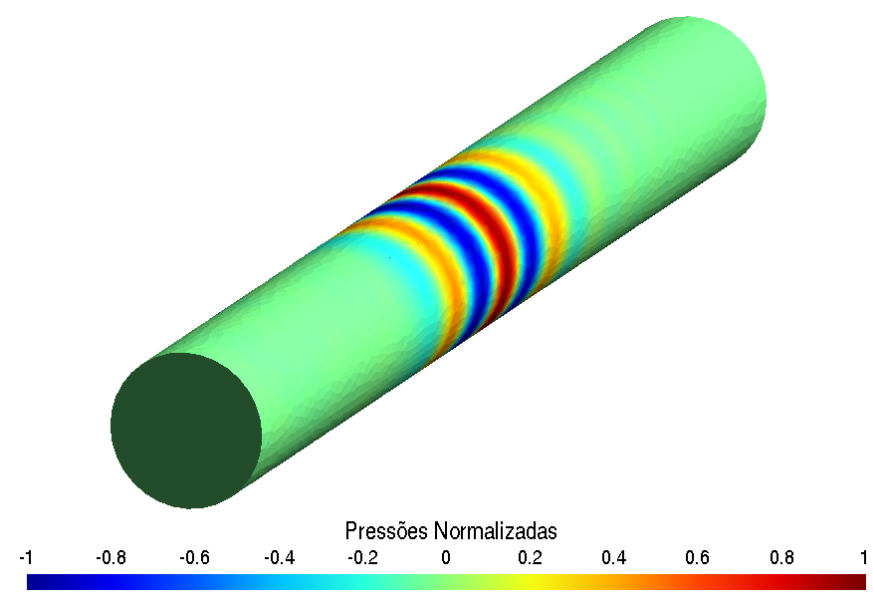

(b) Resultado em $40 \mu s$.

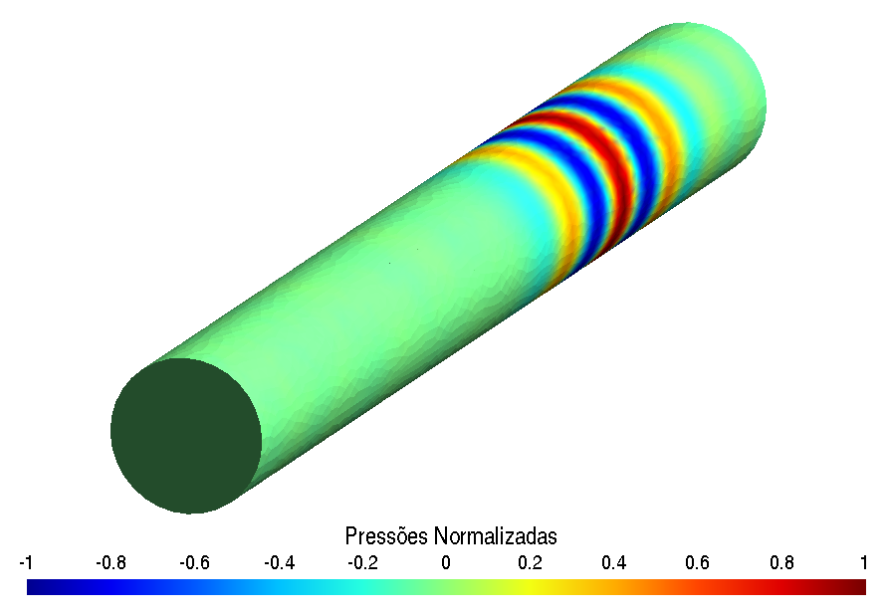

(c) Resultado em $55 \mu \mathrm{s}$.

Figura 4.25: Exemplo de resultado em escala de cores. 


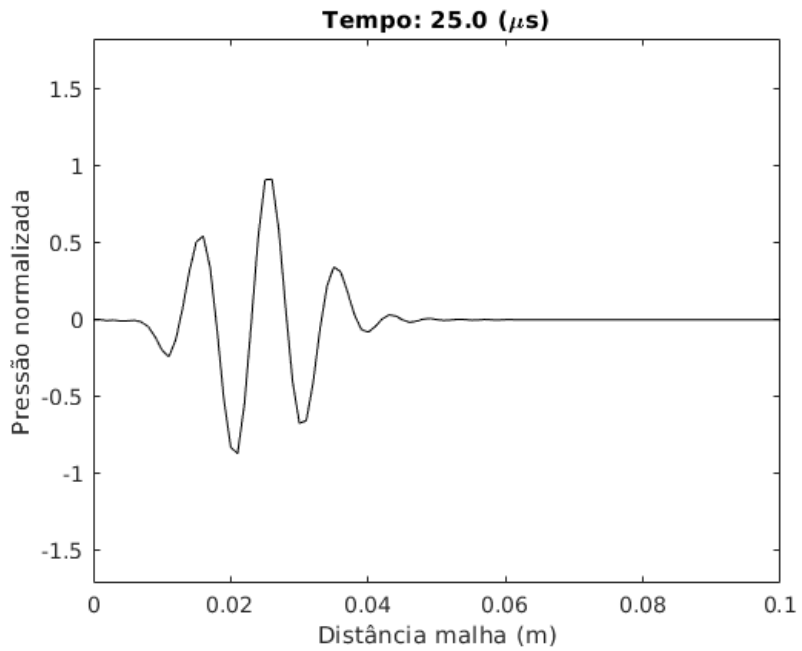

(a) Resultado em $25 \mu \mathrm{s}$.

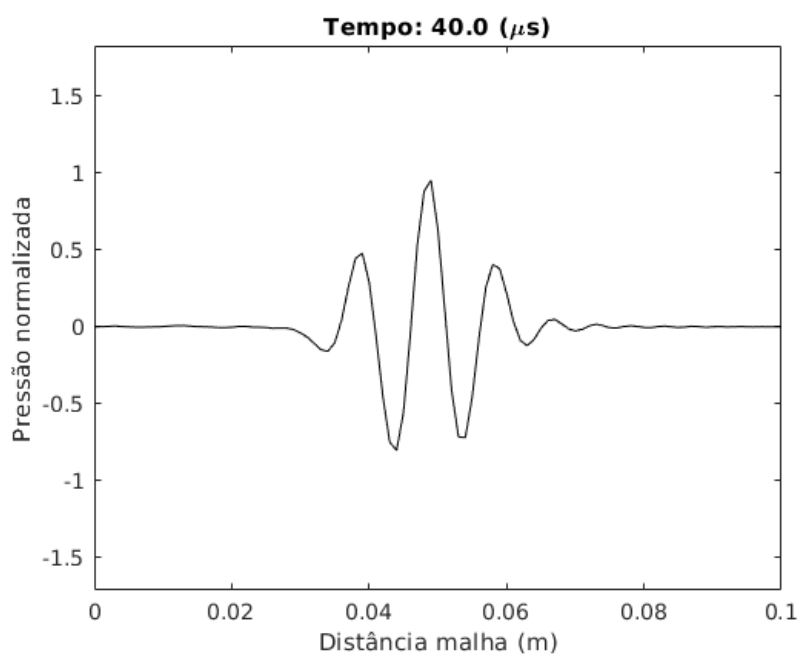

(b) Resultado em $40 \mu \mathrm{s}$.

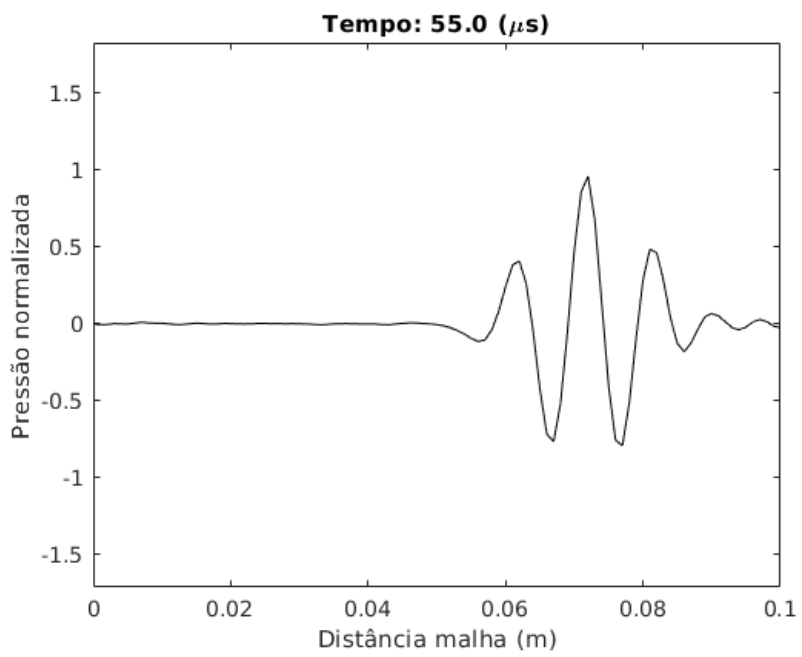

(c) Resultado em $55 \mu \mathrm{s}$.

Figura 4.26: Exemplo de resultado como gráfido do eixo central da malha. 
Em todos os testes considerados a excitação imposta é pressão normalizada (amplitude é unitária) e relativa (pressão basal é nula). A excitação é imposta em todos os nós da malha de elementos finitos considerados como transdutor (superfície amarela da figura 4.24 . por exemplo). A forma de onda utilizada é composta por três ciclos de senoide de amplitude unitária envolvido por uma gaussiana. A figura 4.27 mostra um exemplo de excitacação.

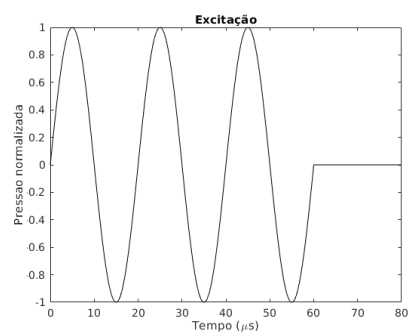

(a) Onda senoidal

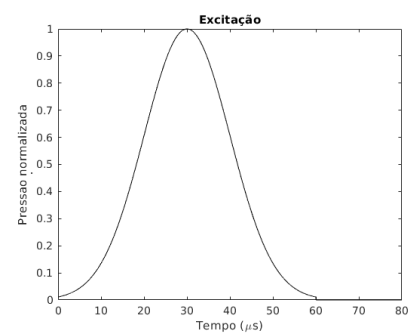

(b) Curva gaussiana

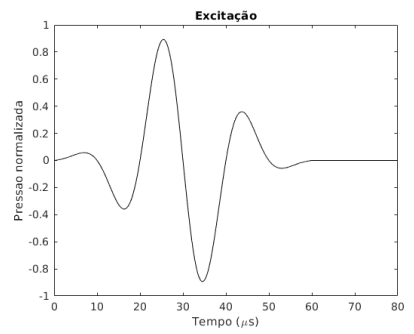

(c) Excitação final

Figura 4.27: Excitação simulada.

\section{Testes com malhas cilíndricas}

O primeiro teste realizado foi sobre o efeito da discretização do comprimento de onda utilizando uma mesma malha. Neste teste, a malha utilizada foi mostrada na figura 4.24. Esta malha possui, aproximadamente, $9,1 k$ nós e $40 k$ elementos. Seu comprimento é de $0,1 \mathrm{~m}$ e seu diâmetro é de $0,01 \mathrm{~m}$.

As frequências utilizadas foram $50 \mathrm{kHz}, 75 \mathrm{kHz}, 150 \mathrm{kHz}$ e $300 \mathrm{kHz}$, resultando em uma discretização de 30, 20, 10 e 5 pontos por comprimento de onda, respectivamente. O desvio padrão da envoltória gaussiana foi mantido proporcial em relação à frequência.

A figura 4.28 mostra as excitações utilizadas e a figura 4.29 mostra a transformada de Fourier destas excitações. Além disso, o valor de velocidade do som foi de $1500 \mathrm{~m} / \mathrm{s}$, coeficiente de atenuação no tempo pequeno o suficiente para que a atenuação seja negligenciada $\left(\alpha=10^{-12} s / m^{2}\right)$, intervalo de tempo de integração foi de $0,01 \mu s$ e tempo total de integração de $80 \mu s$.

As figuras 4.30, 4.31, $4.32,4.33$ mostram as respostas obtidas para frequências de $50 \mathrm{kHz}, 75 \mathrm{kHz}, 150 \mathrm{Khz}$ e $300 \mathrm{Khz}$ respectivamente. Estas figuras mostram a resposta em $25 \mu s, 40 \mu s$ e $55 \mu s$. 


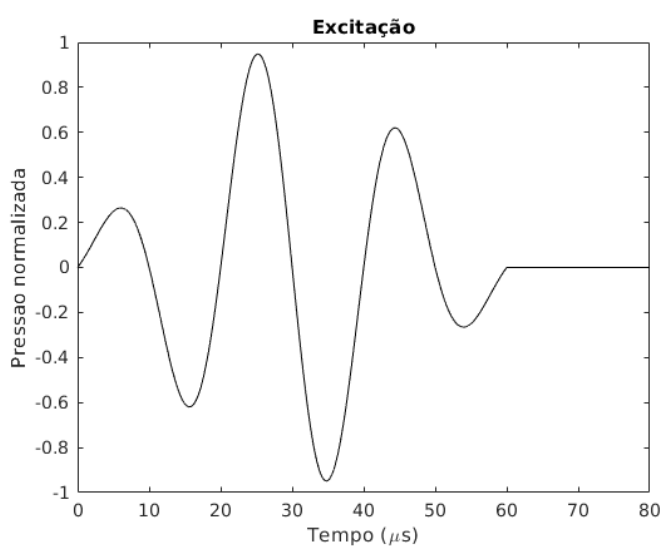

(a) Excitação de 50kHz.

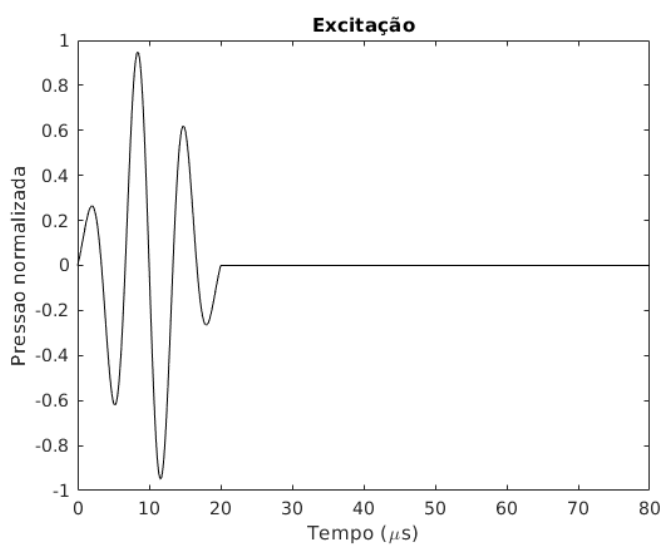

(c) Excitação de 150kHz.

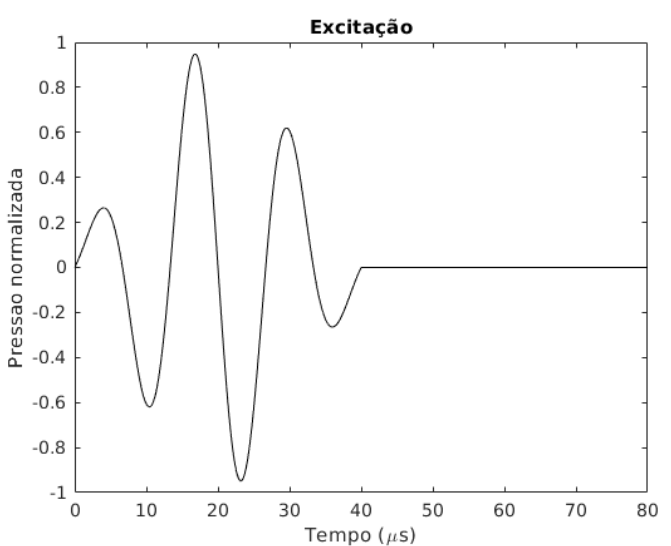

(b) Excitação de $75 \mathrm{kHz}$.

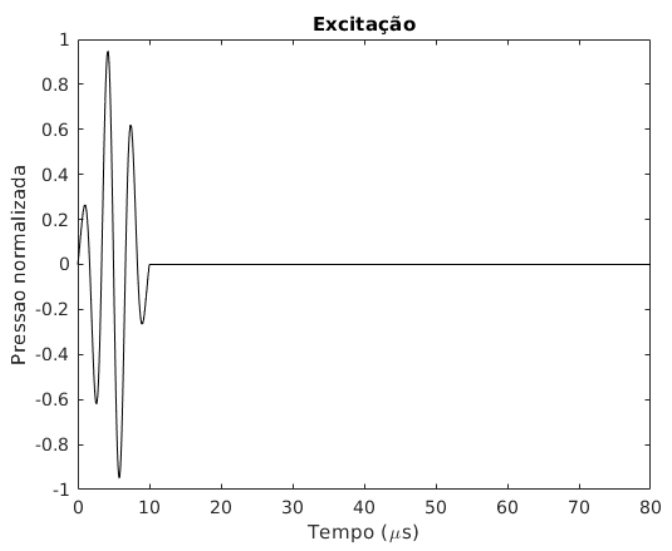

(d) Excitação de 300kHz.

Figura 4.28: Excitações utilizadas. 


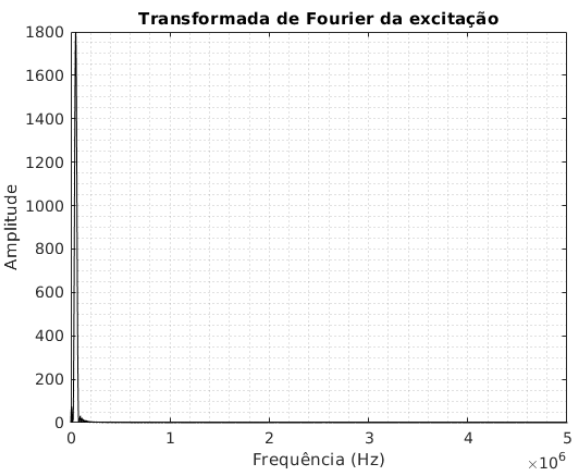

(a) Excitação de $50 \mathrm{kHz}$.

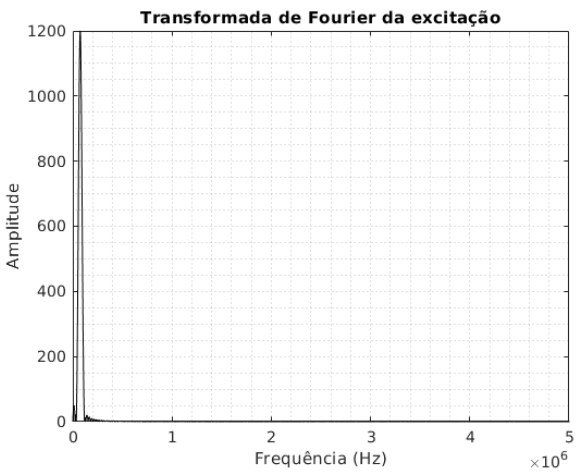

(c) Excitação de $75 \mathrm{kHz}$.

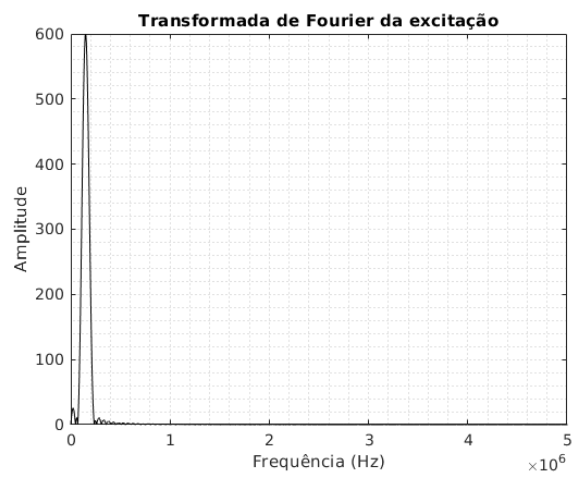

(e) Excitação de 150kHz.

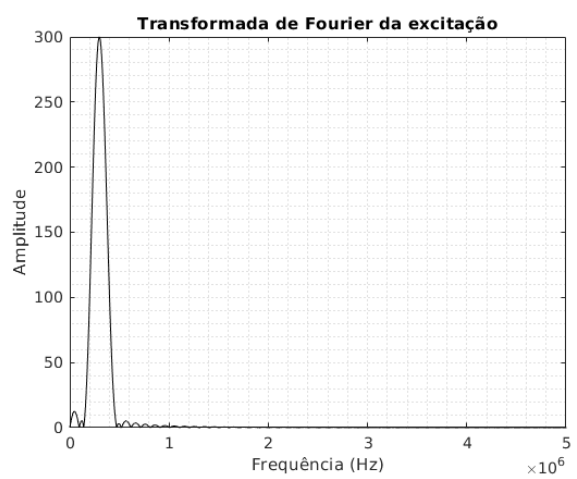

(g) Excitação de 300kHz.

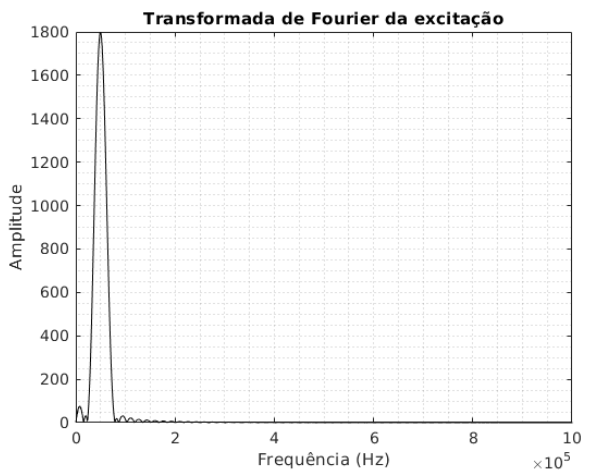

(b) Detalhe da excitação de 50kHz.

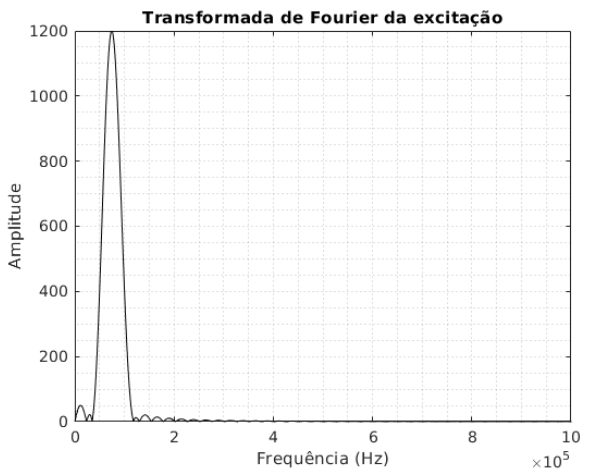

(d) Detalhe da excitação de 75kHz.

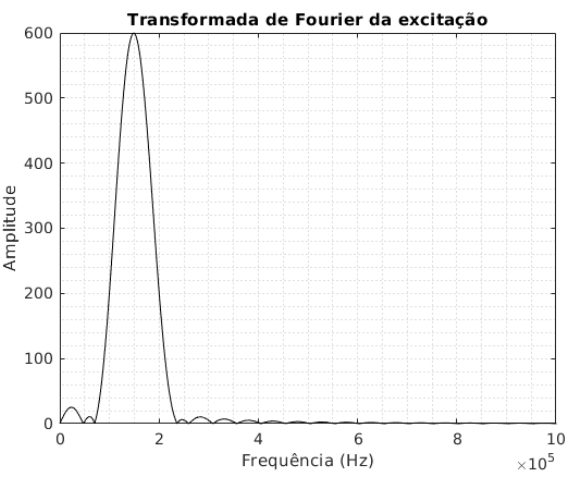

(f) Detalhe da excitação de 150kHz.

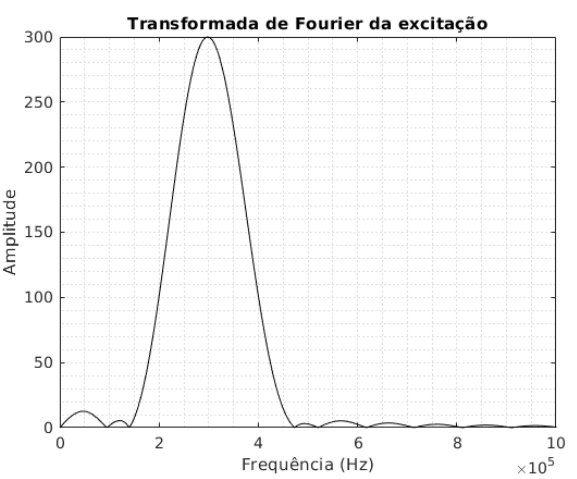

(h) Detalhe da excitação de $300 \mathrm{kHz}$.

Figura 4.29: Transformada de Fourier das excitações utilizadas. 


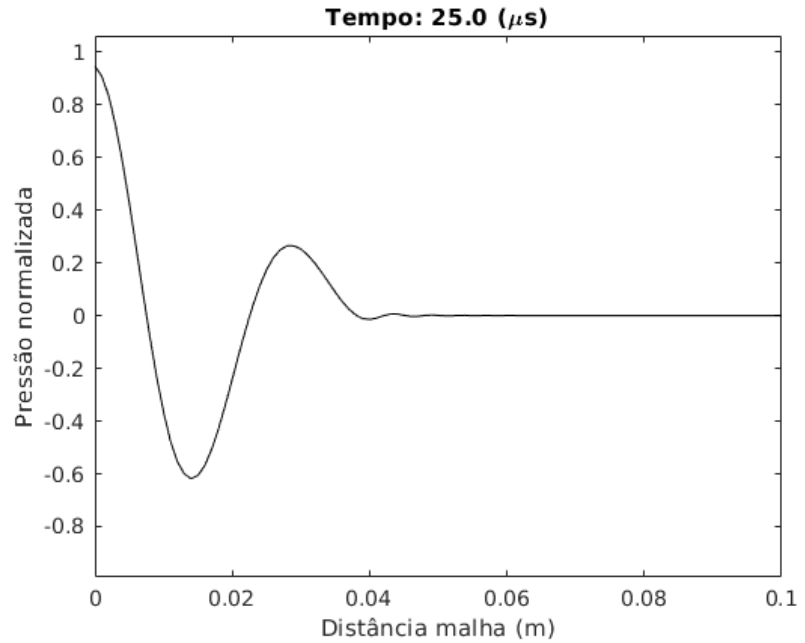

(a) Resultado em $25 \mu \mathrm{s}$.

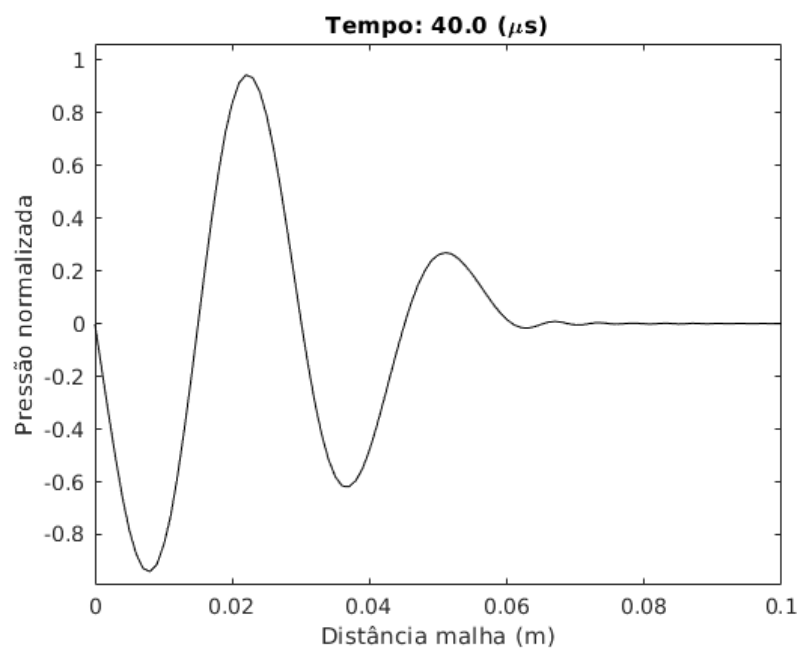

(b) Resultado em $40 \mu s$.

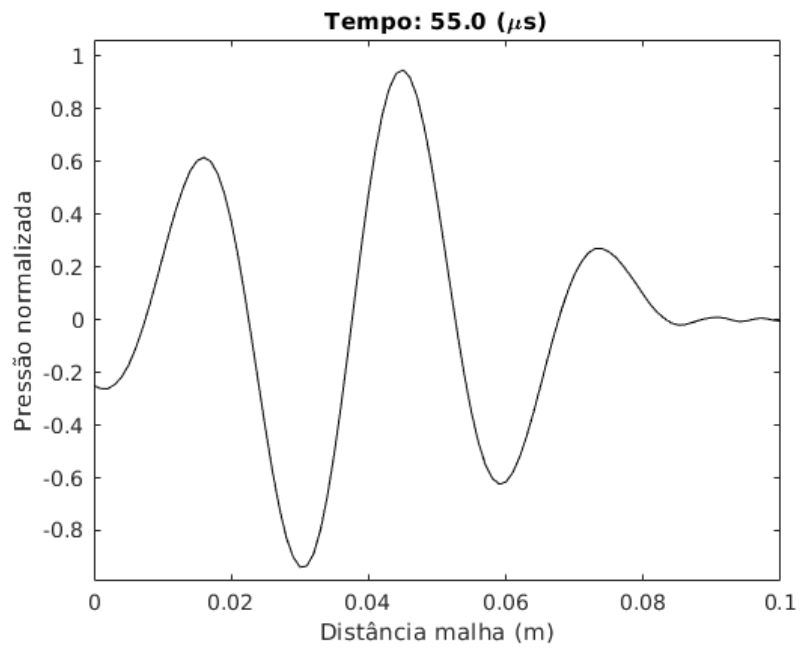

(c) Resultado em $55 \mu \mathrm{s}$.

Figura 4.30: Resultado para excitação de $50 \mathrm{kHz}$ (30 pontos por comprimento de onda). 


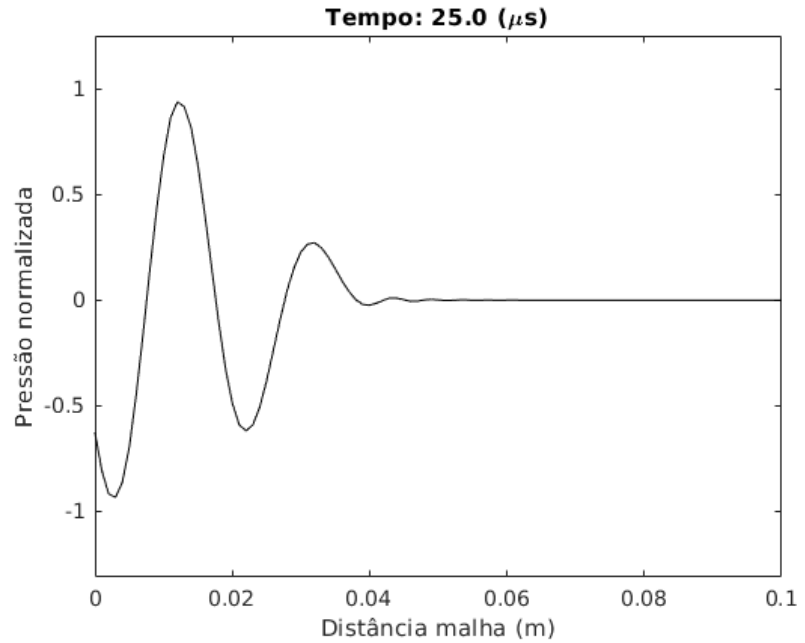

(a) Resultado em $25 \mu s$.

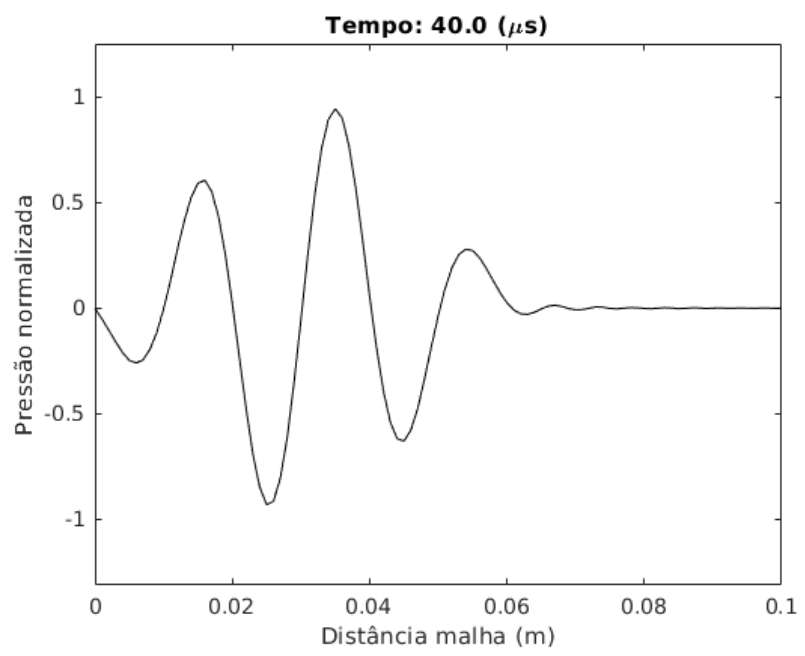

(b) Resultado em $40 \mu s$.

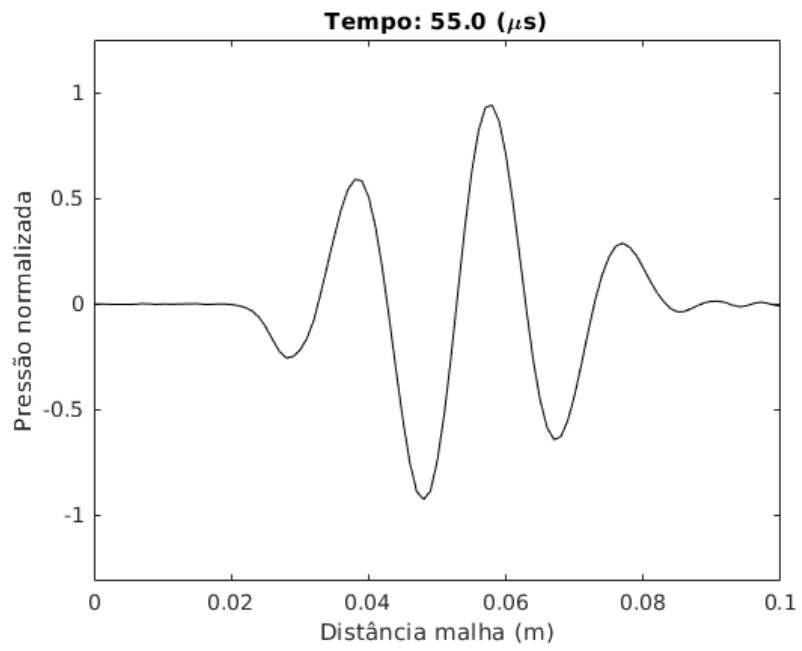

(c) Resultado em $55 \mu s$.

Figura 4.31: Resultado para excitação de $75 \mathrm{kHz}$ ( 20 pontos por comprimento de onda). 


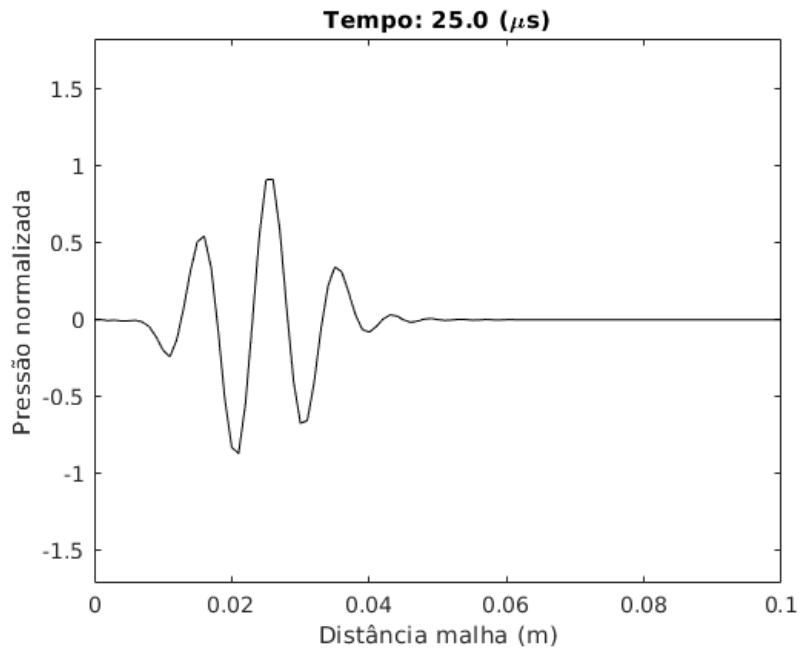

(a) Resultado em $25 \mu \mathrm{s}$.

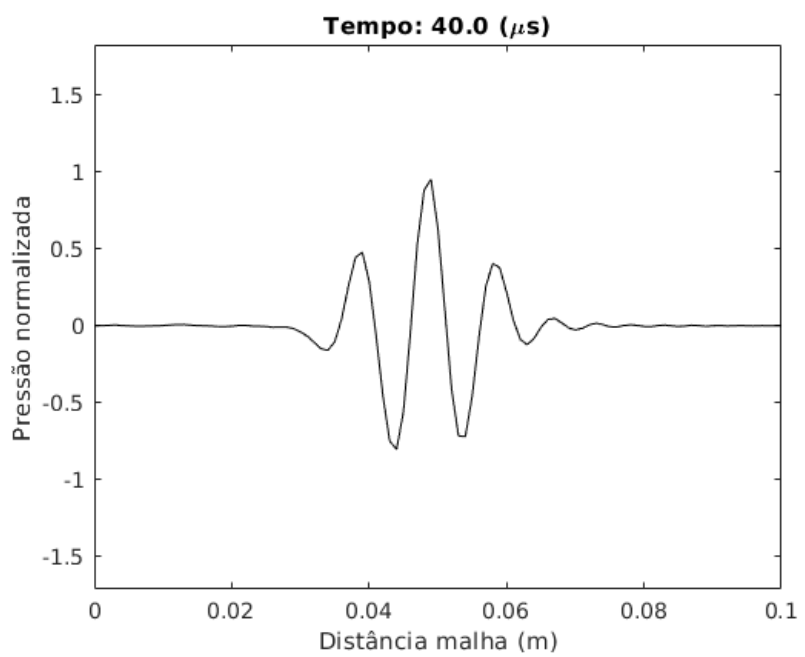

(b) Resultado em $40 \mu s$.

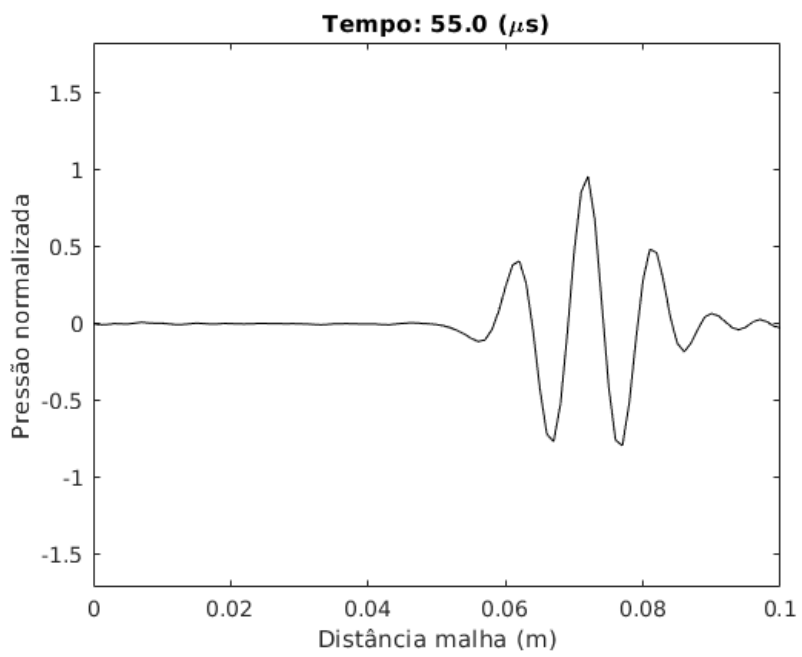

(c) Resultado em $55 \mu s$.

Figura 4.32: Resultado para excitação de $150 \mathrm{kHz}$ (10 pontos por comprimento de onda). 


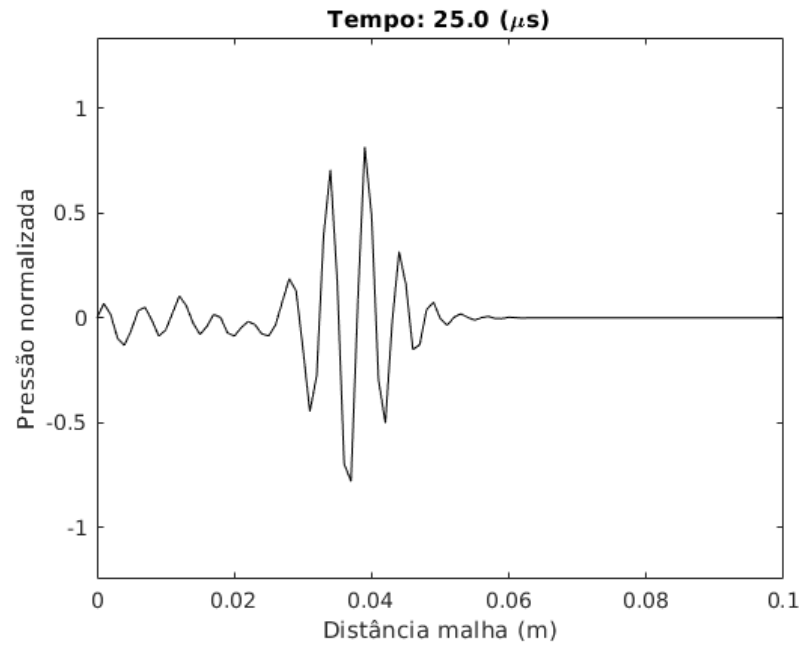

(a) Resultado em $25 \mu \mathrm{s}$.

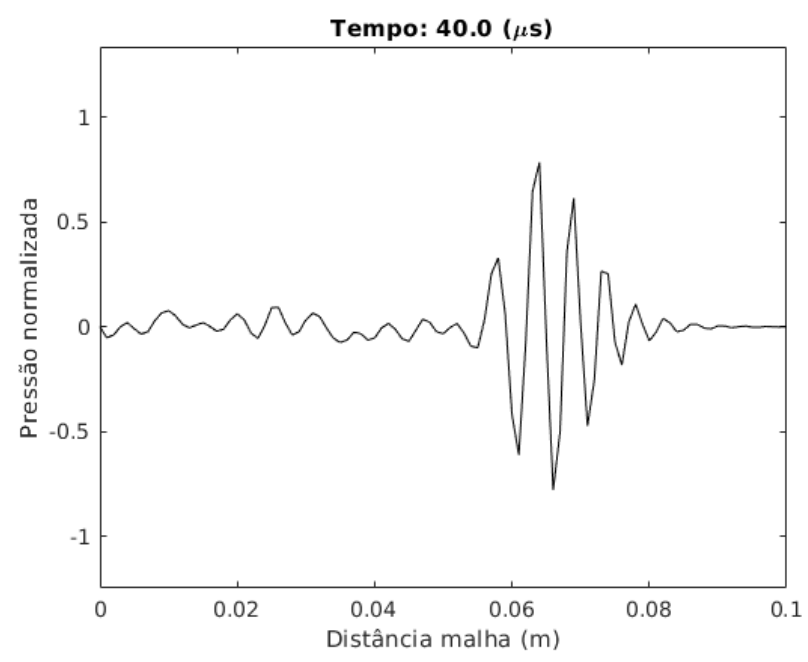

(b) Resultado em $40 \mu s$.

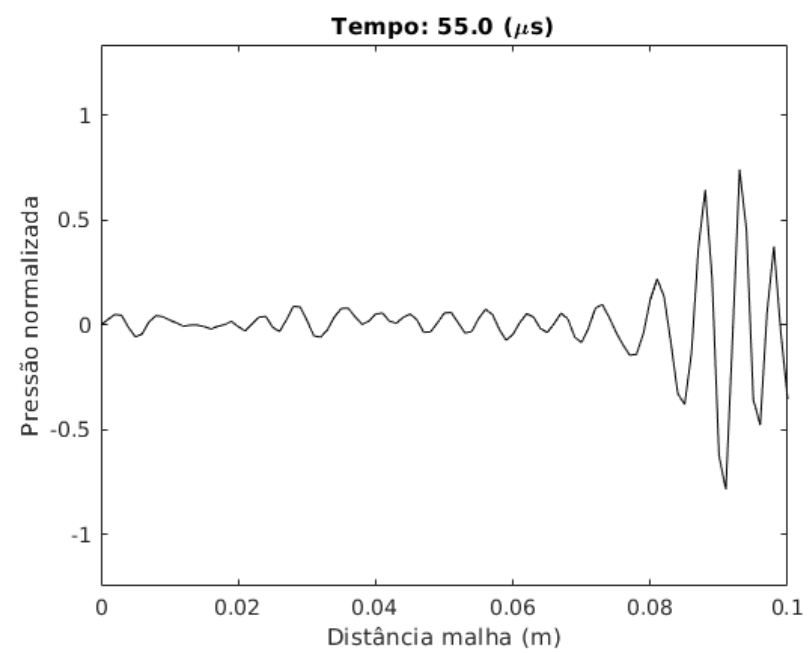

(c) Resultado em $55 \mu s$.

Figura 4.33: Resultado para excitação de $300 \mathrm{kHz}$ (5 pontos por comprimento de onda). 
Como mostrado nas figuras $4.304 .314 .32 \mathrm{e} 4.33$, existe uma pequena ondulação em posições onde a frente de onda ainda não percorreu. Este pode ser um erro de aliasing devido a altas frequências que não foram completamente filtradas, como mostrado na figura da transformada de Fourier das excitações (figura 4.29).

O próximo teste foi considerando uma excitação de $150 \mathrm{kHz}$ e alterando o refinamento da malha. A excitação pode ser vista na figura 4.34 .

As malhas foram geradas de tal forma que o número de pontos por comprimento de onda foram 5, 10, 20 e 30. A figura 4.35 mostra as malhas utilizadas para este teste e o respectivo número de nós e elementos. Todos os outros parâmetros foram mantidos do teste anterior.

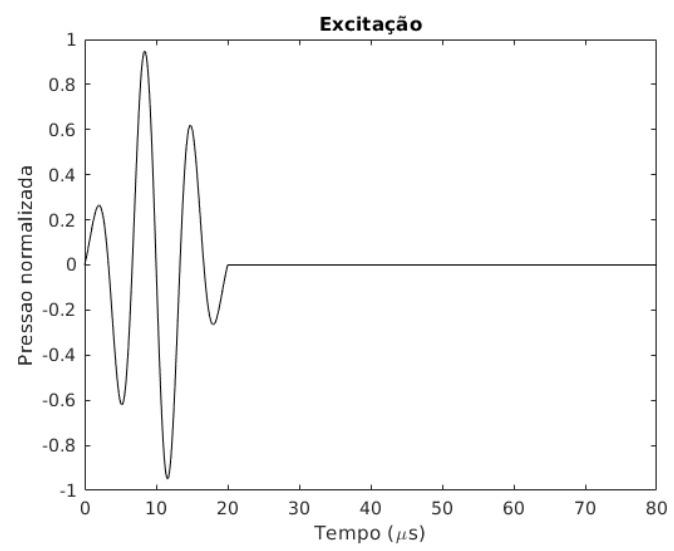

Figura 4.34: Excitação de 150kHz utilizada 

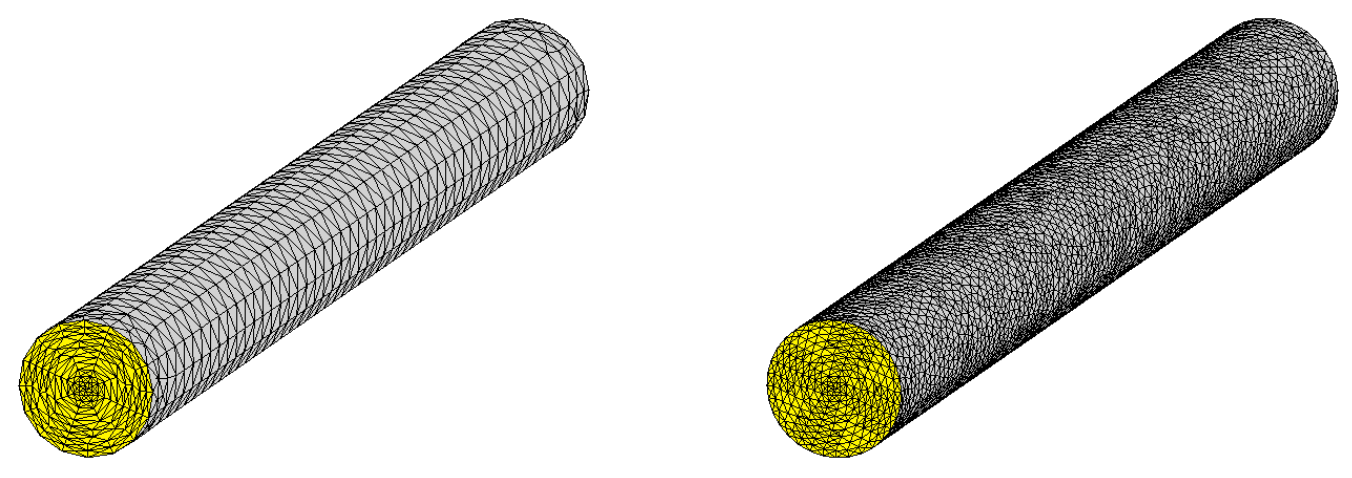

(a) 5 pontos por comprimento de onda, 1,4k nós (b) 10 pontos por comprimento de onda, 9,1k e 5,2k elementos. nós e 40k elementos.
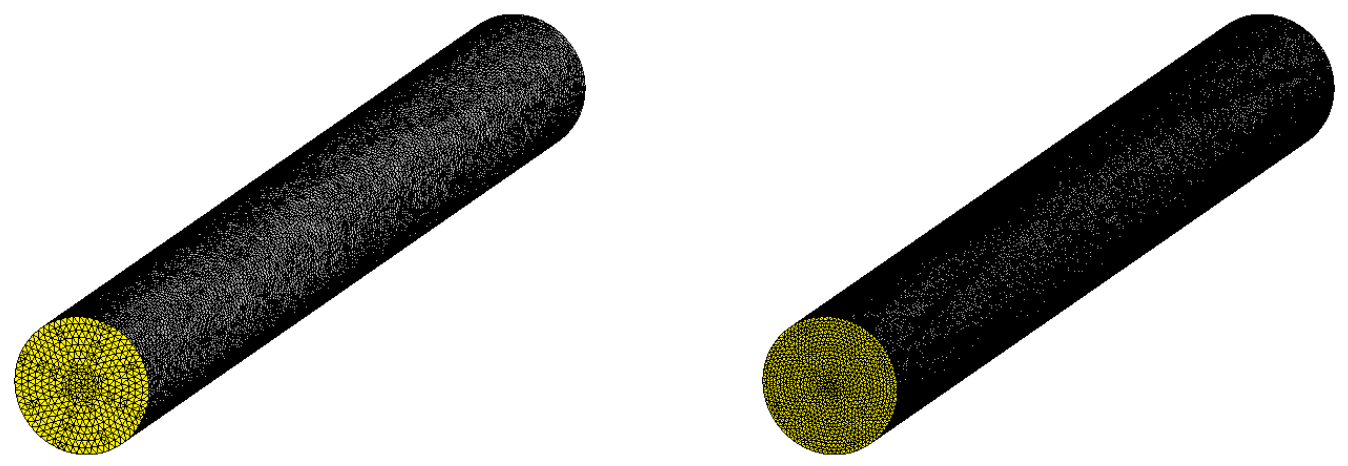

(c) 20 pontos por comprimento de onda, $58 \mathrm{k}$ nós (d) 30 pontos por comprimento de onda, $201 \mathrm{k}$ e 300k elementos. nós e 1091k elementos.

Figura 4.35: Malhas com refinamento diferente

As figuras 4.36, 4.37, 4.38, 4.39 mostram as respostas obtidas para 5, 10, 20 e 30 pontos por comprimento de onda, respectivamente. Estas figuras também mostram a resposta em $25 \mu s, 40 \mu s$ e $55 \mu s$. 


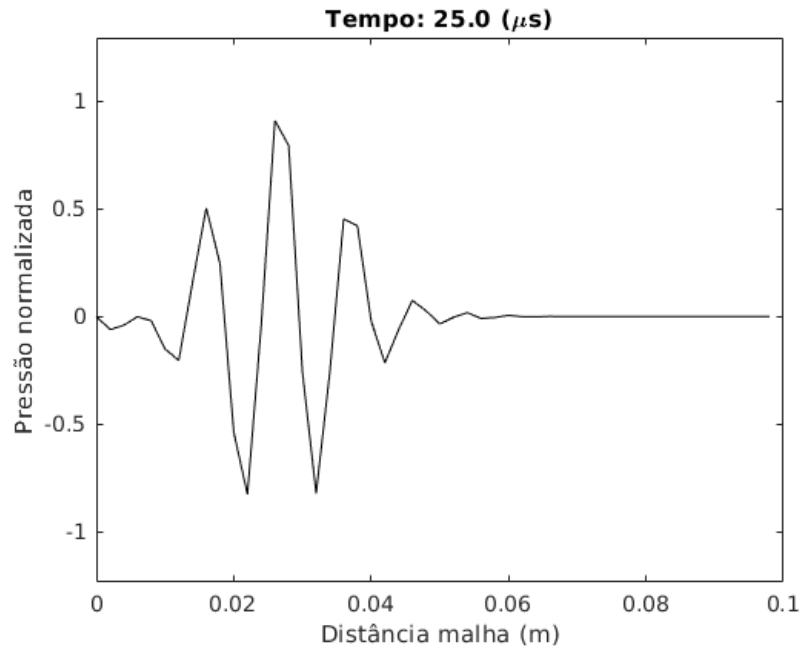

(a) Resultado em $25 \mu s$.

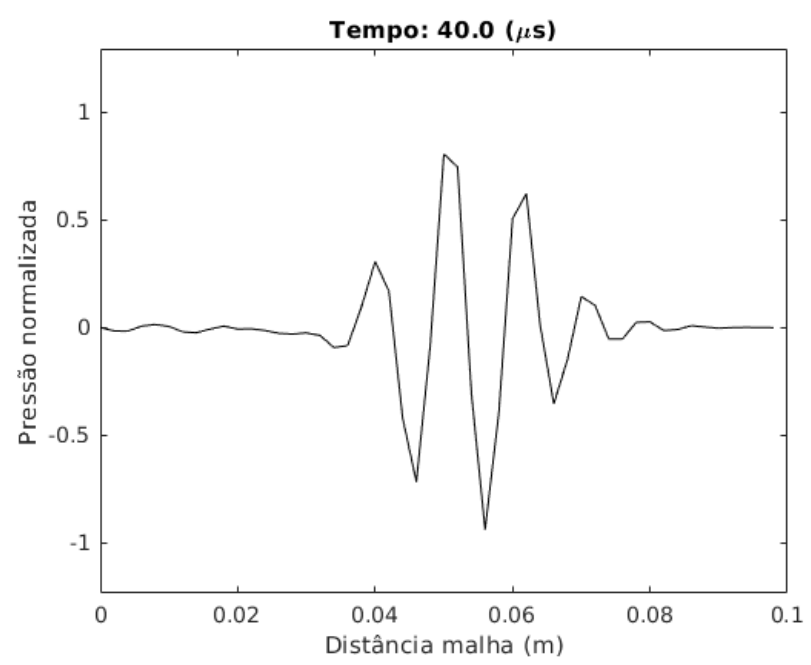

(b) Resultado em $40 \mu s$.

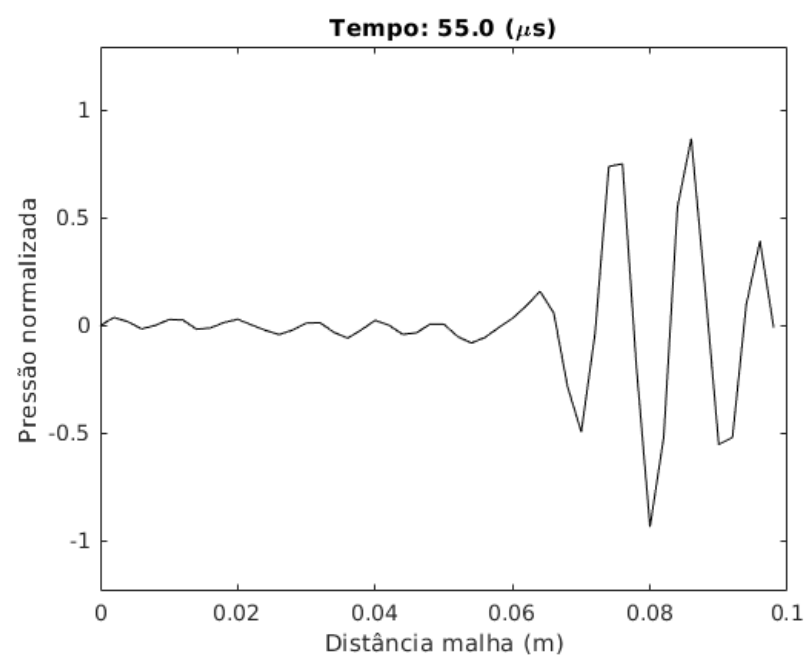

(c) Resultado em $55 \mu s$.

Figura 4.36: Resultado para excitação de $150 \mathrm{kHz}$ e 5 pontos por comprimento de onda. 


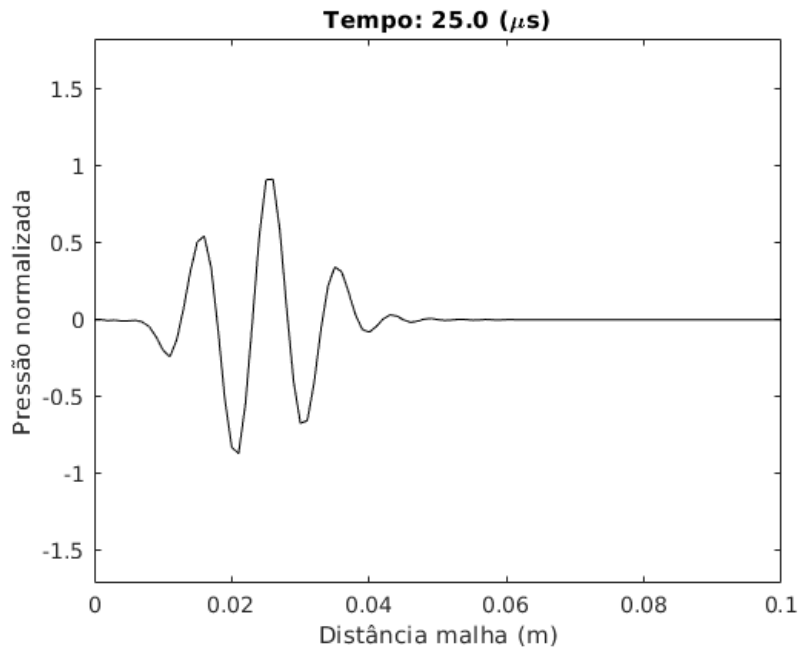

(a) Resultado em $25 \mu s$.

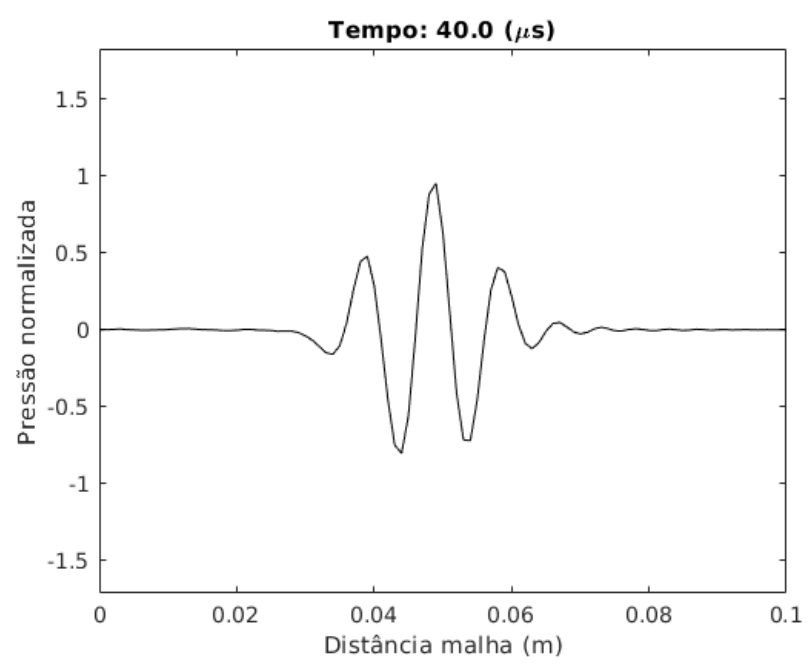

(b) Resultado em $40 \mu \mathrm{s}$.

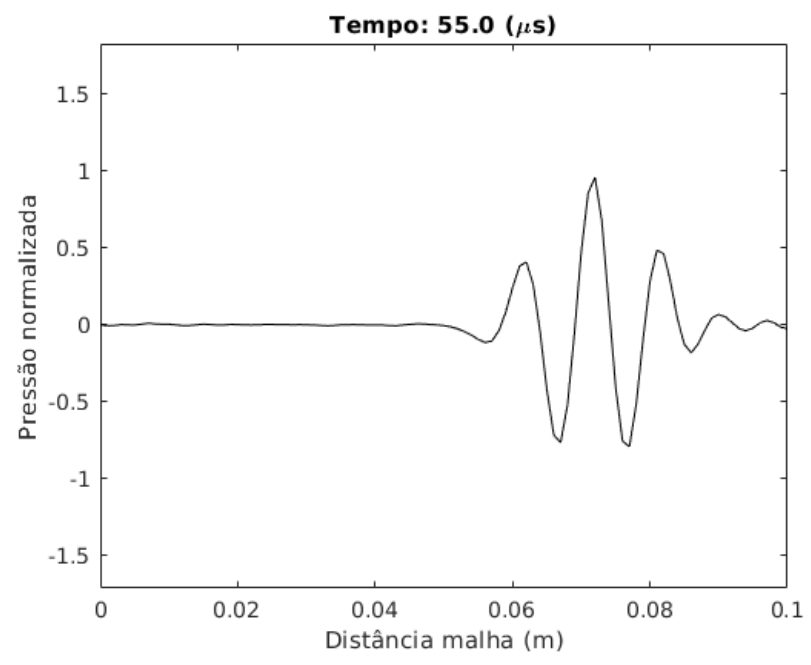

(c) Resultado em $55 \mu s$.

Figura 4.37: Resultado para excitação de $150 \mathrm{kHz}$ e 10 pontos por comprimento de onda. 


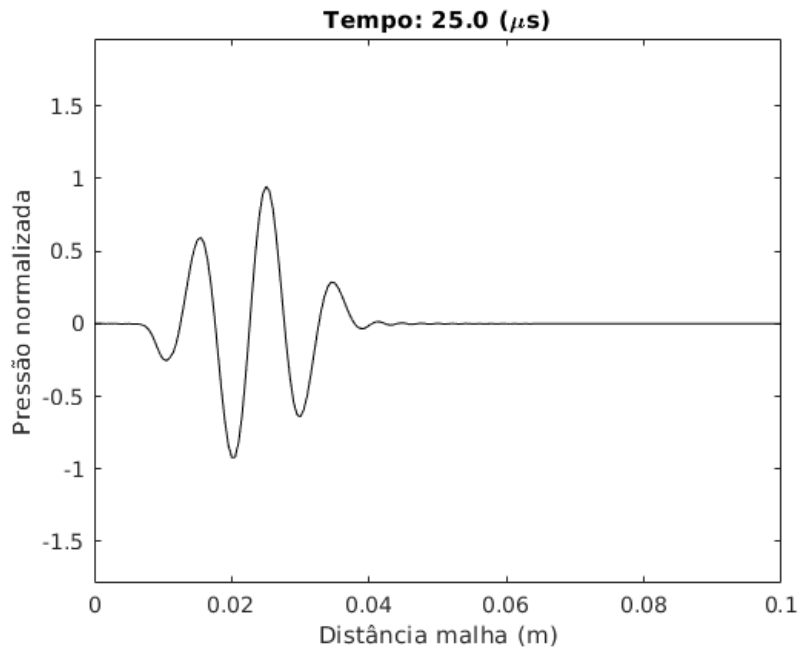

(a) Resultado em $25 \mu s$.

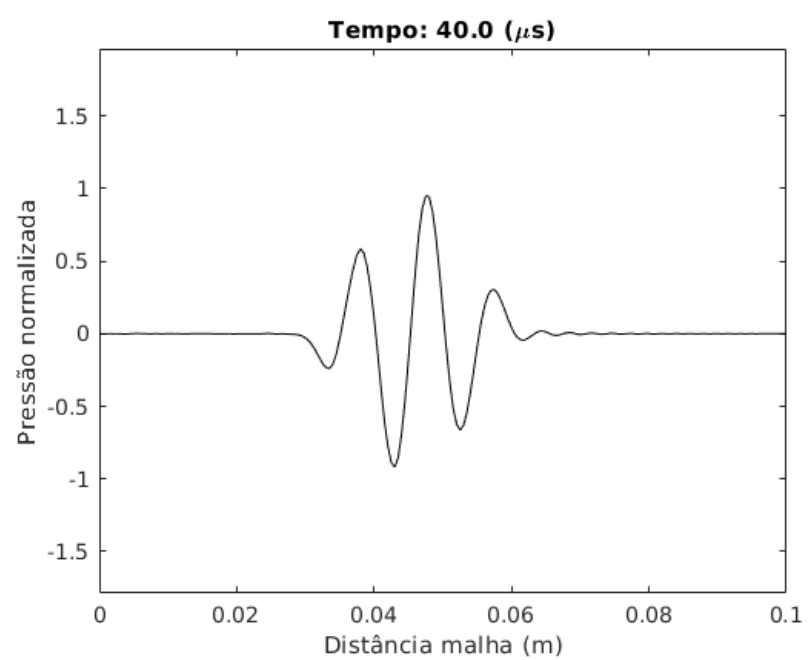

(b) Resultado em $40 \mu s$.

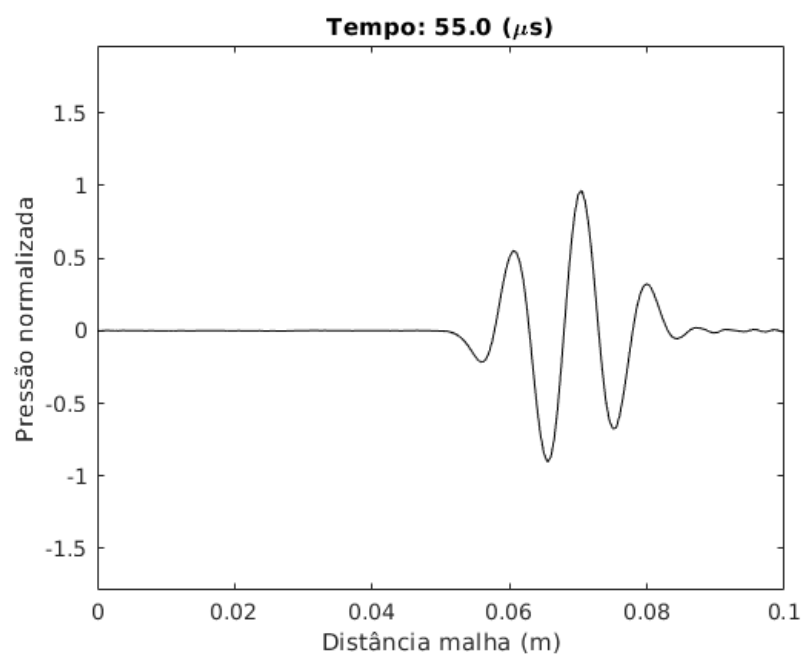

(c) Resultado em $55 \mu \mathrm{s}$.

Figura 4.38: Resultado para excitação de $150 \mathrm{kHz}$ e 20 pontos por comprimento de onda. 


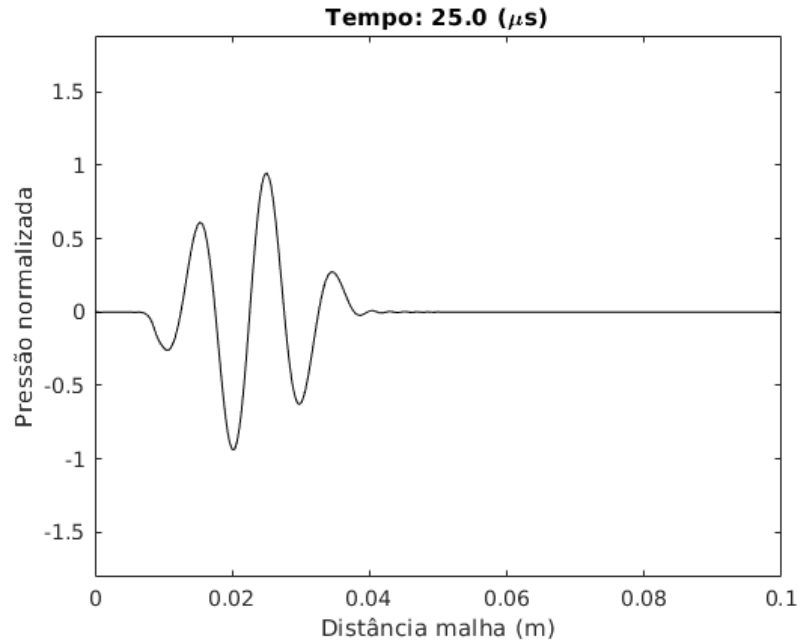

(a) Resultado em $25 \mu \mathrm{s}$.

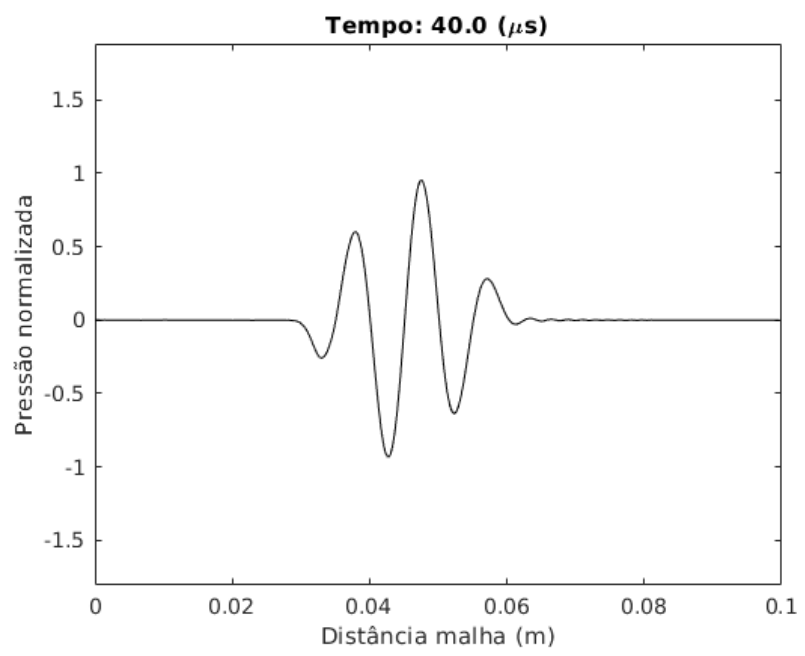

(b) Resultado em $40 \mu s$.

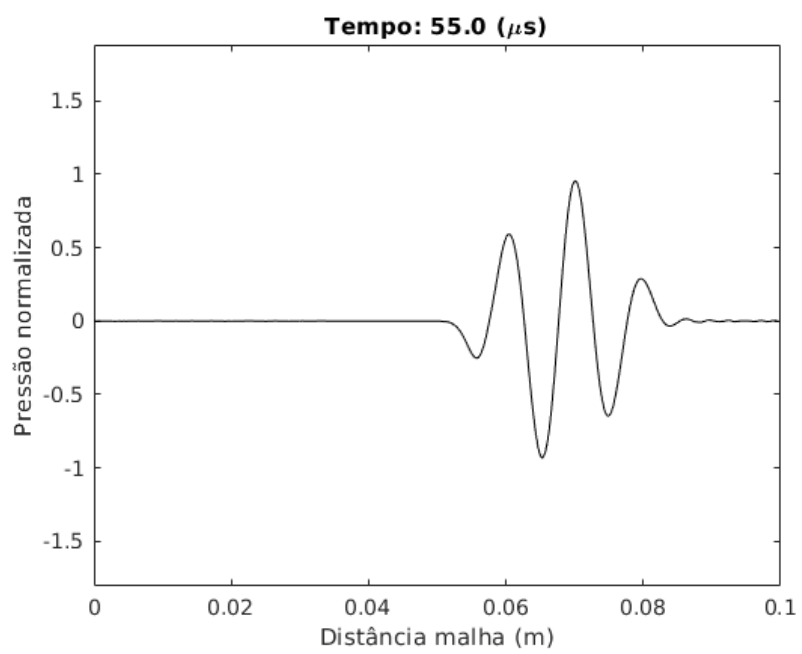

(c) Resultado em $55 \mu s$.

Figura 4.39: Resultado para excitação de $150 \mathrm{kHz}$ e 30 pontos por comprimento de onda. 
Como mostrado nas figuras $4.36,4.37,4.38 \mathrm{e} 4.39$, a ondulação onde a frente de onda ainda não percorreu também existe para este teste. A amplitude deste erro diminui com o aumento do número de pontos por comprimento de onda.

Além disso, a figura 4.36 apresenta grandes erros, indicando que este número de pontos por comprimento de onda é insatisfatório. A figura 4.37 apresenta erros menores, porém seu comportamento é diferente das respostas mostradas nas figuras $4.38 \mathrm{e}$ 4.39. Existe uma pequena diferença entre as respostas das figuras $4.38 \mathrm{e} 4.39$, porém esta diferença pode ser desconsiderada.

Os resultados dos dois testes anteriores mostram que a resposta apresenta um comportamento indesejado quando são utilizados poucos pontos por comprimento de onda. Para estes testes realizados, o erro de discretização aparenta se tornar desprezível a partir de 20 pontos por comprimento de onda. Caso a excitação utilizada possuísse uma largura de banda menor e sem componentes de alta frequência, é possível que o número de pontos necessários seja menor.

Os próximos testes têm como objetivo verificar a velocidade de propagação da onda. Neste teste foi utilizado a malha mostrada na figura 4.40. Esta malha possui $0,2 m$ de comprimento e $0,01 m$ de diâmetro. Seu número de nós é $364 k$ e seu número de elementos é $1980 k$.

No centro desta malha, existe uma região de $0,035 \mathrm{~m}$ que foi considerada como meio no primeiro teste (velocidade do som de $1500 \mathrm{~m} / \mathrm{s}$ ) e como um objeto no segundo teste (velocidade do som de $3500 \mathrm{~m} / \mathrm{s}$ ). A figura 4.41 mostra este objeto na malha de elementos finitos.

O refinamento desta malha foi de 30 pontos por comprimento de onda para uma excitação de $150 \mathrm{kHz}$. O intervalo de integração foi mantido dos testes anteriores, porém o tempo máximo de simulação foi de $110 \mu$ s. 


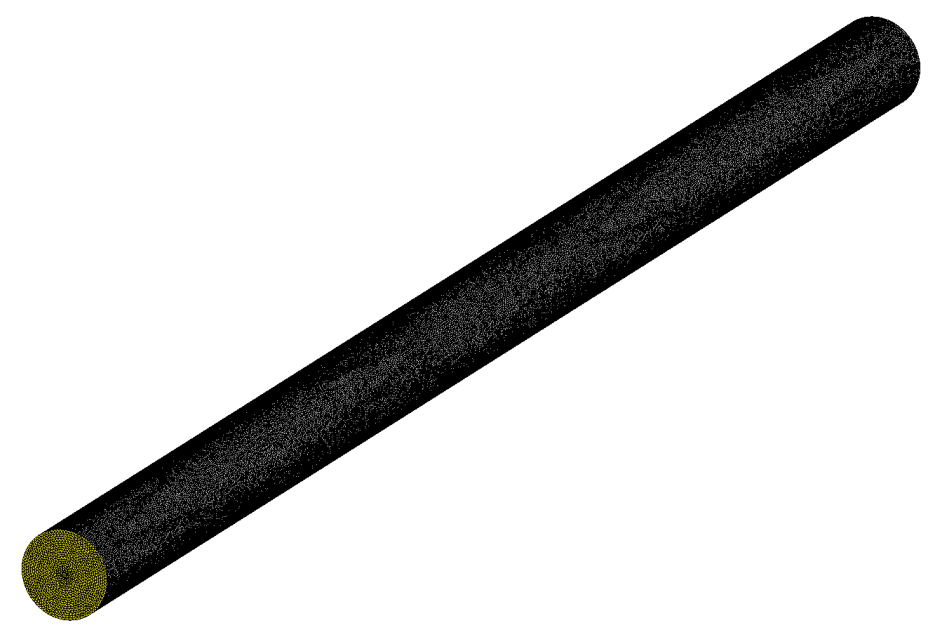

Figura 4.40: Malha utilizada para os testes de velocidade do som

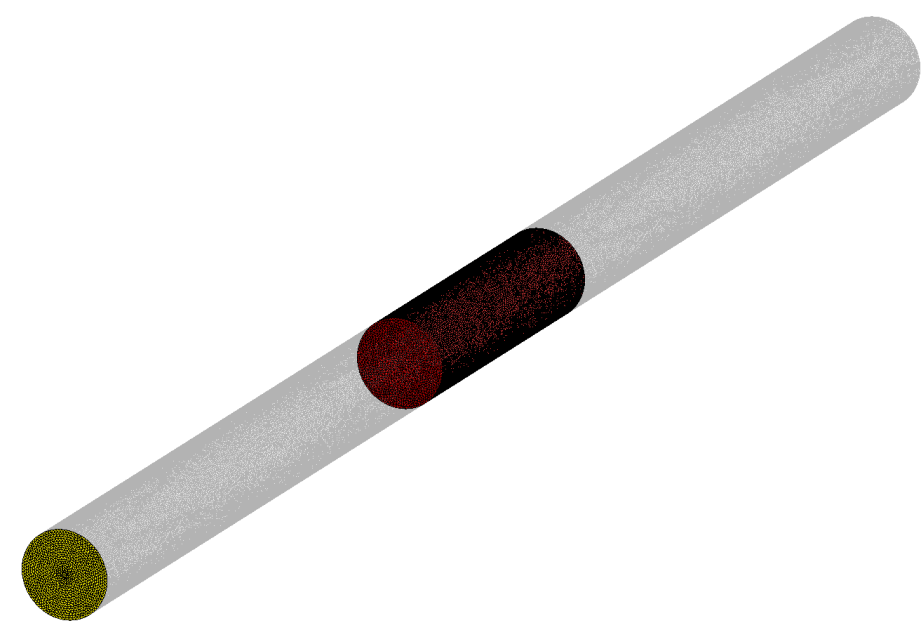

Figura 4.41: Objeto na malha de elementos finitos

A figura 4.42 mostra os valores de dois instantes de tempo distintos do primeiro teste. 


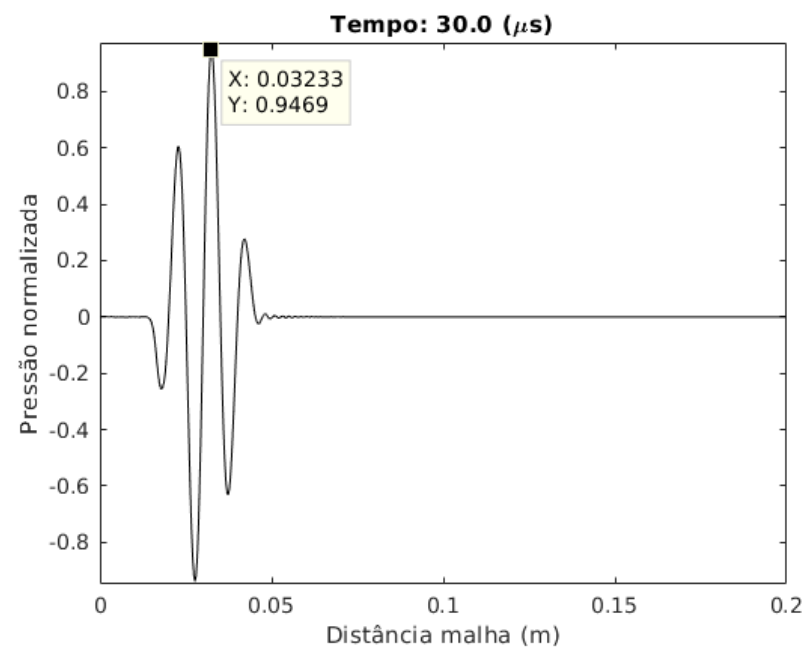

(a) Resultado em $30 \mu s$.

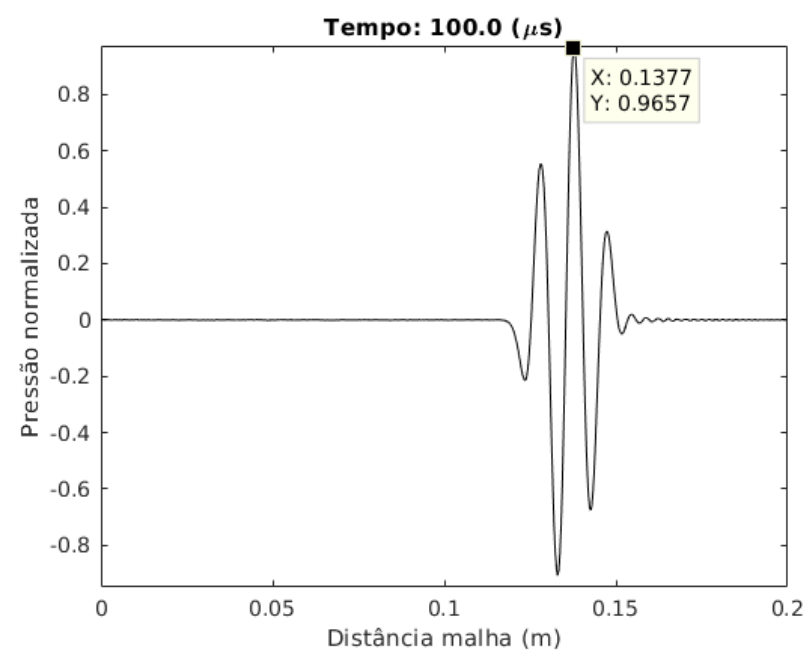

(b) Resultado em $100 \mu \mathrm{s}$.

Figura 4.42: Distância e tempo percorrido pela onda.

Pela figura 4.42, a distância percorrida pela onda foi de $\Delta x_{n}=0,1377-0,03233=$ $0,1054 m$ e o tempo de propagação $\Delta t_{n}=70 \mu \mathrm{s}$. Logo, a velocidade do som numérica estimada é $c_{n}^{\text {meio }}=0,1054 \mathrm{~m} / 70 \mu \mathrm{s} \approx 1505,3 \mathrm{~m} / \mathrm{s}$. Como a velocidade do som no meio imposta foi de $1500 \mathrm{~m} / \mathrm{s}$, o erro da velocidade do som no meio é de, aproximadamente, $0,35 \%$.

Da mesma forma, a figura 4.43 mostra os valores de dois instantes de tempo distintos com um objeto inserido entre os trasdutores (segundo teste). 


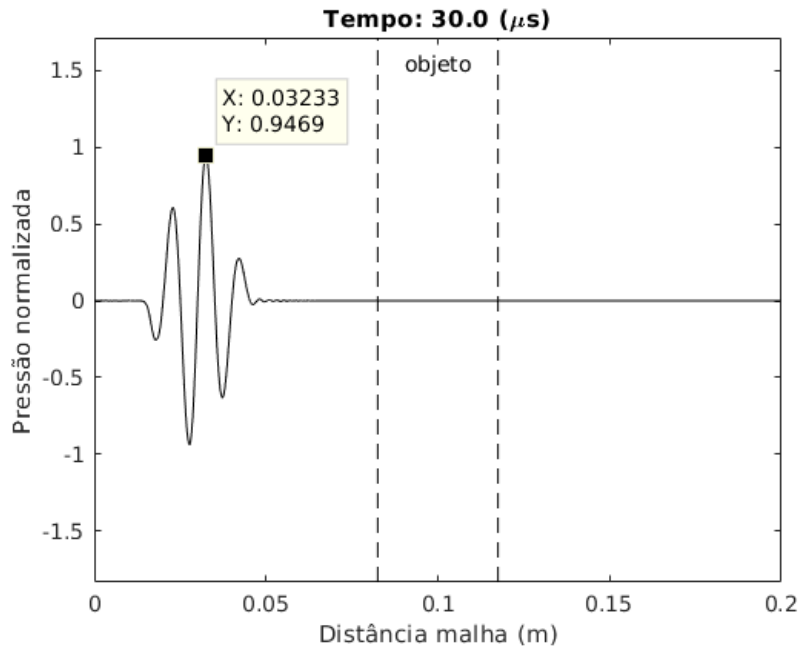

(a) Resultado em $30 \mu s$.

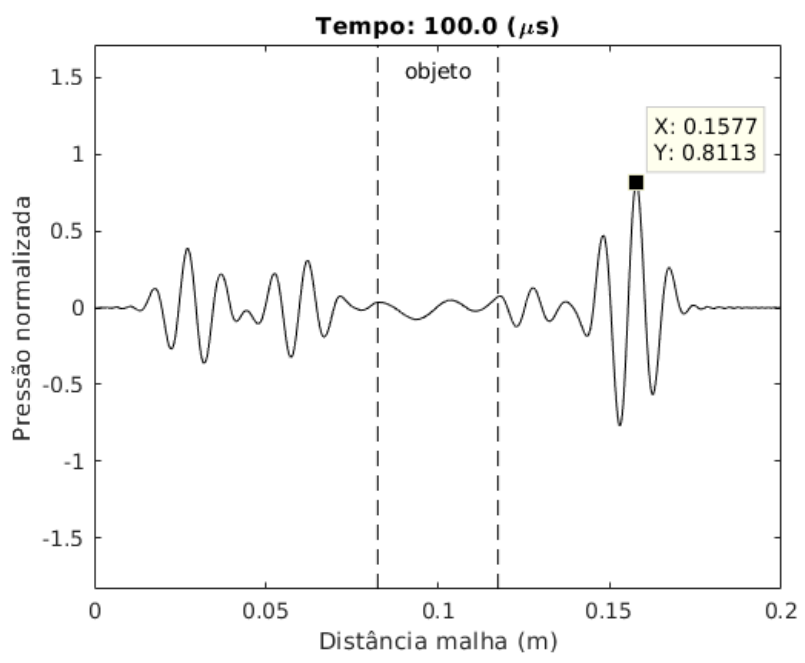

(b) Resultado em $100 \mu \mathrm{s}$.

Figura 4.43: Distância e tempo percorrido pela onda com um objeto inserido entre os transdutores.

Neste caso, a distância total percorrida foi de $d_{n}^{\text {tot }}=0,1577-0,03233=0,1254 m$ e o tempo de propagação total foi de $t_{n}^{\text {tot }}=70 \mu \mathrm{s}$. O objeto inserido possui espessura $d_{n}^{o b j}=0,035 \mathrm{~m}$. Utilizando a velocidade do meio calculada no teste anterior $\left(c_{n}^{\text {meio }}=\right.$ $1505,3 \mathrm{~m} / \mathrm{s}$ ), a velocidade do som no objeto calculada é $c_{n}^{o b j} \approx 3512,1 \mathrm{~m} / \mathrm{s}$. Como a velocidade do som no objeto imposta foi de $3500 \mathrm{~m} / \mathrm{s}$, o erro da velocidade do som no objeto é de, aproximadamente, $0,35 \%$.

Como os erros da velocidade do som no meio e da velocidade do som no objeto são pequenos, o parâmetro de velocidade do som aparenta estar coerente. 
Além disso, no caso do teste com o objeto inserido, pode-se observar que existem fenômenos de transmissão da onda. A figura 4.44 mostra o mesmo teste em mais instantes de tempo.

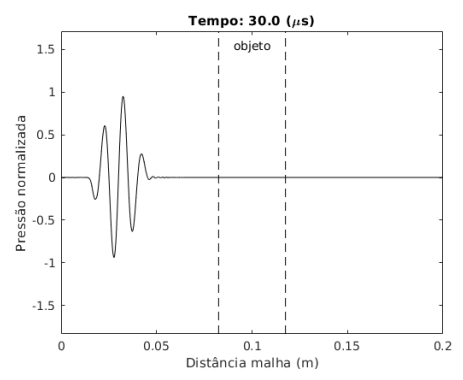

(a) Resultado em $30 \mu s$.

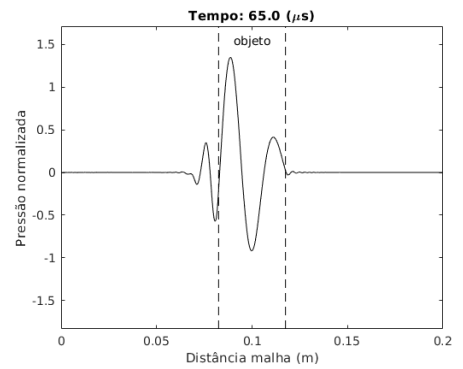

(d) Resultado em $65 \mu \mathrm{s}$.

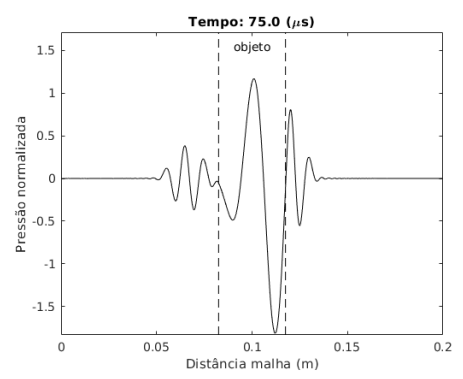

(g) Resultado em $75 \mu \mathrm{s}$.

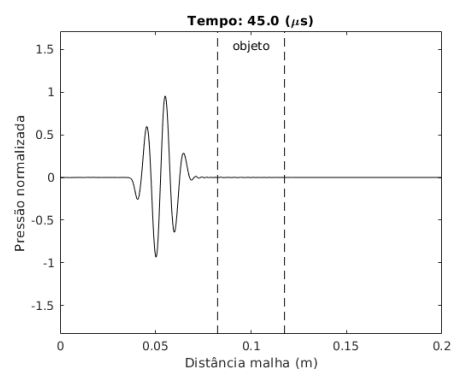

(b) Resultado em $45 \mu \mathrm{s}$.

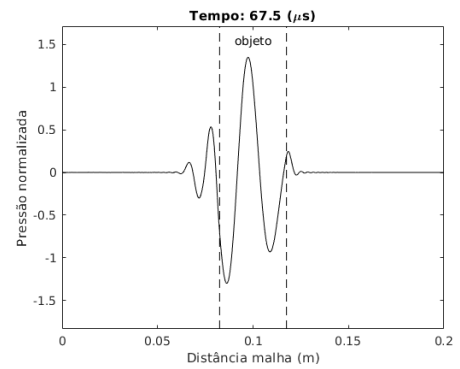

(e) Resultado em $67,5 \mu s$.

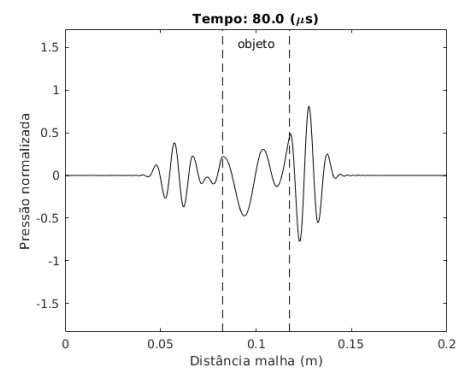

(h) Resultado em $80 \mu \mathrm{s}$.

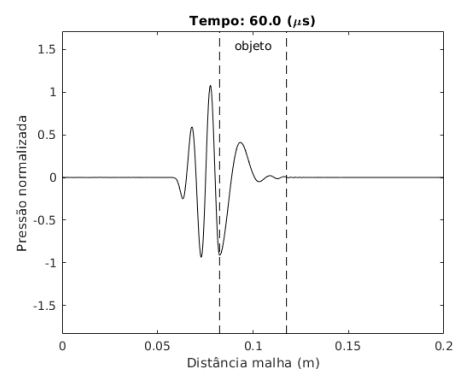

(c) Resultado em $60 \mu \mathrm{s}$.

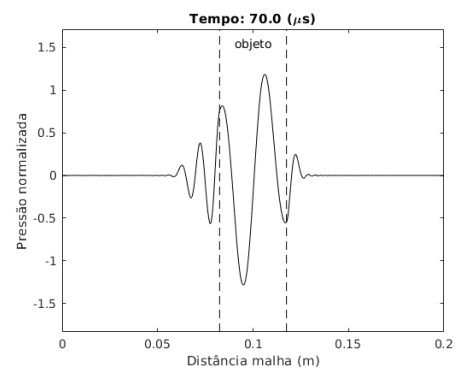

(f) Resultado em $70 \mu \mathrm{s}$.

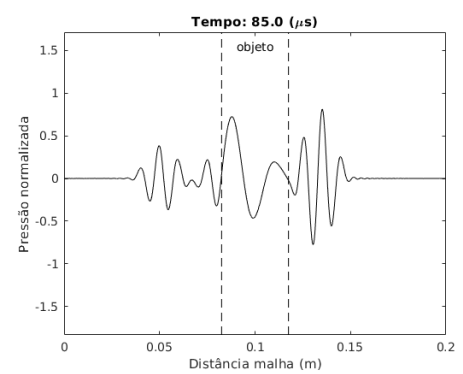

(i) Resultado em $85 \mu \mathrm{s}$.

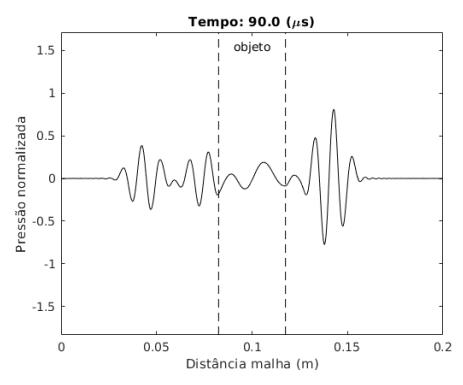

(j) Resultado em $90 \mu \mathrm{s}$.

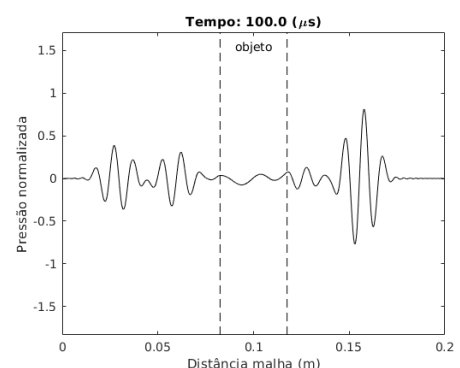

(k) Resultado em $100 \mu \mathrm{s}$.

Figura 4.44: Propagação da onda com objeto inserido entre transdutores. 
O gráfico da figura 4.45, mostra os valores máximos da amplitude da onda, ao longo de todo o espaço, para todos os instantes de tempo.

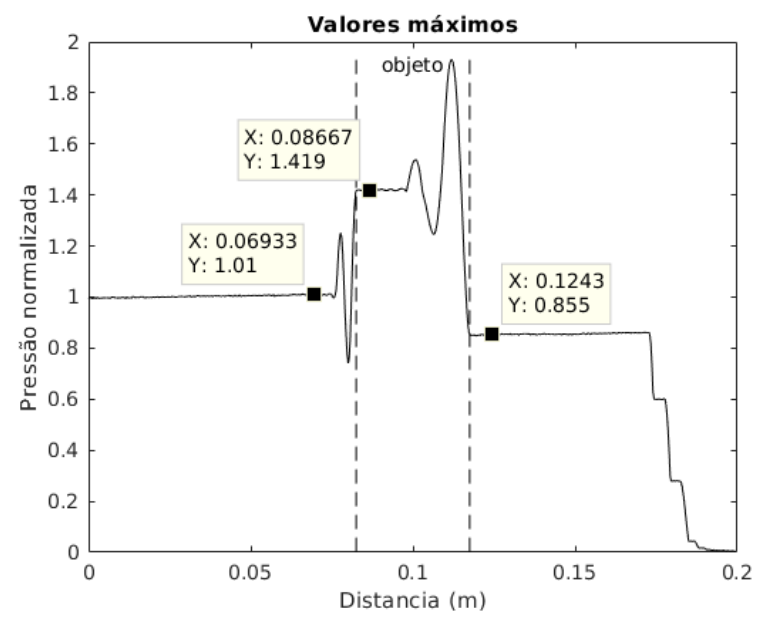

Figura 4.45: Valores máximos da amplitude da onda propagada

Utilizando os valores de velocidade do som ao invés da impedância acústica para calcular a relação de amplitudes da onda transmitida com a onda incidente, para o caso em que a onda passa do meio para o objeto a relação fica $2 \times 3500 /(1500+3500)=1,4$ e do objeto para o meio fica $2 \times 1500 /(1500+3500)=0,6$. Utilizado os valores da figura 4.45, a relação de amplitudes do meio para o objeto é $1,419 / 1,01=1,4050$ e do objeto para o meio é de $0,855 / 1,419=0,6025$. Portanto os valores de reflexão parecem coerentes.

O próximo teste tem como objetivo verificar o comportamento do parâmetro de atenuação. A figura 4.46 mostra o valor da amplitude da onda quando um valor não desprezível de atenuação é utilizado $\left(\alpha=10^{-2} s / m^{2}\right)$. A figura 4.47 mostra os valores máximos desta amplitude ao longo do tempo. Como pode ser visto, o comportamento de decaimento aparentemente exponencial ao longo do espaço é observado. O valor do coeficiente de atenuação no tempo $(\alpha)$ está relacionado com o coeficiente de atenuação no espaço e a velocidade do som. Novos testes devem ser desenvolvidos para se obter a relação exata. 


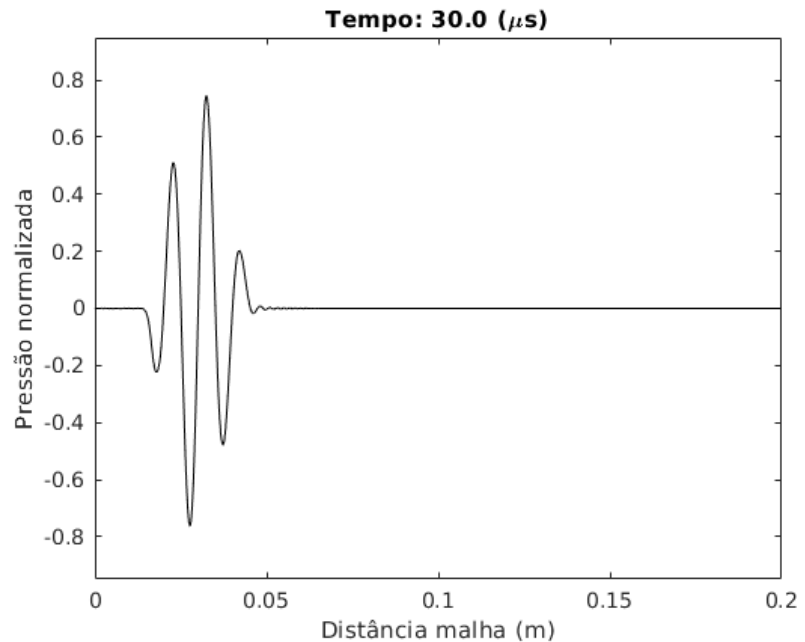

(a) Resultado em $30 \mu \mathrm{s}$.

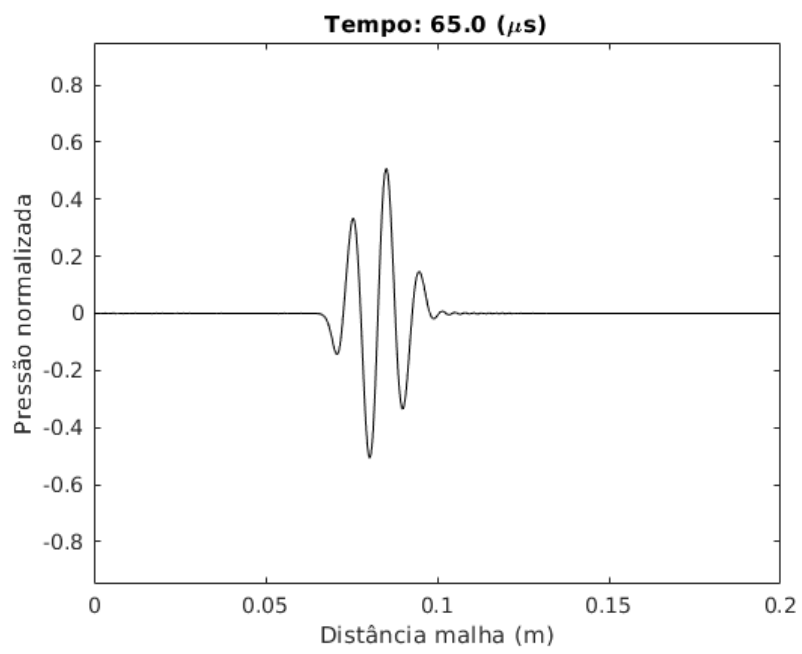

(b) Resultado em $65 \mu \mathrm{s}$

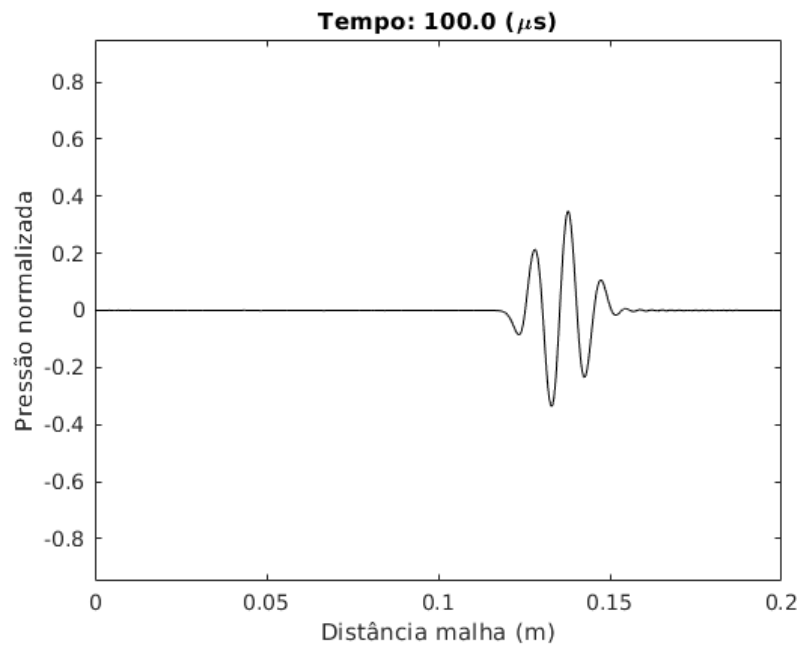

(c) Resultado em $100 \mu \mathrm{s}$.

Figura 4.46: Amplitude em diferentes instante de tempo para um valor de atenuação não desprezível. 


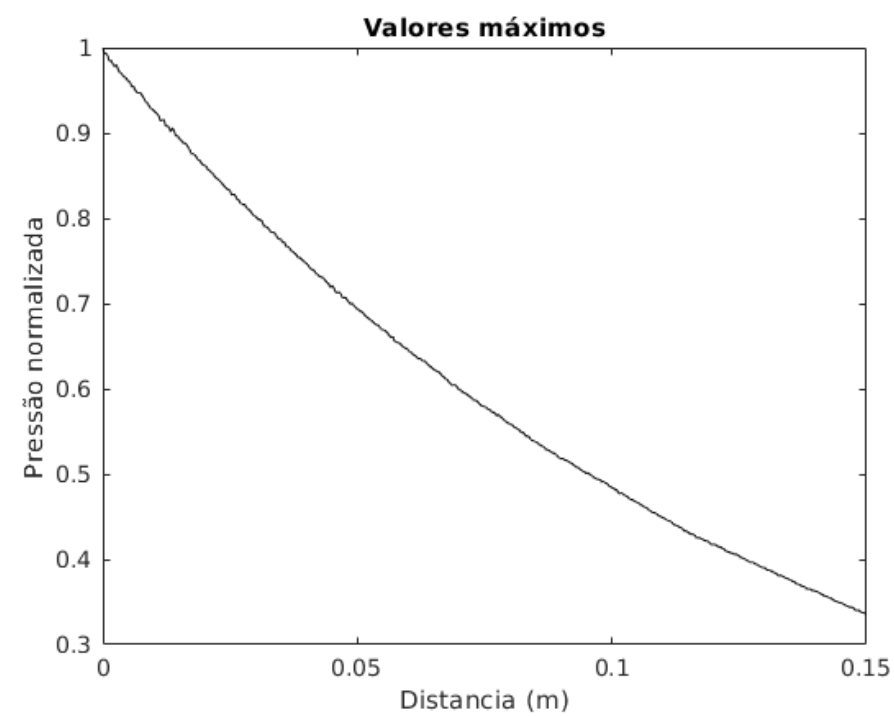

Figura 4.47: Máximo valor das amplitude para um valor de atenuação não desprezível.

\section{Testes com malhas semi-esféricas}

Os próximos testes verificam o comportamento da onda em um espaço tridimensional. Para este teste, foram utilizadas malhas com formato semi-esférico, cujo raio é igual à $0,1 \mathrm{~m}$. Este raio escolhido para que não ocorra reflexões da onda no espaço de interesse.

Foram utilizadas duas malhas, uma para uma excitação de $75 \mathrm{kHz}$ e outra para uma excitação de $150 \mathrm{kHz}$. As excitações utilizadas foram as mesmas do teste de discretização da malha, mostradas nas figuras 4.28(b) e 4.28(c). A malha para a excitação de $75 \mathrm{kHz}$ possui, aproximadamente, $189 k$ nós e $1074 k$ elementos e a malha para a excitação de $150 \mathrm{kHz}$ possui, aproximadamente, $1326 k$ nós e $7859 k$ elementos. Ambas as malhas possuem discretização de tal forma que sua respectiva excitação possua 10 pontos por comprimento de onda. A figura 4.48 mostra a malha utilizada para excitação de $75 \mathrm{kHz}$ e a figura 4.49 mostra a malha utilizada para a excitação de $150 \mathrm{kHz}$. A velocidade do som do meio utilizada foi $1500 \mathrm{~m} / \mathrm{s}$, atenuação foi $\alpha=10^{-12} \mathrm{~s} / \mathrm{m}^{2}$, intervalo de integração foi de $0,01 \mu$ s e tempo total de integração foi de $80 \mu s$. 


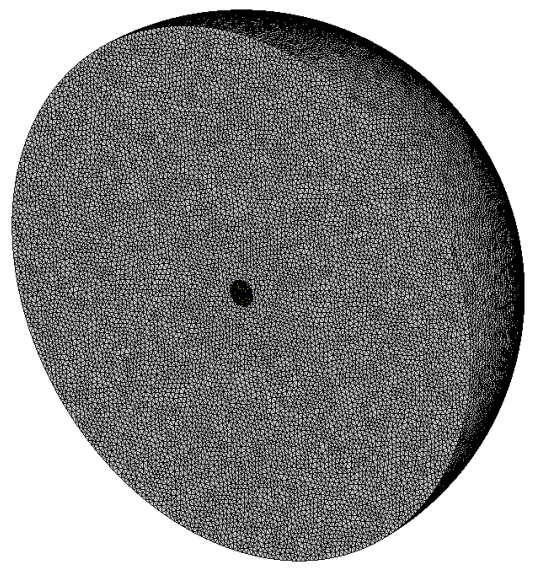

(a) Malha utilizada.

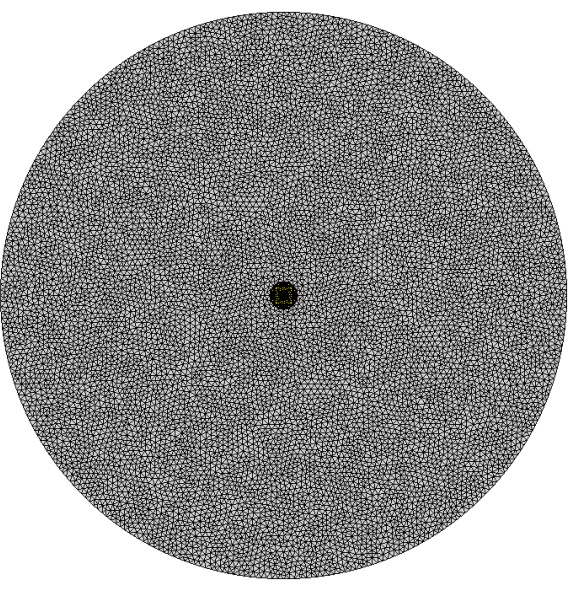

(b) Vista Frontal.

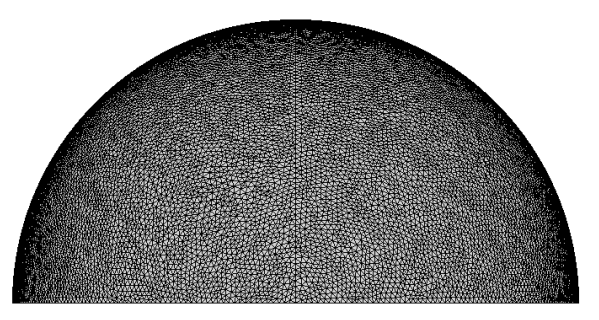

(c) Vista Superior.

Figura 4.48: Malha esférica utilizada para excitação de $75 \mathrm{kHz}$. 


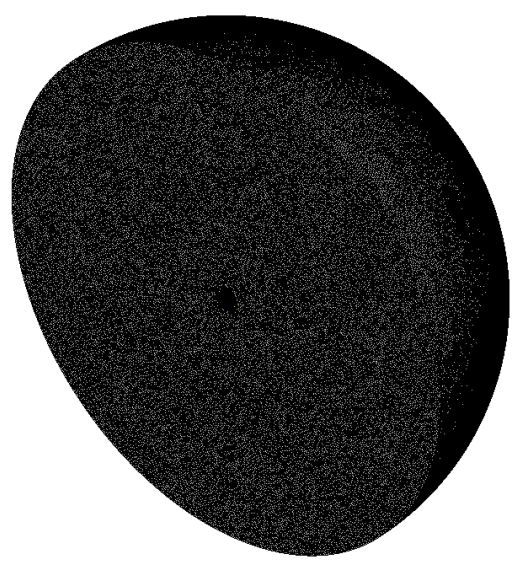

(a) Malha utilizada.

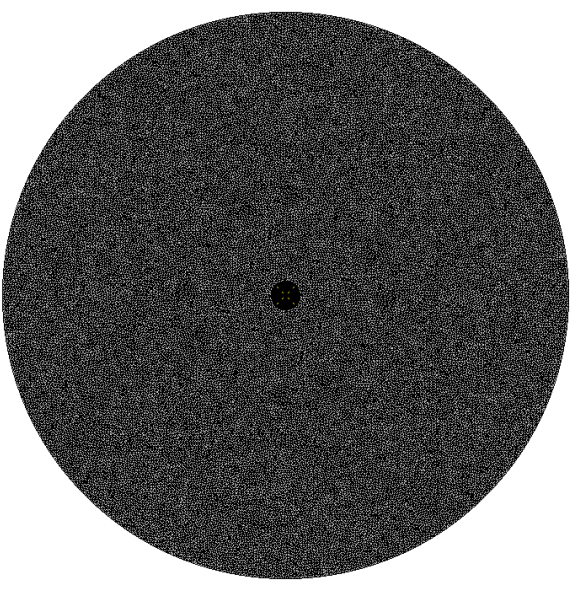

(b) Vista Frontal.

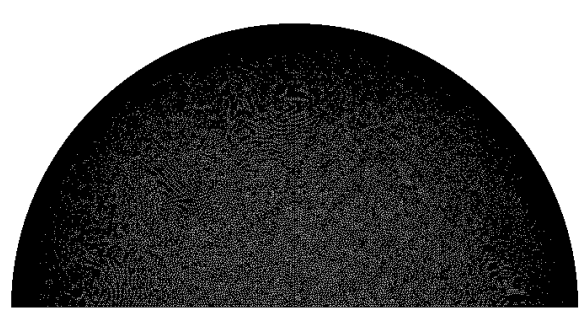

Figura 4.49: Malha esférica utilizada para excitação de 150kHz.

As figuras 4.50 e 4.51 mostram as saídas obtidas para a excitação de $75 \mathrm{kHz}$ e $150 \mathrm{kHz}$, respectivamente. As figuras $4.52 \mathrm{e} 4.53$ mostram os valores máximos da saída em função da distância, para a excitação de $75 \mathrm{kHz}$ e $150 \mathrm{kHz}$, respectivamente. 


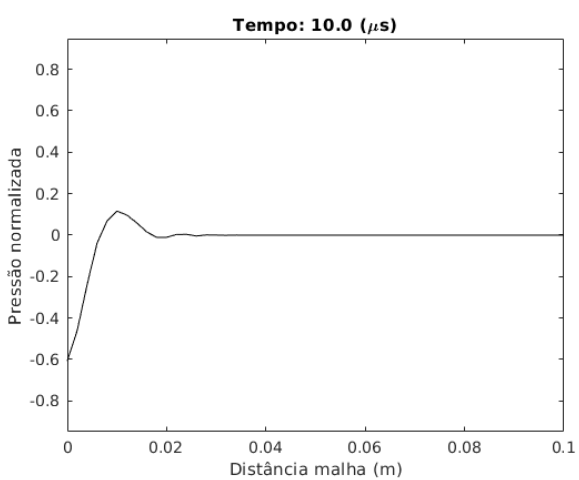

(a) Resultado em $10 \mu \mathrm{s}$.

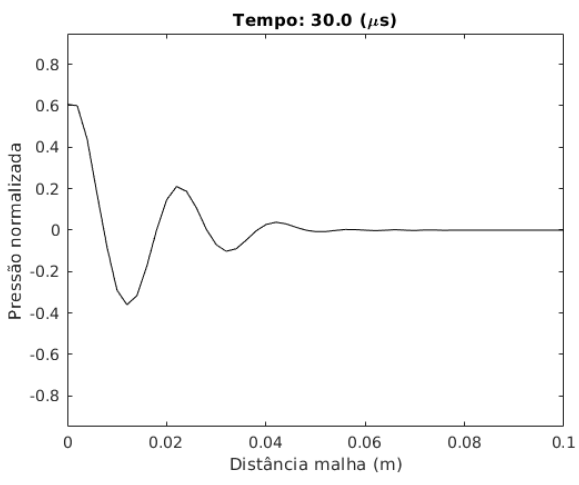

(c) Resultado em $30 \mu s$.

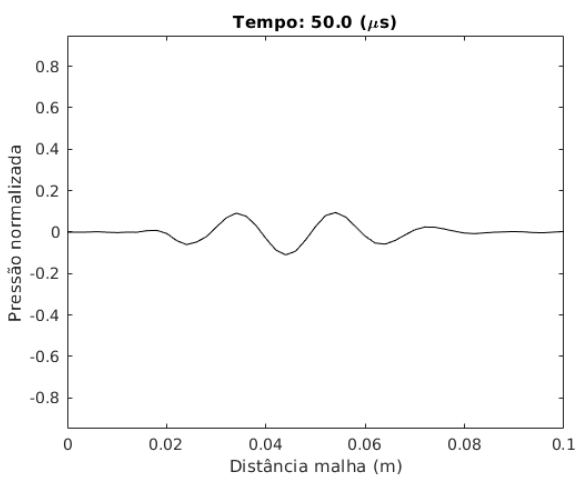

(e) Resultado em $50 \mu s$.

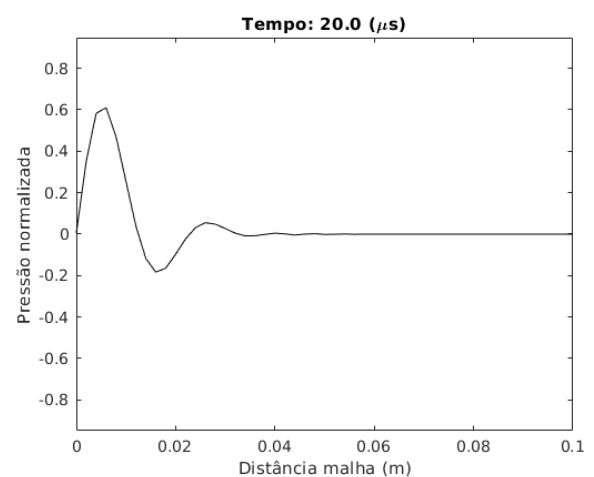

(b) Resultado em $20 \mu s$.

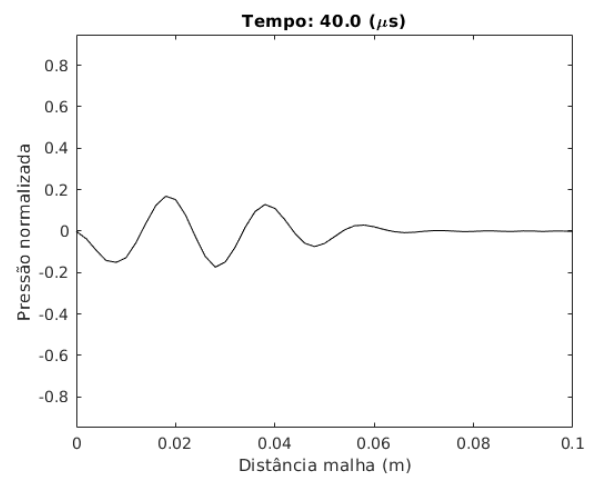

(d) Resultado em $40 \mu \mathrm{s}$.

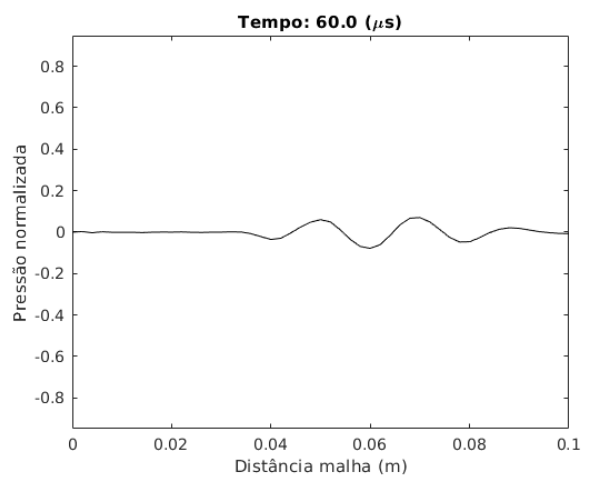

(f) Resultado em $60 \mu \mathrm{s}$.

Figura 4.50: Resultado para malha esférica utilizando excitação de 75kHz. 


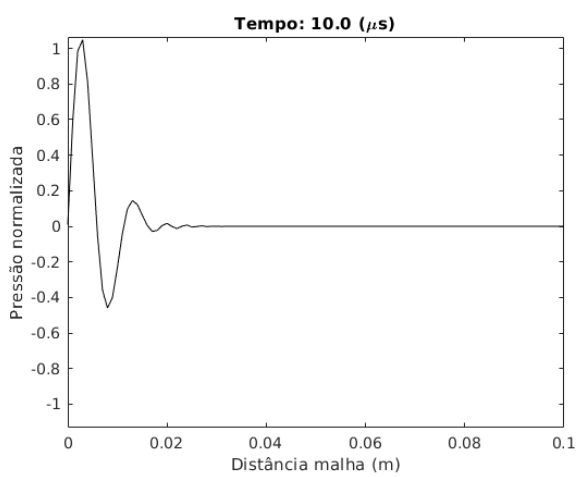

(a) Resultado em $10 \mu \mathrm{s}$.

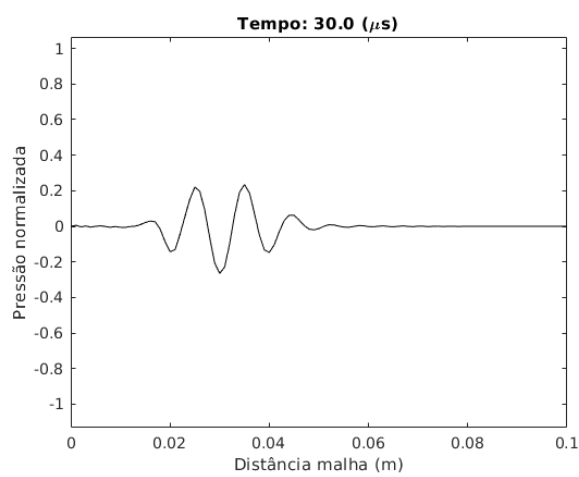

(c) Resultado em $30 \mu \mathrm{s}$.

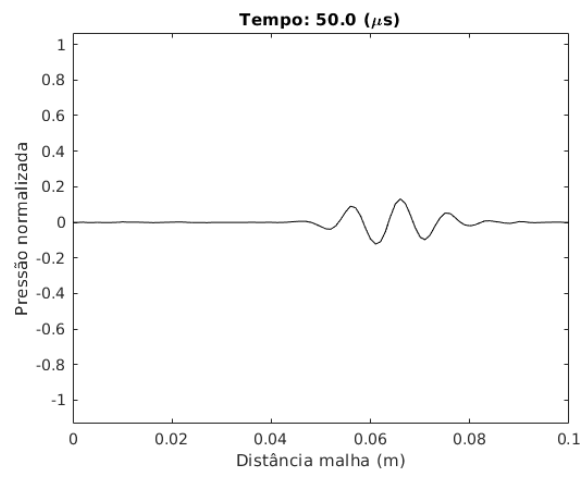

(e) Resultado em $50 \mu s$.

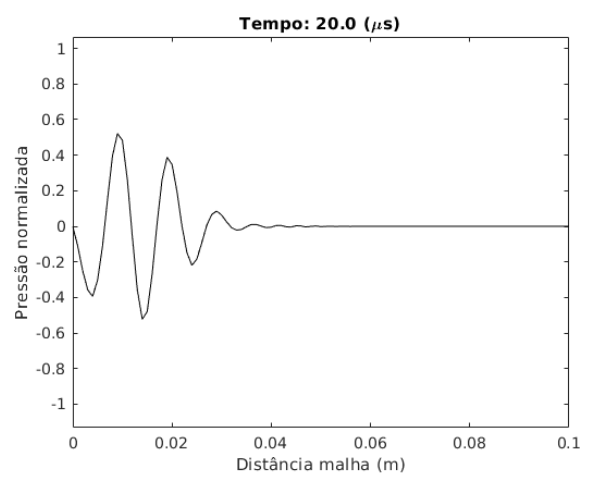

(b) Resultado em $20 \mu \mathrm{s}$.

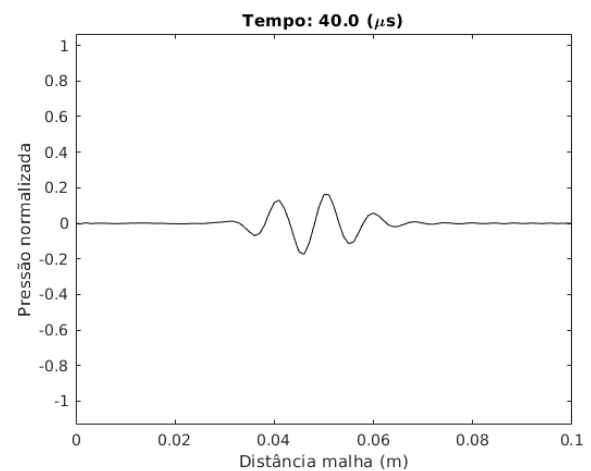

(d) Resultado em $40 \mu s$.

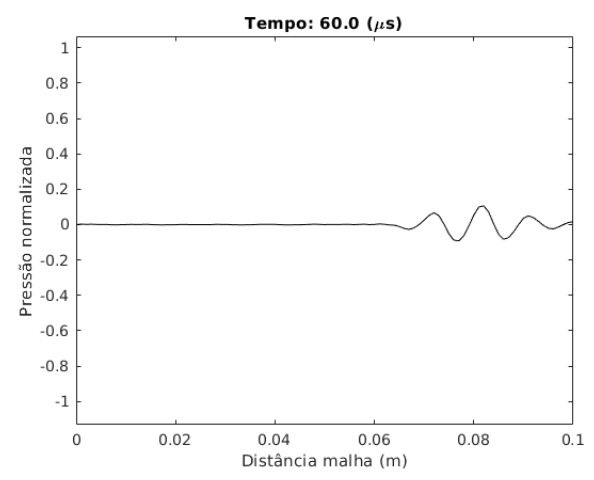

(f) Resultado em $60 \mu \mathrm{s}$.

Figura 4.51: Resultado para malha esférica utilizando excitação de 150kHz. 


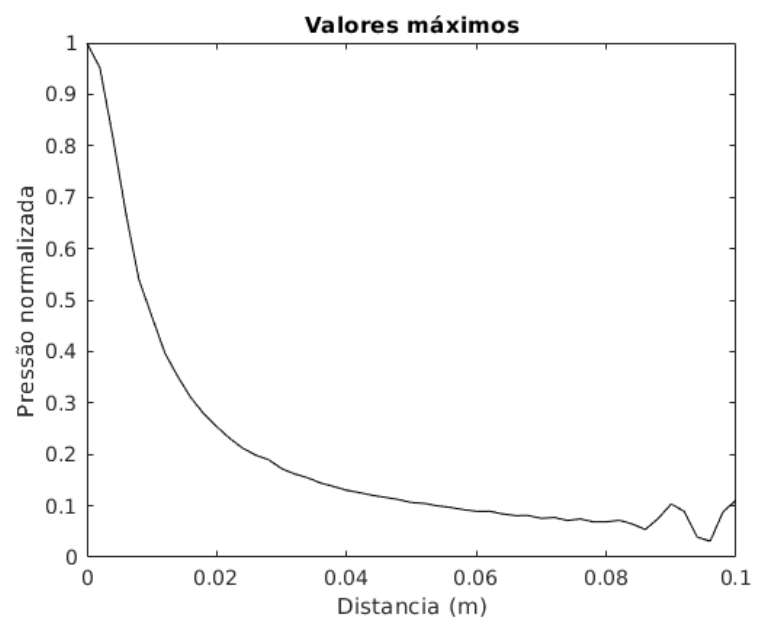

Figura 4.52: Valores máximos de amplitude para excitação de $75 \mathrm{kHz}$

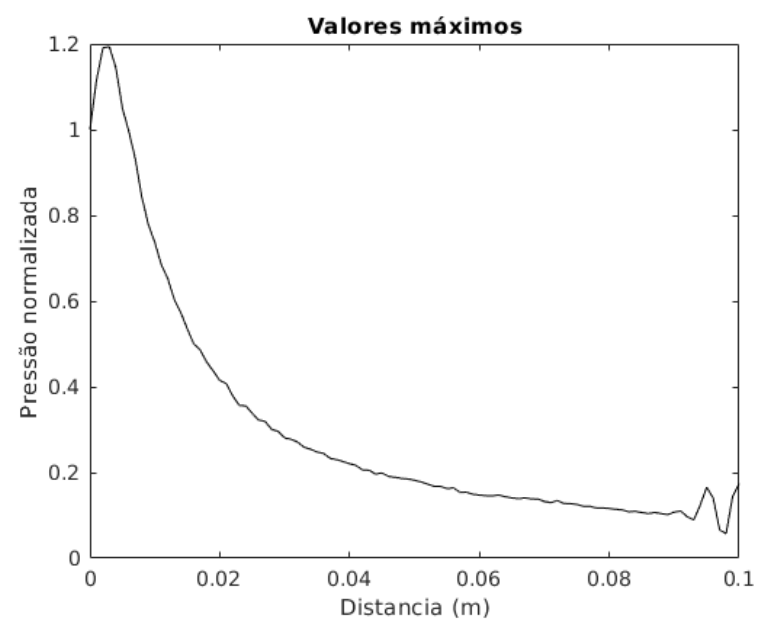

Figura 4.53: Valores máximos de amplitude para excitação de $150 \mathrm{kHz}$

O final das curvas apresentadas nas figuras 4.52 e 4.53 mostra uma ondulação devido à reflexão da onda no final da malha e devem ser desconsiderados. Pode-se observar por estes mesmos gráficos que, para a frequência de $150 \mathrm{kHz}$, a curva apresenta um aumento inicial seguido de uma queda, enquanto que para a frequência de $75 \mathrm{kHz}$ apresenta apenas um comportamento de queda.

O número de pontos por comprimento de onda para estes testes não é ideal. Este número foi adotado como uma solução de compromisso entre a qualidade da resposta e o custo computacional.

Para os testes do ajuste do foco foi utilizado a malha esférica e a excitação de $75 \mathrm{kHz}$ 
utilizadas no teste anterior. A figura 4.54 mostra a superfície do transdutor na malha de elementos finitos em detalhe. Cada aro do transdutor (representado pelas diferentes cores na figura 4.54(b) pode ser acionado em tempos diferentes e com amplitudes diferentes. O transdutor foi dividido em 10 aros independentes e com a mesma espessura.

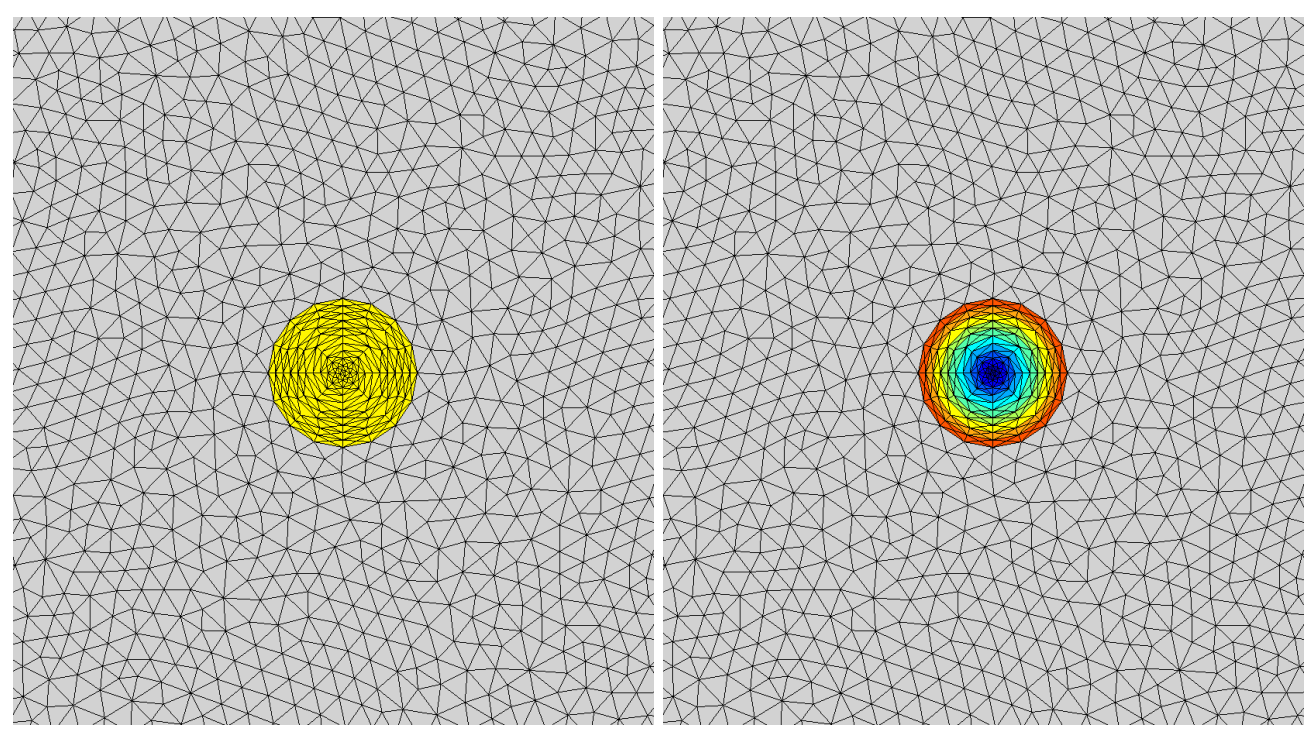

$\begin{array}{ll}\text { (a) Detalhe do transdutor na malha. } & \text { (b) Aros do transdutor. }\end{array}$

Figura 4.54: Aros do transdutor utilizados para o teste do foco.

Nestes testes apenas o tempo de acionamento foi modificado, mantendo a mesma amplitude da excitação para cada aro. Foram feitos dois testes: o primeiro onde é acionado primeiro o aro mais externo e por fim o centro do transdutor, gerando um efeito de foco "na frente" do transdutor. O segundo teste foi acionado primeiro o centro do transdutor e por fim o aro mais externo, gerando um efeito de foco "atrás" do transdutor.

A figura 4.55 mostra os tempos em que os aros foram acionados para ambos os teste, onde o aro 1 é o centro do transdutor e o aro 10 é o aro mais externo. A figura 4.56 mostra a comparação entre os valores máximos das respostas obtidas com ambos os focos testados e a referência. 


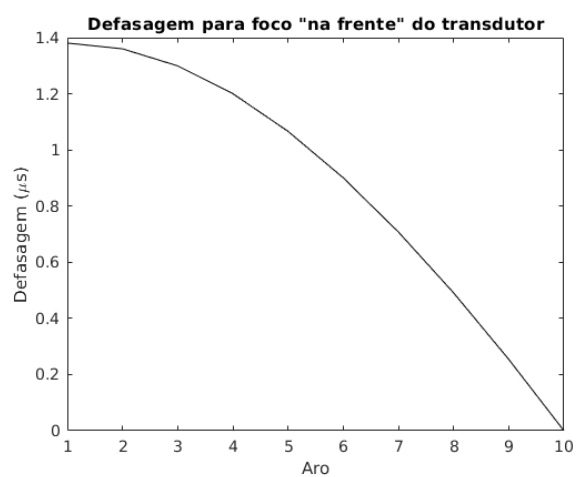

(a) Foco "na frente".

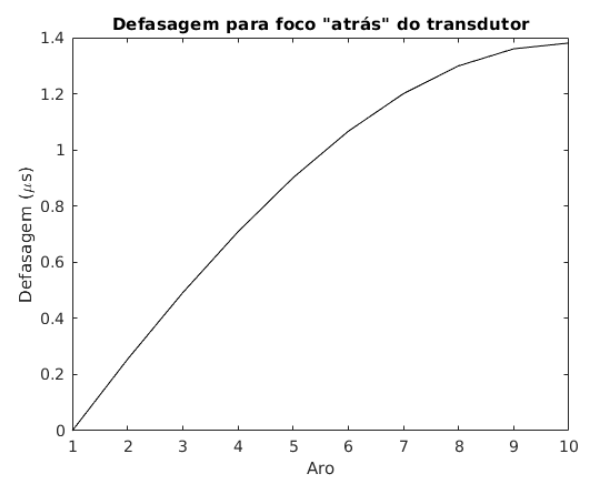

(b) Foco "atrás".

Figura 4.55: Defasagens utilizadas para cada aro da malha.

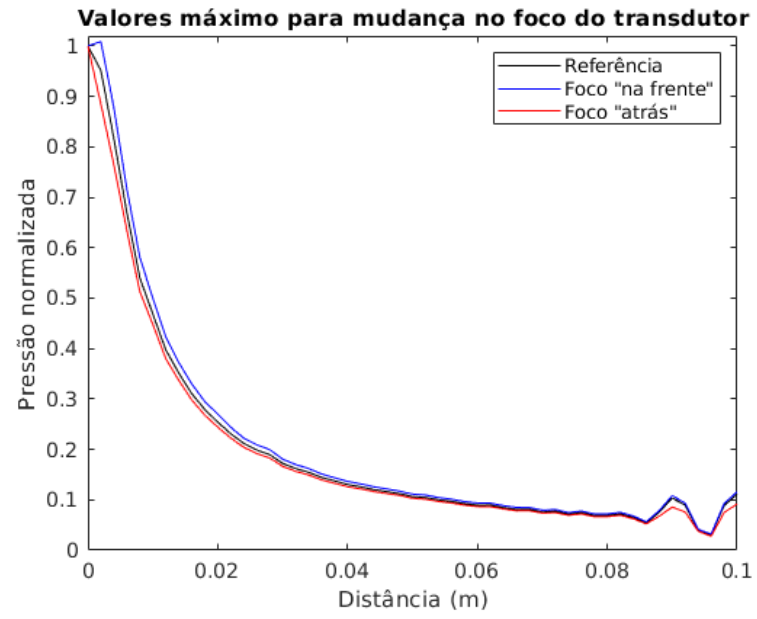

Figura 4.56: Comparação dos máximos para diferentes focos.

Como pode ser visto pela imagem 4.56 existe uma pequena diferença entre a refência e as respostas dos testes. O efeito observado é de aumento da amplitude quando o foco está "na frente" do transdutor e de diminuição da amplitude quando o foco está "atrás", como esperado.

Testes modificando tanto a amplitude da excitação quanto o tempo de acionamento podem ser feitos, aumentando a capacidade de simulação de diferentes excitações. Além disso, o número de aros e suas espessuras também podem ser modificados. 


\section{Testes de otimização do método}

A figura 4.57 mostra a malha utilizada nos testes do PML. Esta malha possui $0,1 \mathrm{~m}$ de comprimento, 0,01 $\mathrm{m}$ de diâmetro do eixo central e uma espessura da camada atenuadora igual a $0,02 \mathrm{~m}$, totalizando um diâmetro de $0,05 \mathrm{~m}$. A camada atenuadora foi divida em 10 camadas, onde é atribuído um valor de atenuação diferente para camada. A figura 4.58 mostra estas camadas, onde cada cor representa uma camada diferente. A malha possui, aproximadamente, $204 k$ nós e $1150 k$ elementos, para uma discretização de 10 pontos por comprimento de onda de uma excitação de $150 \mathrm{kHz}$. Os outros parâmetros foram mantidos os mesmos do teste da malha esférica com excitação de $150 \mathrm{kHz}$.

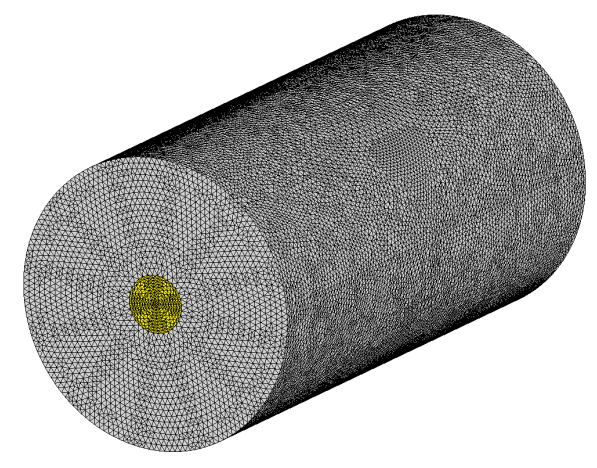

(a) Malha utilizada.
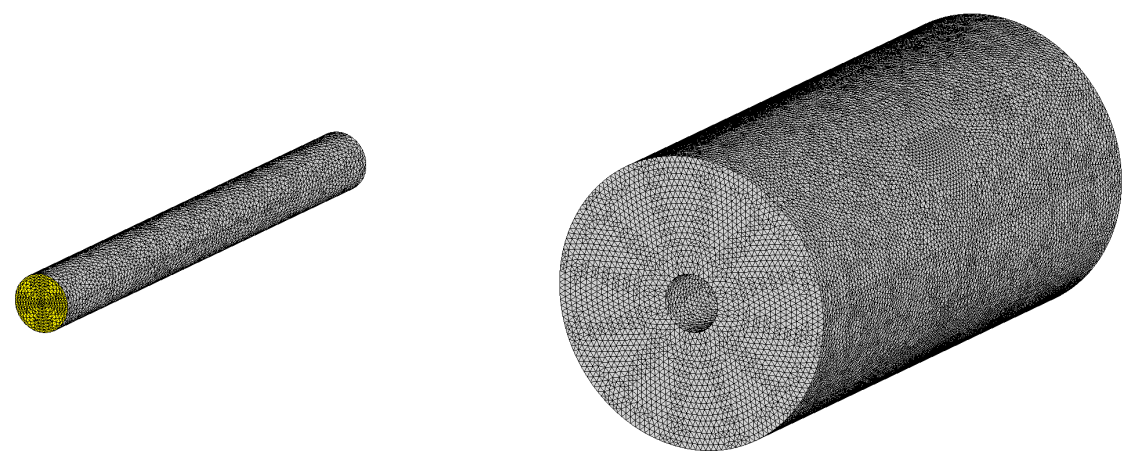

(b) Apenas eixo.

(c) Apenas PML.

Figura 4.57: Malha utilizada para teste do PML. 


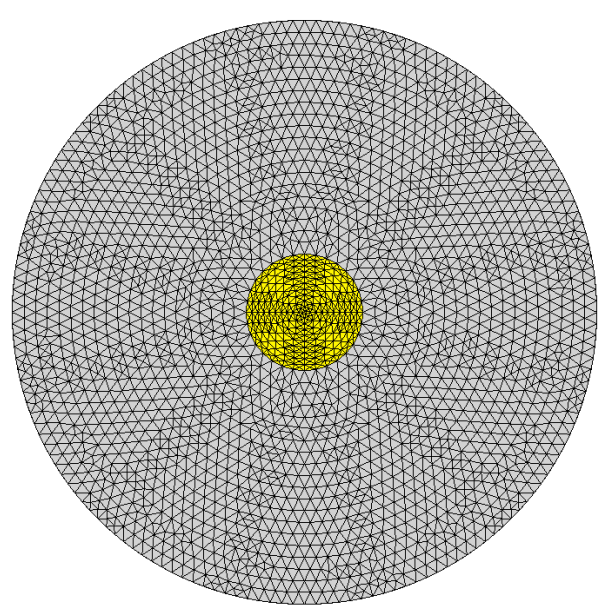

(a) Vista Frontal.

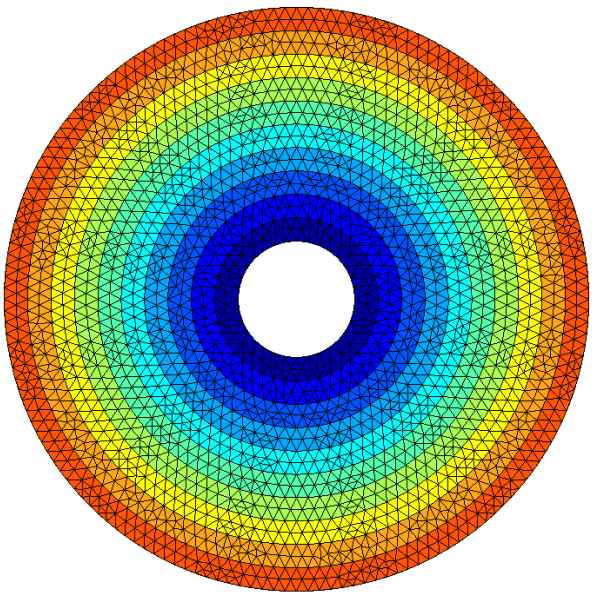

(b) Camadas do PML.

Figura 4.58: Camadas da malha utilizada para teste do PML.

A figura 4.59 mostra os valores utilizados para cada uma das 10 camadas do PML. A camada 1 é a mais interna e a camada 10 é a mais externa.

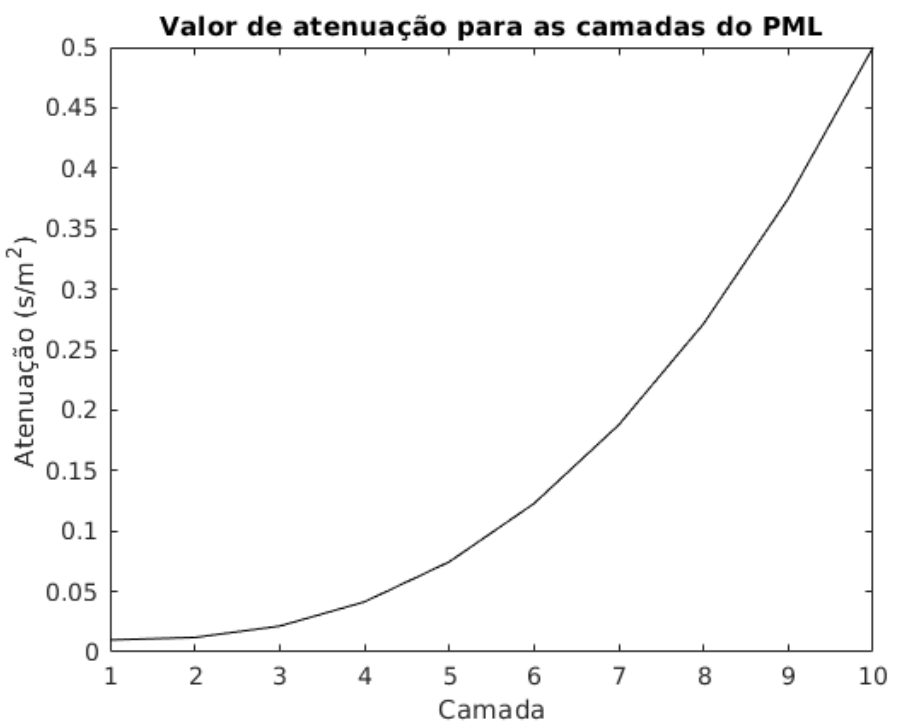

Figura 4.59: Atenuação utilizada nas camadas do PML. 


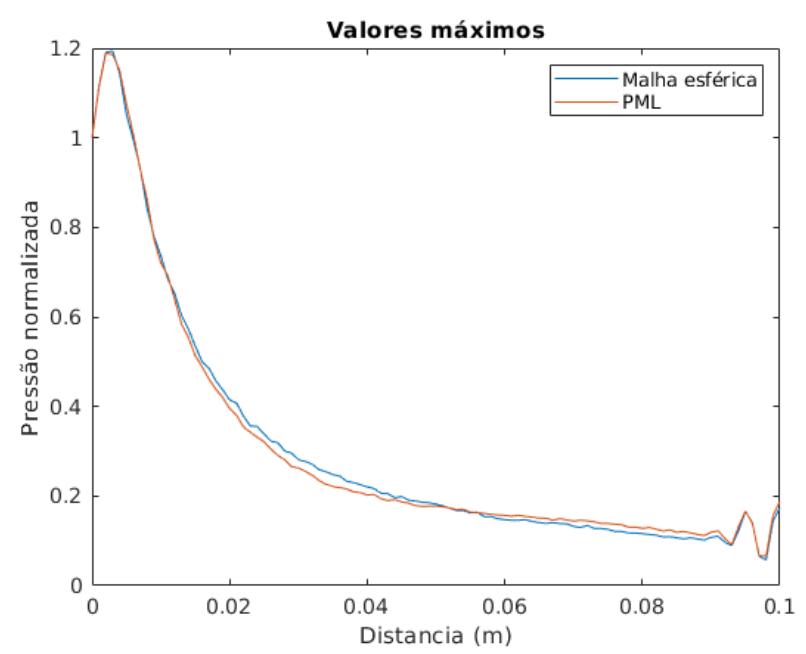

(a) Valores máximos.

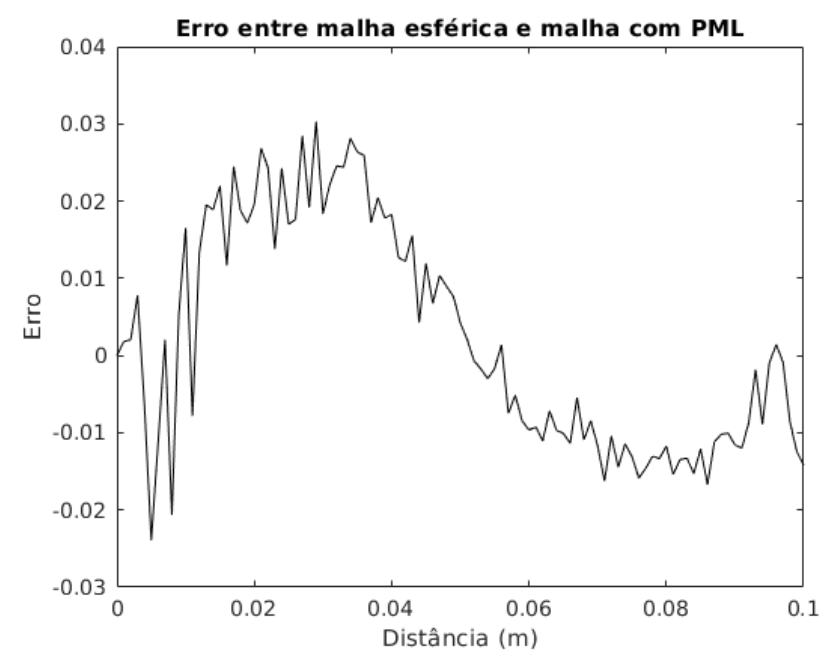

(b) Diferença entre resultados.

Figura 4.60: Comparação entre resultados da malha esférica e malha usando PML.

A figura 4.60 mostra a comparação entre o resultado obtido utilizando a malha esférica e a malha com PML. Como pode ser visto pelos gráficos, exite uma diferença menor que $3 \%$ entre os resultados.

A malha utilizando o PML possui $204 k$ nós e $1150 k$ elementos, enquanto a malha esférica equivalente possui $1326 k$ nós e $7859 k$ elementos. Outros testes variando a atenuação, velocidade do som do meio e espessura do PML podem ser feitos visando diminuir o erro. Esta técnica pode ser utilizada para diminir o número de elementos da malha, quando for possível delimitar uma região de interesse.

Para os testes da superposição modal, uma mesma condição foi resolvida utili- 
zando o integrador de diferenças finitas no tempo e método de superposição modal. A simulação modal foi feita 3 vezes com diferentes números de autovetores utilizados. Foram utilizados 30, 70 e 200 autovetores nestas simulações.

Nestes testes foi utilizado a malha mostrada na figura 4.61. Esta malha tem aproximadamente 22k nós e 96k elementos. Seu diâmetro é de $0,01 \mathrm{~m}$ e seu comprimento é de $0,2 m$.

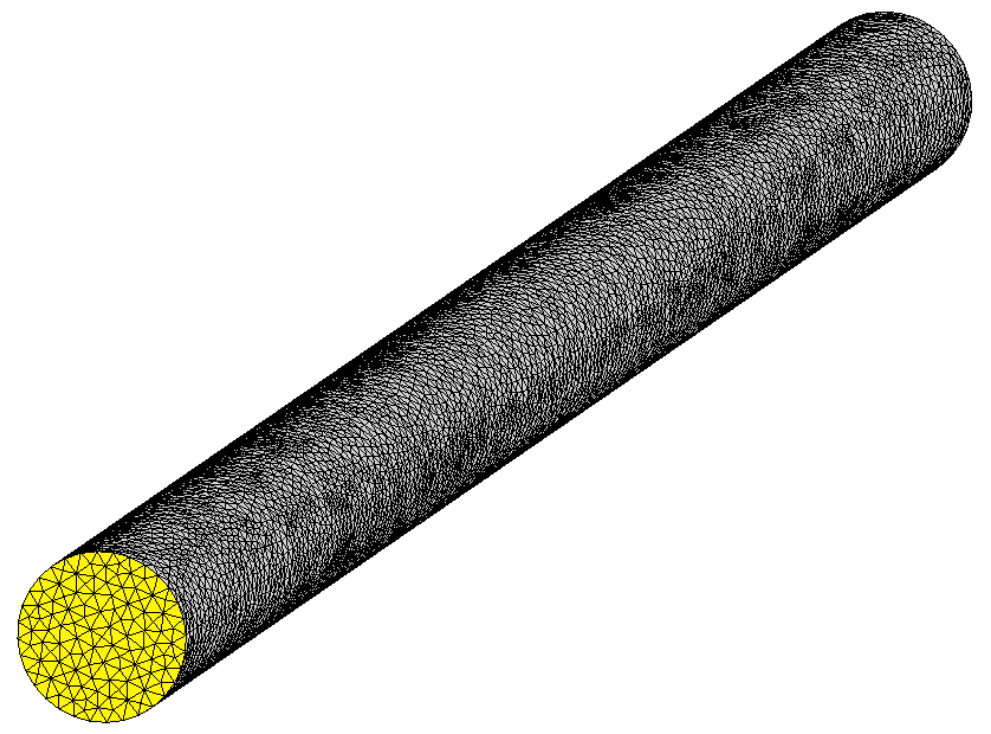

Figura 4.61: Malha utilizada para superposição modal.

A excitação utilizada foi uma onda senoidal ponderada por uma curva gaussiana. Foram utilizados 3 ciclos de senoide com frequência de $50 \mathrm{kHz}$ e amplitude unitária. A figura 4.62 mostra a excitação simulada. 


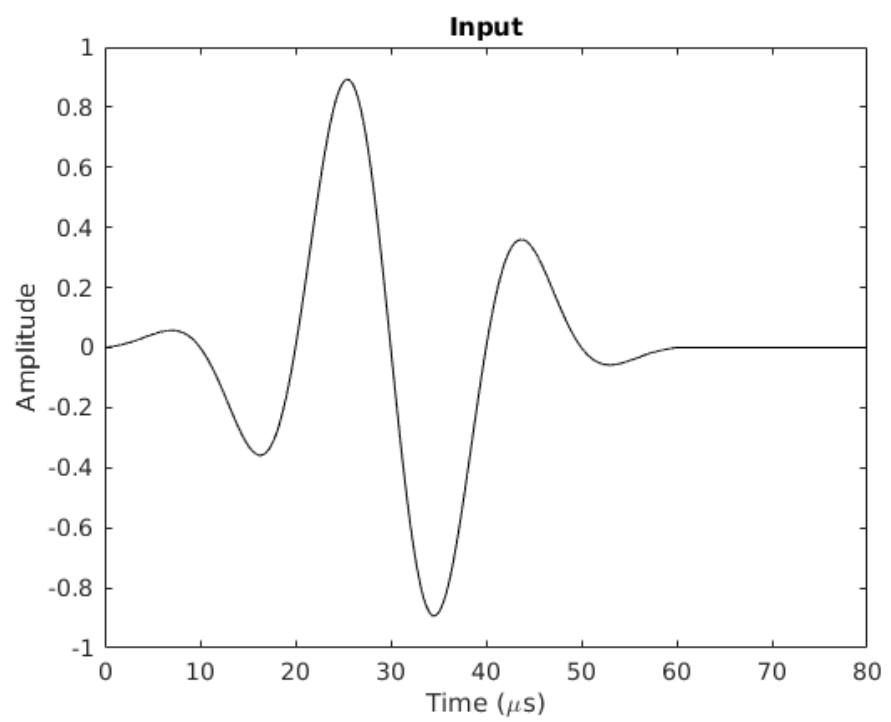

Figura 4.62: Excitação utilizada na superposição modal.

A simulação usou um intervalo de integração de $0,01 \mu \mathrm{s}$ e um tempo total de simulação de $80 \mu \mathrm{s}$. A velocidade do som no meio foi $1500 \mathrm{~m} / \mathrm{s}$ e o coeficiente de atenuação $\alpha=10^{-12} s / m^{2}$.

As saídas são comparadas apenas no eixo central da malha e o erro de amplitude e o erro de posição são calculados. O erro de amplitude é a diferença entre as soluções normalizada pela amplitude da solução temporal, já o erro de posição é a diferença na posição calculada a partir da correlação cruzada entre as soluções e normalizada pelo comprimento da malha.

Para calcular os autovalores e autovetores o Método de Arnoldi Implicitamente Reiniciado (IRAM) é usado. O método é implementado pela biblioteca ARPACK [22] e a rotina que invoca esta biblioteca está no apêndice A. As outras tarefas numéricas (incluindo solução de sistema linear) são resolvidas pela biblioteca Eigen [23] usando Intel Math Kernel Library [24]. O processador utilizado para as simulações foi um Intel Core $i 7$ de sexta geração. 
A figura 4.63 mostra os 11 primeiros modos de vibrar da malha.
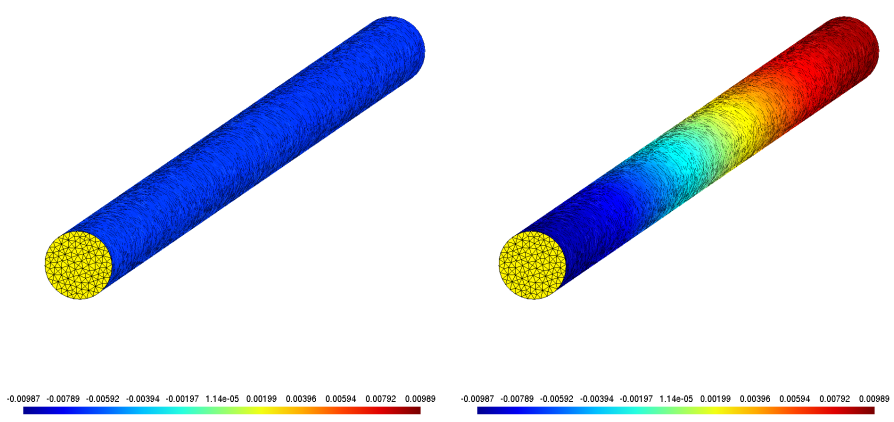

(a) Modo 1

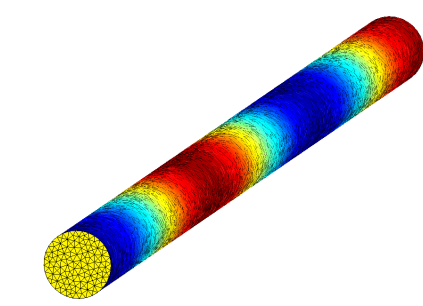

(c) Modo 3

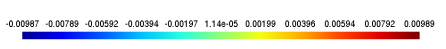

(d) Modo 4

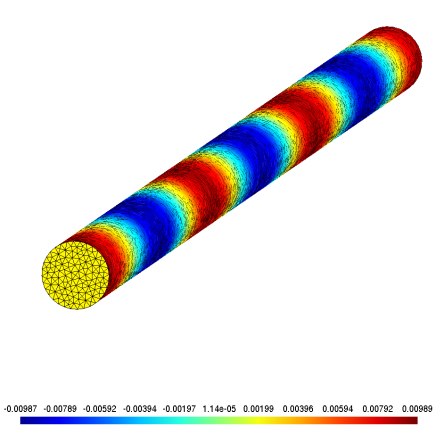

(g) Modo 7

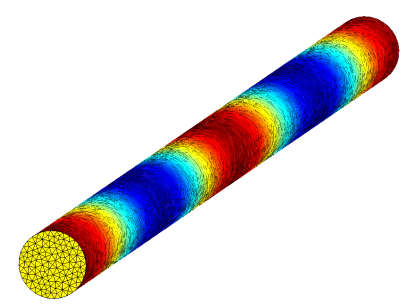

(b) Modo 2
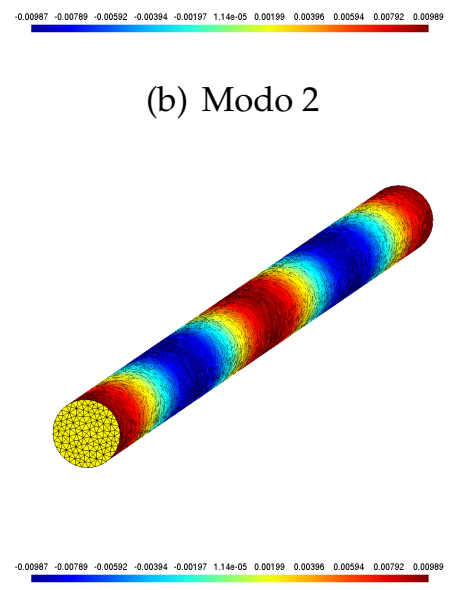

(e) Modo 5 (f) Modo 6

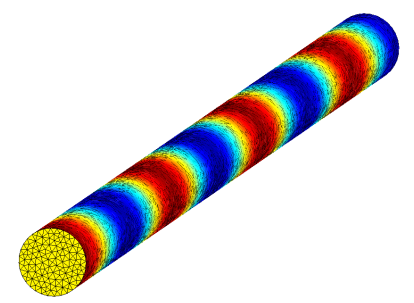

(i) Modo 9

(h) Modo 8
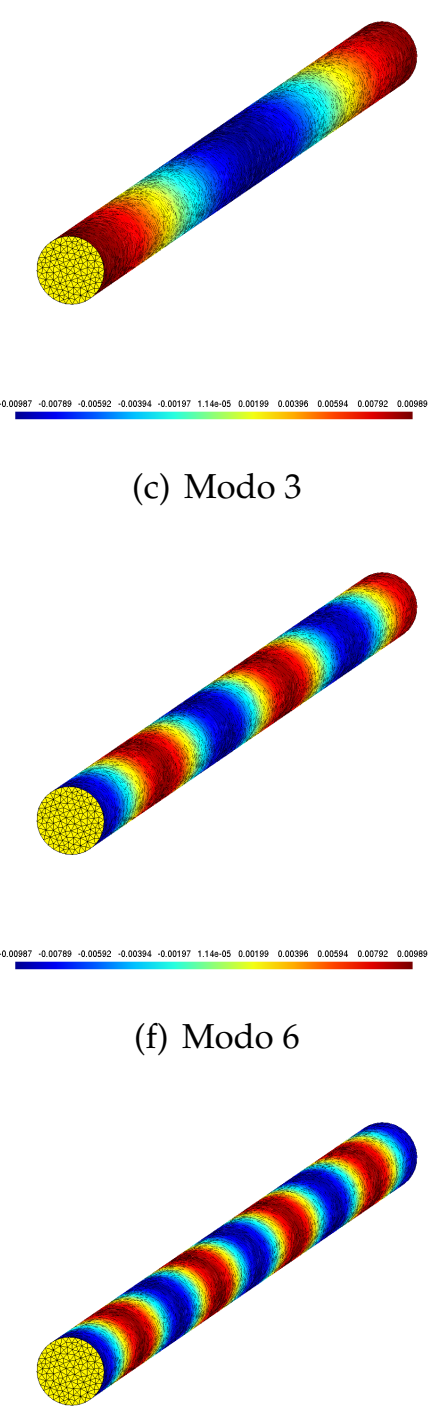

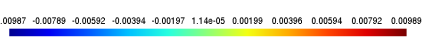
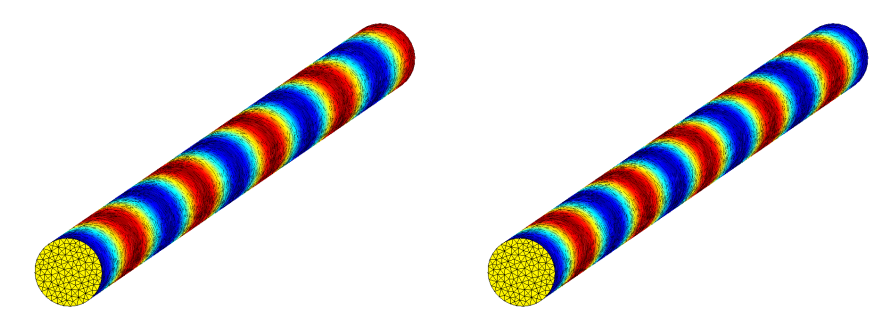

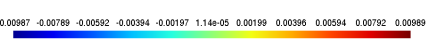

(j) Modo 10

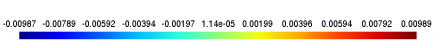

(k) Modo 11

Figura 4.63: Primeiros 11 modos de vibrar. 
A figura 4.64 mostra os resultados para a simulação com 30 modos em 8 instantes de tempo. A referência em vermelho é a resposta no domínio do tempo.

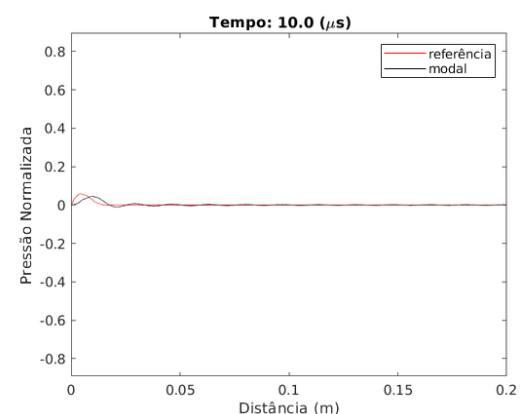

(a) Tempo $=10 \mu \mathrm{s}$

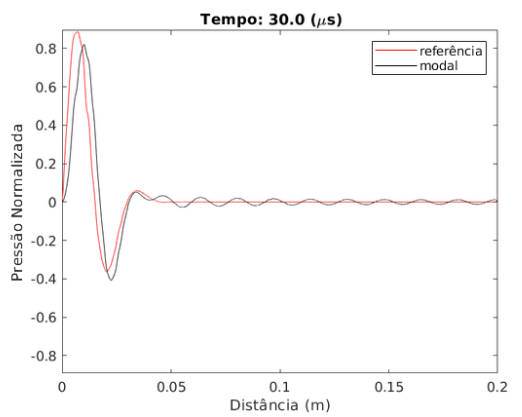

(c) Tempo $=30 \mu \mathrm{s}$

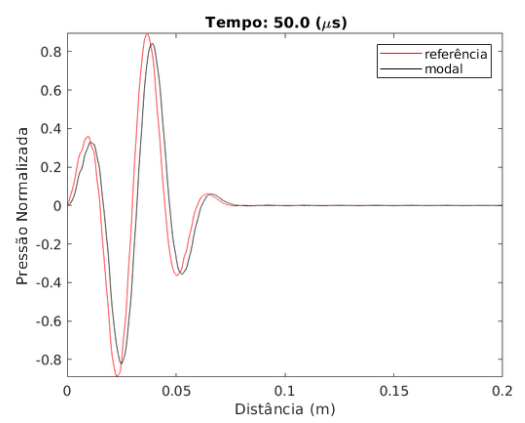

(e) Tempo $=50 \mu \mathrm{s}$

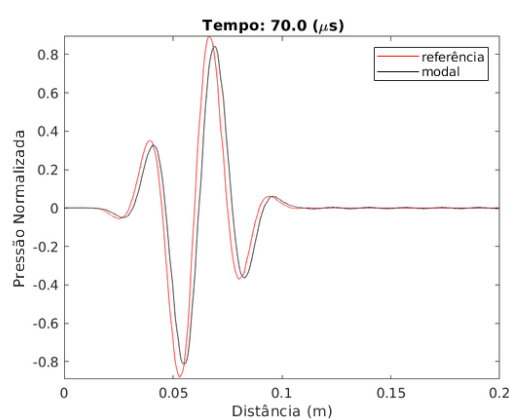

(g) Tempo $=70 \mu \mathrm{s}$

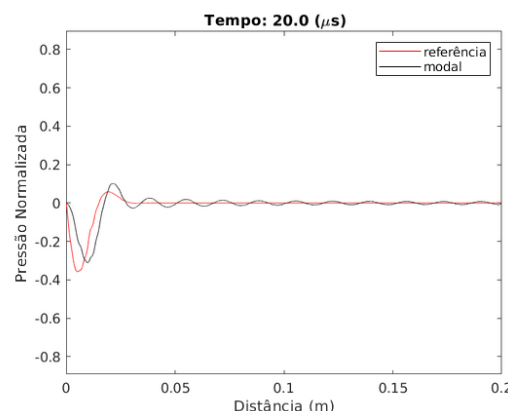

(b) Tempo $=20 \mu \mathrm{s}$

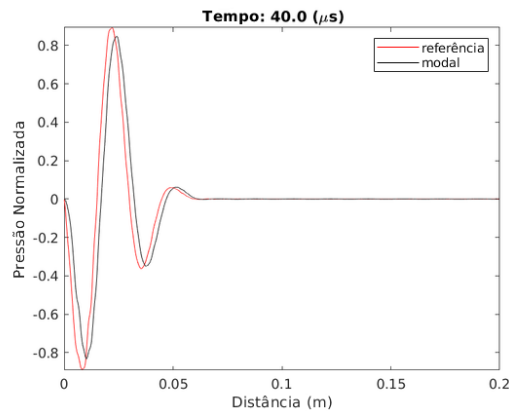

(d) Tempo $=40 \mu \mathrm{s}$

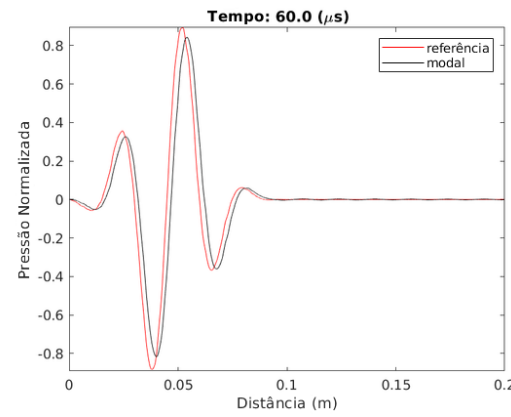

(f) $T e m p o=60 \mu \mathrm{s}$

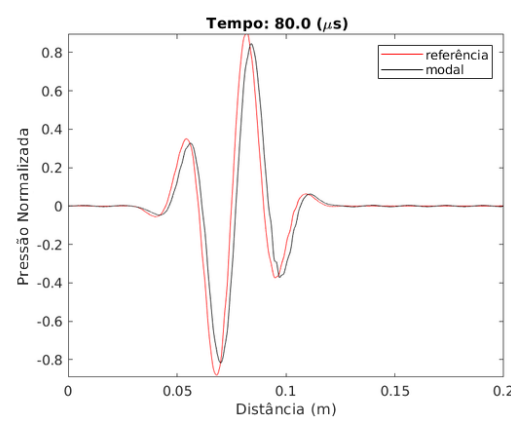

(h) Tempo $=80 \mu \mathrm{s}$

Figura 4.64: Simulação com 30 modos. 
A figura 4.65 mostra os resultados para a simulação com 70 modos em 8 instantes de tempo. A referência em vermelho é a resposta no domínio do tempo.

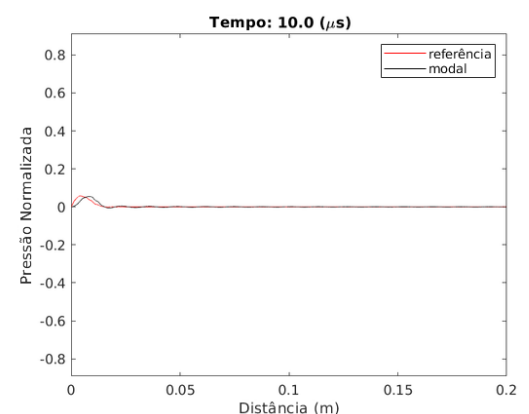

(a) Tempo $=10 \mu \mathrm{s}$

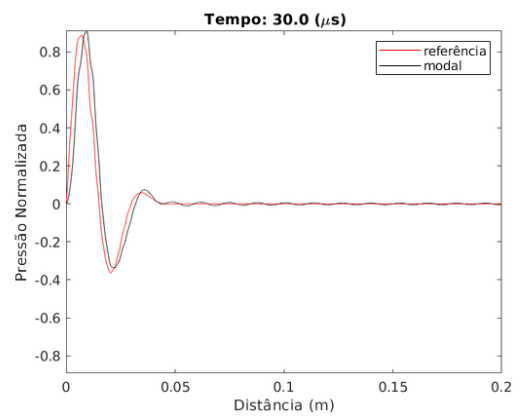

(c) Tempo $=30 \mu \mathrm{s}$

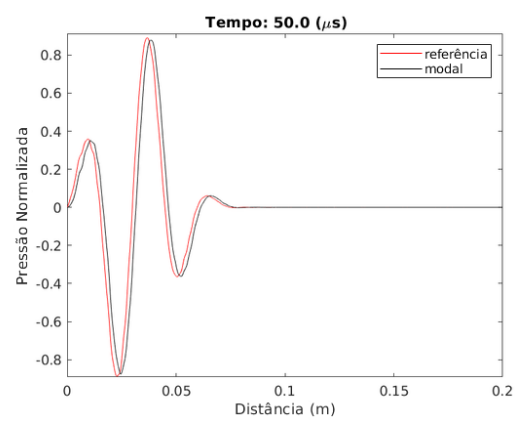

(e) Tempo $=50 \mu \mathrm{s}$

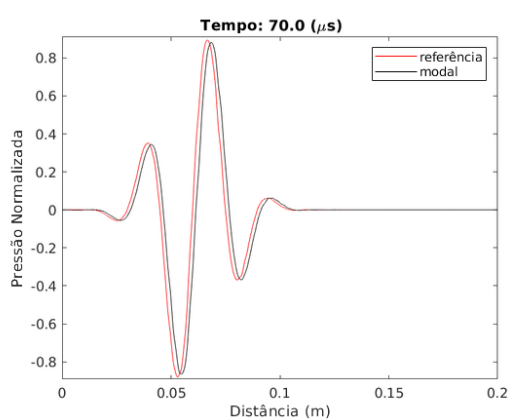

(g) Tempo $=70 \mu \mathrm{s}$

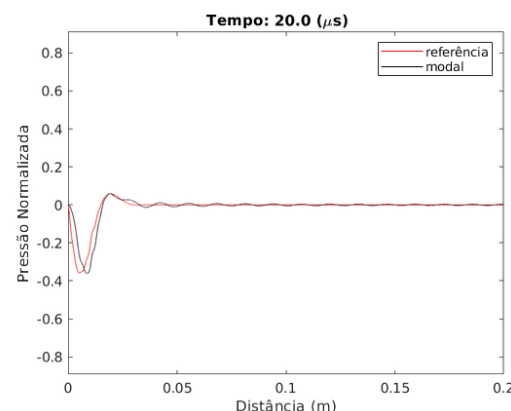

(b) Tempo $=20 \mu \mathrm{s}$

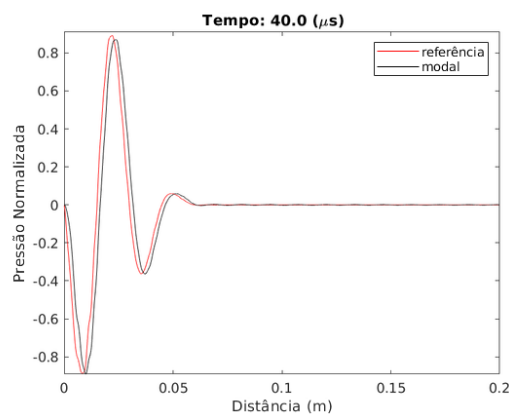

(d) Tempo $=40 \mu \mathrm{s}$

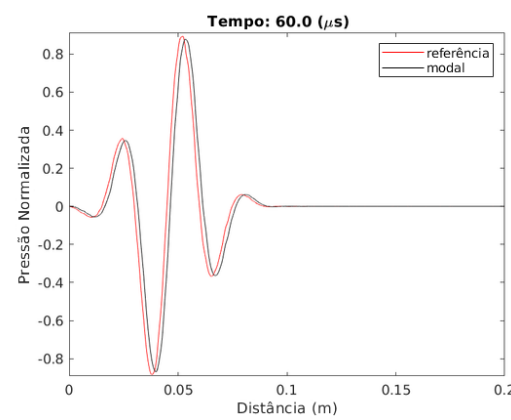

(f) $T e m p o=60 \mu \mathrm{s}$

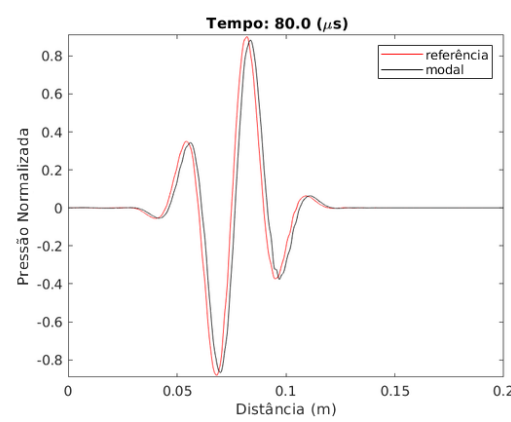

(h) Tempo $=80 \mu \mathrm{s}$

Figura 4.65: Simulação com 70 modos. 
A figura 4.66 mostra os resultados para a simulação com 200 modos em 8 instantes de tempo. A referência em vermelho é a resposta no domínio do tempo.

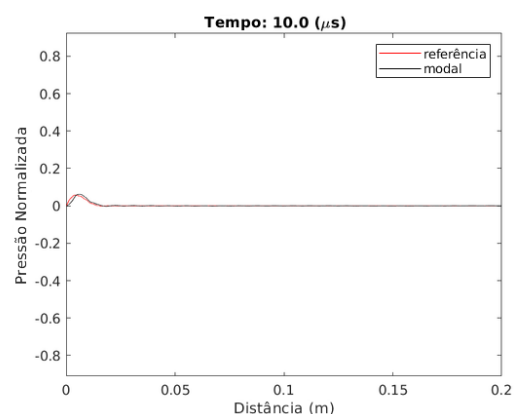

(a) Tempo $=10 \mu \mathrm{s}$

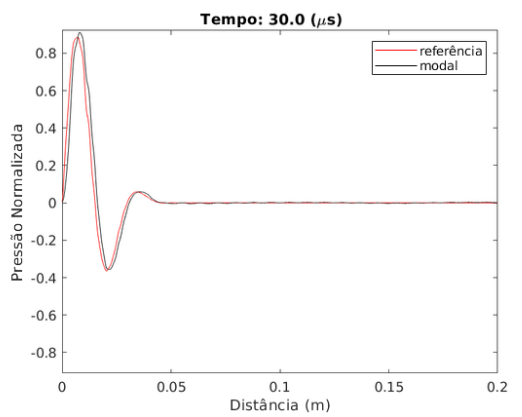

(c) Tempo $=30 \mu \mathrm{s}$

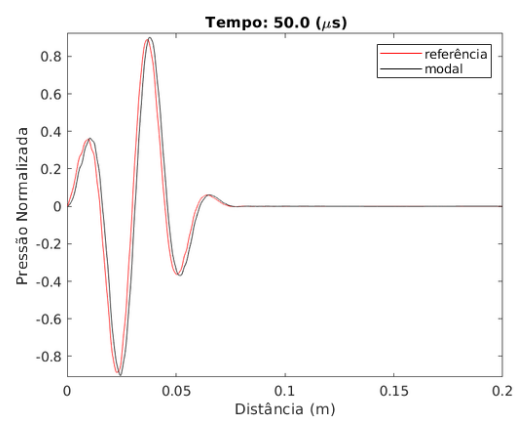

(e) Tempo $=50 \mu \mathrm{s}$

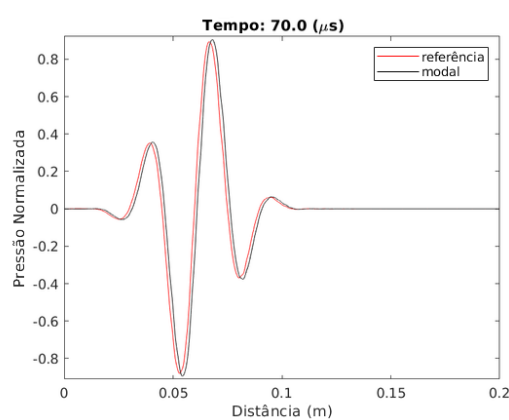

(g) Tempo $=70 \mu \mathrm{s}$

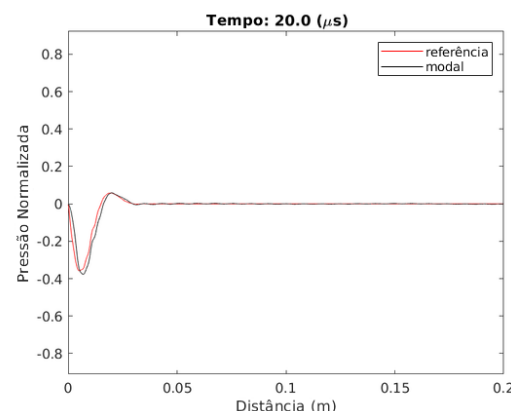

(b) Tempo $=20 \mu \mathrm{s}$

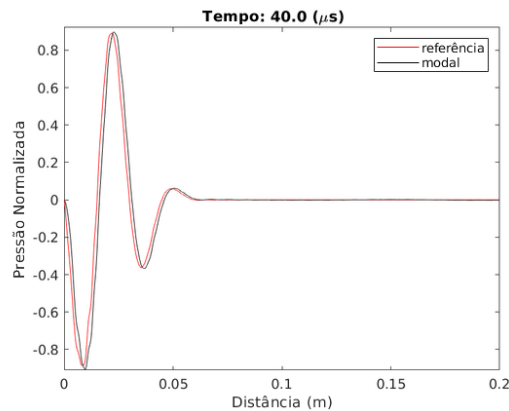

(d) Tempo $=40 \mu \mathrm{s}$

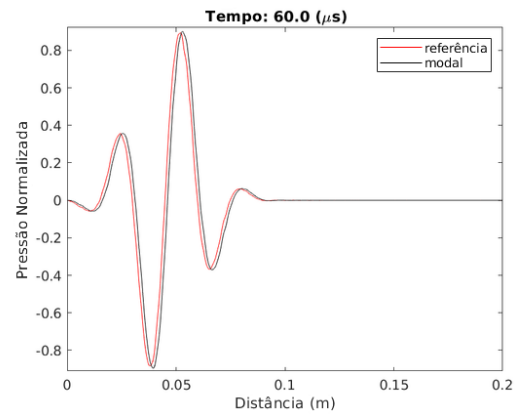

(f) $T e m p o=60 \mu \mathrm{s}$

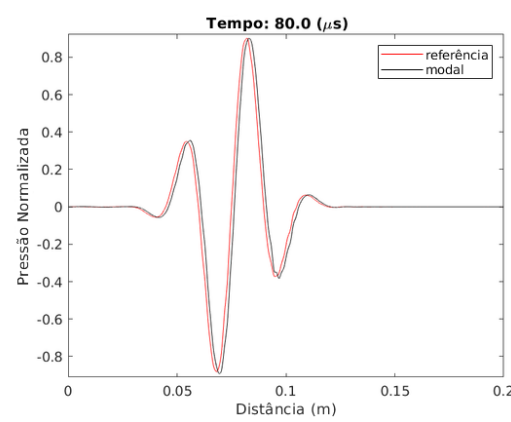

(h) Tempo $=80 \mu \mathrm{s}$

Figura 4.66: Simulação com 200 modos. 
A figura 4.67 compara o erro de amplitude normalizado para todo o tempo de simulação nos três casos.

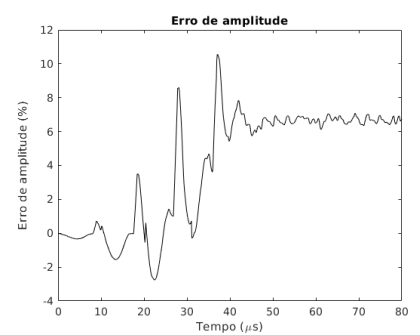

(a) 30 modos

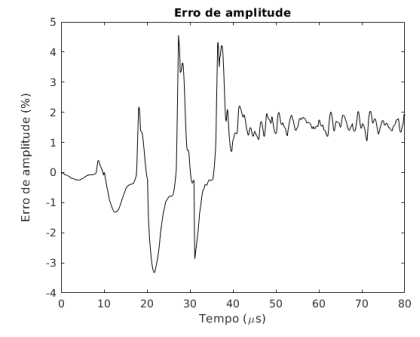

(b) 70 modos

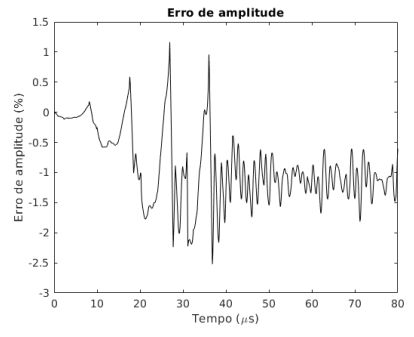

(c) 200 modos

Figura 4.67: Erro de amplitude normalizado.

A figura 4.68 compara o erro de posição normalizado para todo o tempo de simulação nos três casos.

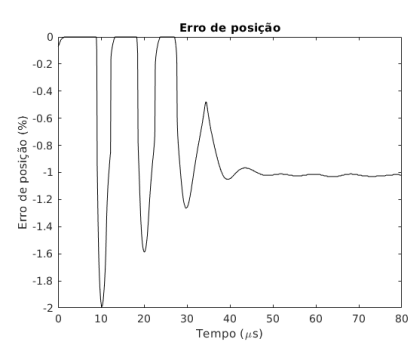

(a) 30 modos

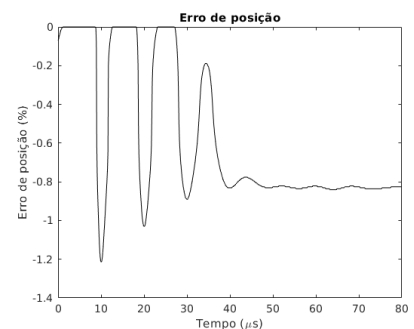

(b) 70 modos

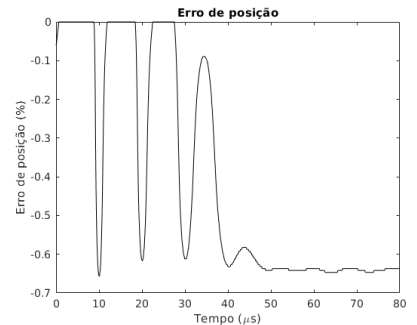

(c) 200 modos

Figura 4.68: Erro de posição normalizado.

A tabela 4.1 mostra o erro máximo de amplitude, erro máximo de posição, consumo de memória, tempo de execução e tempo na etapa de integração para cada caso.

\begin{tabular}{c|c|c|c|c|c} 
Caso & $\begin{array}{c}\text { Tabela 4.1: Resumo dos resultados. } \\
\text { Amplitude }\end{array}$ & $\begin{array}{c}\text { Erro de } \\
\text { Posição }\end{array}$ & $\begin{array}{c}\text { Consumo } \\
\text { de } \\
\text { Memória }\end{array}$ & $\begin{array}{c}\text { Tempo de } \\
\text { Execução }\end{array}$ & $\begin{array}{c}\text { Tempo de } \\
\text { Integração }\end{array}$ \\
\hline Domínio & - & - & $4,4 \mathrm{MiB}$ & $83 \mathrm{~s}$ & $82 \mathrm{~s}$ \\
do tempo & $10,56 \%$ & $1,99 \%$ & $126,2 \mathrm{MiB}$ & $22 \mathrm{~s}$ & $17 \mathrm{~s}$ \\
30 modos & $4,56 \%$ & $1,21 \%$ & $147,1 \mathrm{MiB}$ & $37 \mathrm{~s}$ & $29 \mathrm{~s}$ \\
70 modos & $2,52 \%$ & $0,65 \%$ & $221,1 \mathrm{MiB}$ & $93 \mathrm{~s}$ & $68 \mathrm{~s}$
\end{tabular}

Os resutados modais convergem para a solução no domínio do tempo quando o número de modos utilizados aumenta. Para o caso de 200 modos, o erro máximo de amplitude foi $2,52 \%$ e o erro máximo de posição foi $0,65 \%$. O erro é maior nas primeiras 
iterações onde a excitação ainda é incompleta. Entretanto, o tempo de execução total é 10 segundos mais demorado e o consumo de memória é 50 vezes maior.

O passo de maior consumo de memória é o cálculo dos autovetores e autovalores. Neste passo uma matriz densa de dimensões de número de nós por números de modos é alocada. Para malhas mais complexas, o número de nós aumenta e o número de modos necessários deve ser maior, portanto, o consumo de memória pode se tornar um problema.

\subsection{Comparação}

A comparação foi feita utilizando uma malha semi-esférica, com $1680 k$ nós e $9990 k$ elementos. A discretização da malha foi de 10 pontos por comprimento de onda para uma excitação de $150 \mathrm{kHz}$. A excitação utilizada foi a de $150 \mathrm{kHz}$ mostrada na figura 4.28(c). Esta malha possui superfícies internas utilizadas para o cálculo da média espacial ao longo do tempo. Estas superfícies são mostradas em amarelo na figura 4.69. Esta figura mostra um corte passando pelo meio dos trasdutores. Esta malha possui 0,11m de raio e as superfícies estão separadas a cada $0,005 \mathrm{~m}$ como foi feito no experimento.

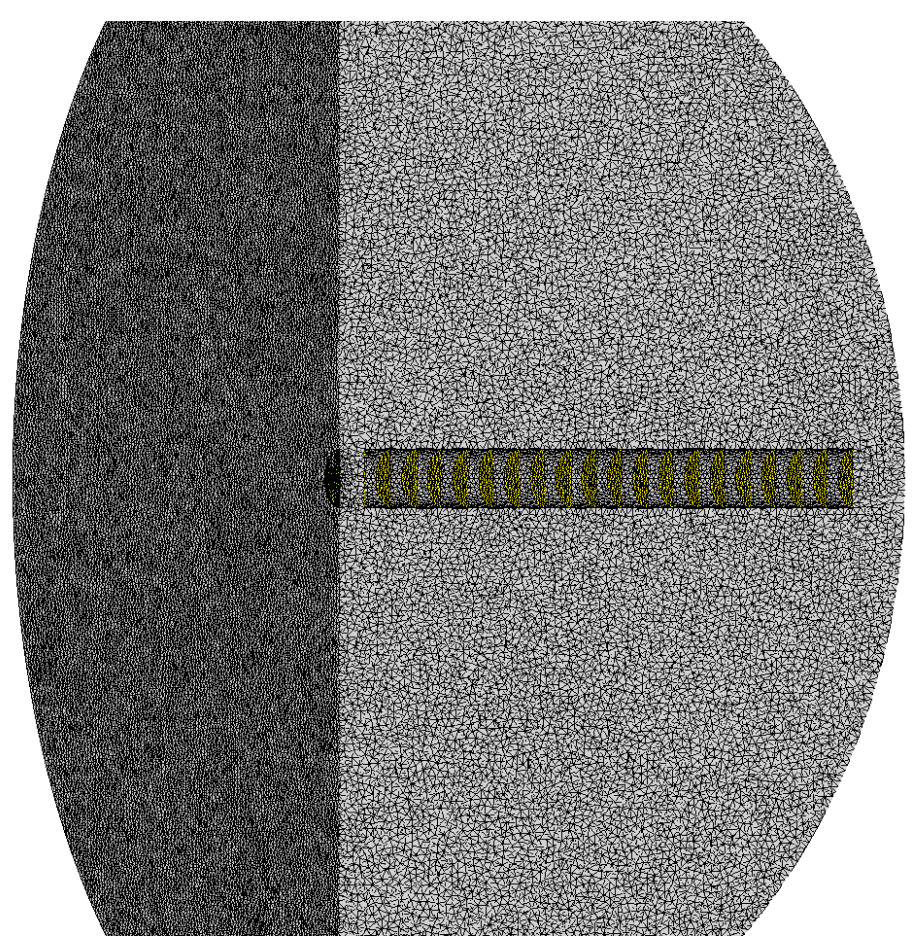

Figura 4.69: Superfícies utilizadas para o teste de comparação 
A figura 4.70 mostra as médias espaciais ao longo do tempo obtidas na simulação numérica.

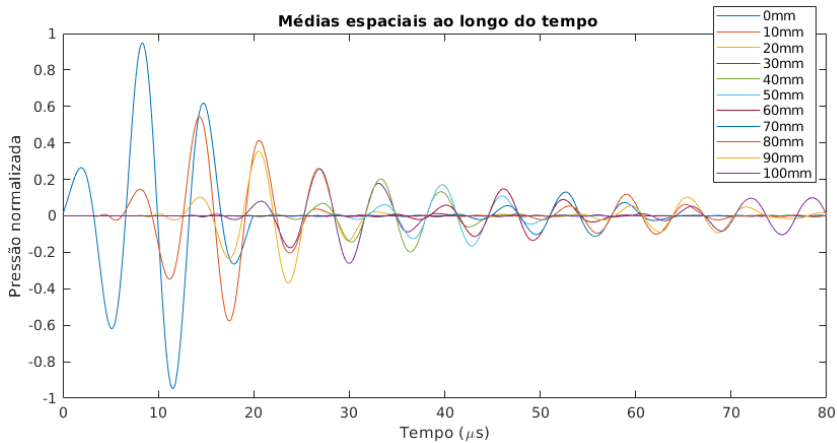

Figura 4.70: Médias espaciais ao longo do tempo obtidas na simulação numérica

A figura 4.71(a) mostra a comparação entre os dados experimentais e simulados. A figura $4.71(\mathrm{~b})$ mostra a diferença entre os dois resultados. 


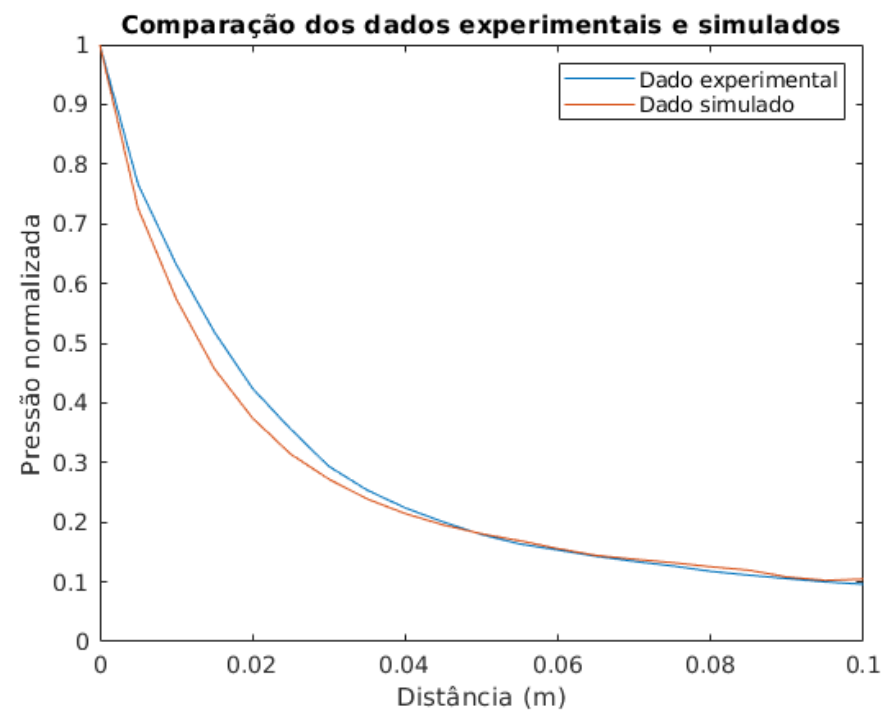

(a) Valores máximos.

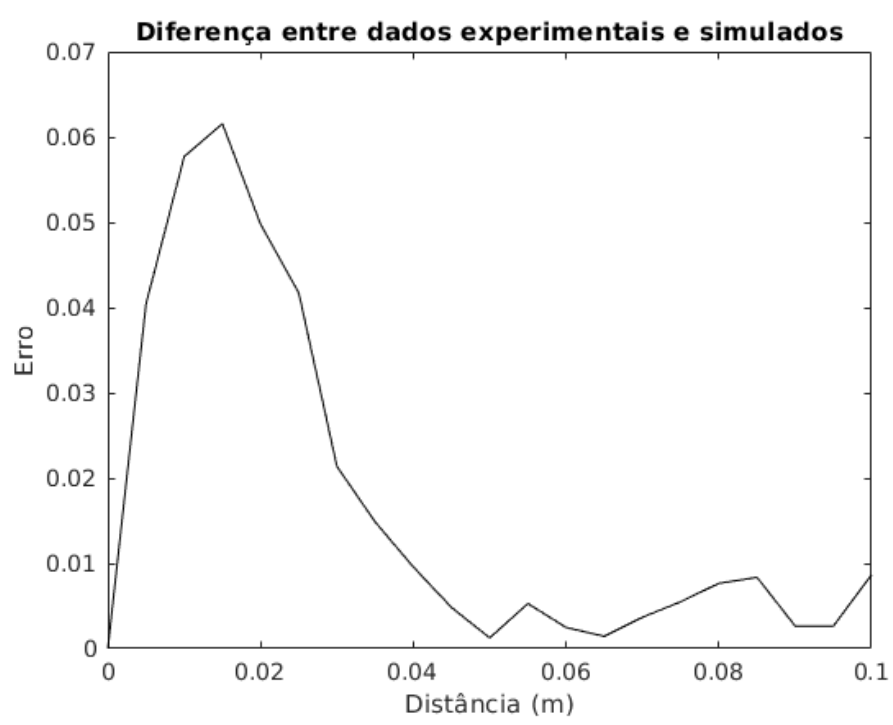

(b) Diferença entre resultados.

Figura 4.71: Comparação entre resultados experimentais e simulados.

Como pode ser visto pela figura 4.71, existe uma diferença máxima de, aproximadamente, $6 \%$ entre os dados experimentais e os dados simulados. Esta diferença pode ser explicada pela diferença da velocidade do som entre o ensaio experimental e a simulação, diferença no formato de onda da excitação e pela existência de multiplas reflexões da onda entre os transdutores no caso experimental. 


\section{Capítulo 5}

\section{Conclusões}

O transdutor de $500 \mathrm{kHz}$ fabricado consegue emitir sinais de ultrassom e medir os sinais de resposta, entretanto a amplitude observada é menor do que a referência e possui maior ruído. Os transdutores de $150 \mathrm{kHz}$ também conseguem emitir sinais de ultrassom e medir os sinais de resposta, porém não foi possível a comparação com um transdutor de referência. A frequência, forma de onda do eixo acústico e os tempos de propagação das ondas estão de acordo com o esperado.

A simulação de elementos finitos mostra que é necessário adequar a discretização da malha (número de pontos por comprimento de onda da excitação) dependendo da excitação utilizada para não ocorrer erros de aliasing.

Os parâmetros físicos avaliados apresentam resultados próximos do esperado. A velocidade de propagação, com e sem objeto, está coerente, a atenuação apresenta o comportamento de decaimento exponencial esperado e as relações entre amplitudes das ondas transmitidas e incidentes condizem com os valores teóricos. Além disso, o comportamento para a onda em um espaço tridimensional apresenta comportamento esperado e a utilização da técnica da mudança do foco do transdutor também apresenta comportamento esperado.

O uso do PML mostrou resultados com erros de, aproximadamente, 3\%. Esta técnica pode ser aperfeiçoada e usada quando for possível delimitar uma região de interesse.

A análise modal mostra que é possível compor a resposta utilizando um truncamento modal. Porém o custo computacional para calcular os autovalores e autovetores é maior do que no caso temporal, parcialmente porque a matriz de atenuação 
não foi diagonalizada. Quando a matriz de atenuação for diagonalizada, técnicas de paralelização podem ser empregadas.

A comparação entre os dados experimentais e simulados apresentou um erro de, aproximadamente, 6\%. Este erro pode ser explicado pela diferença da velocidade do som entre o ensaio experimental e a simulação, diferença no formato de onda da excitação e pela existência de multiplas reflexões da onda entre os transdutores no caso experimental.

\subsection{Próximos Passos}

Testes avaliando o comportamento da onda fora do eixo acústico podem ser propostos. Testes percorrendo não apenas o eixo central podem ser realizados. Outro teste que poderia contribuir para avaliar o sistema é utilizar uma cuba circular com diversos transdutores em sua circunferência, simulando uma estrutura de tomografia por ultrassom.

O valor da pressão absoluta pode ser avaliado. Testes utilizando hidrofones calibrados podem ser realizados para obtenção do valor absoluto da pressão. Assim, um método para a calibração dos transdutores pode ser desenvolvido.

Pode ser imposto o formato de onda encontrado nos ensaios experimentais como entrada no método dos elementos finitos como tentativa de representar melhor a forma de onda da excitação. Alternativamente, pode ser desenvolvido um modelo numérico do transdutor para gerar uma excitação mais próxima da excitação experimental.

Como não foi considerado a matriz de amortecimento $C$ no cálculo dos autovetores e autovalores, não foi possível desacoplar totalmente os modos de vibrar. É sugerida uma nova análise, onde esta matriz é levada em consideração, podendo melhorar o desempenho do método baseado na análise modal. 


\section{Apêndice A}

\section{Rotina ARPACK}

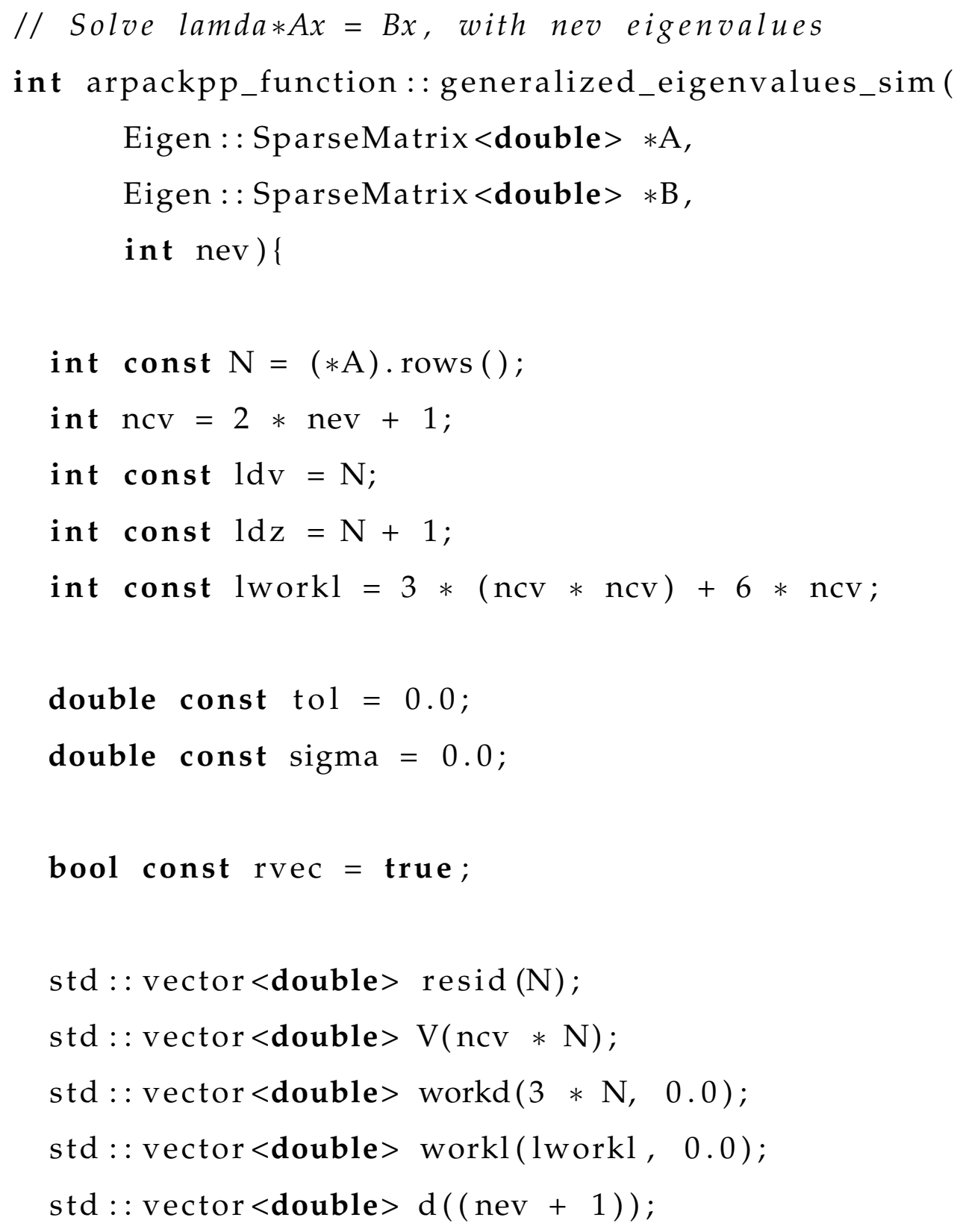




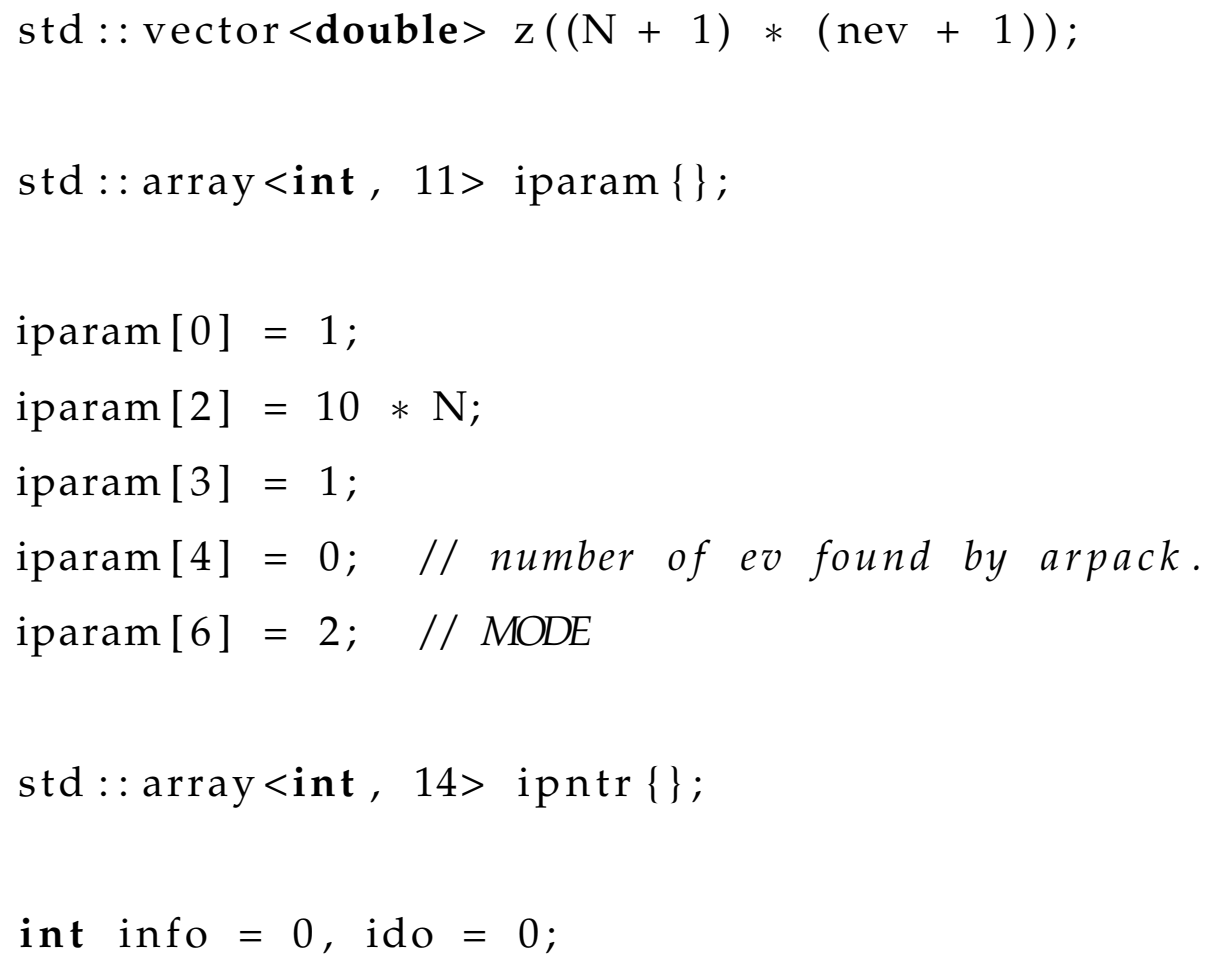


Eigen : : Map< Eigen : : VectorXd $>x(\&($ workd $[\operatorname{ipntr}[0]-1]), \mathrm{N})$;

Eigen : :Map<Eigen : : VectorXd $>y(\&($ workd $[\operatorname{ipntr}[1]-1]), N)$; $\mathrm{y}=(* \mathrm{~B}) * \mathrm{x} ;$

\}

\}

// check number of ev found by arpack.

if (iparam [4] != nev || info != 0) \{

std : : cout $<<$ "ERROR $("<$ info $<$ " $)$ " $<<$ std: : endl;

throw std:: domain_error ("Error ${ }_{\sqcup}$ inside ${ }_{\lrcorner}$ARPACK_routines" );

\}

std : : vector $<$ int $>$ select $($ ncv $)$;

arpack:: seupd(rvec, arpack::howmny:: ritz_vectors, select.data(), d.data(), z.data(), ldz, sigma, arpack:: bmat:: generalized, $\mathrm{N}$, arpack:: which:: largest_magnitude, nev, tol, resid.data(), ncv, V.data (), ldv, iparam.data(), ipntr.data(), workd.data(), workl.data(), lworkl, info);

eigenvalues . resize (nev);

for (int $\mathrm{i}=0 ; \mathrm{i}<$ nev; $\mathrm{i}++)\}$

eigenvalues $(i)=d[i]$;

\}

eigenvectors. resize (N, nev);

for (int $\mathrm{j}=0 ; \mathrm{j}<\operatorname{nev} ; \mathrm{j}++)\{$

for (int $\mathrm{i}=0 ; \mathrm{i}<\mathrm{N} ; \mathrm{i}++)\}$ 
eigenvectors $(i, j)=z[j *(N+1)+i]$;

\}

\}

\} 


\section{Referências Bibliográficas}

[1] H Gemmeke and NV Ruiter. 3d ultrasound computer tomography for medical imaging. Nuclear Instruments and Methods in Physics Research Section A: Accelerators, Spectrometers, Detectors and Associated Equipment, 580(2):1057-1065, 2007.

[2] K Kirk Shung and M Zippuro. Ultrasonic transducers and arrays. IEEE Engineering in Medicine and Biology Magazine, 15(6):20-30, 1996.

[3] D.L. Logan. First Course in the Finite Element Method. Thomson, 2007.

[4] Thiago de Castro Martins, André Kubagawa Sato, Fernando Silva de Moura, Erick Dario León Bueno de Camargo, Olavo Luppi Silva, Talles Batista Rattis Santos, Zhanqi Zhao, Knut Möeller, Marcelo Brito Passos Amato, Jennifer L Mueller, et al. A review of electrical impedance tomography in lung applications: Theory and algorithms for absolute images. Annual Reviews in Control, 2019.

[5] Jari Kaipio and Erkki Somersalo. Statistical and computational inverse problems, volume 160. Springer Science \& Business Media, 2006.

[6] MR Bailey, VA Khokhlova, OA Sapozhnikov, SG Kargl, and LA Crum. Physical mechanisms of the therapeutic effect of ultrasound (a review). Acoustical Physics, 49(4):369-388, 2003.

[7] Thomas L Szabo. Diagnostic ultrasound imaging: inside out. Academic Press, 2004.

[8] L.E. Kinsler. Fundamentals of acoustics. Wiley, 2000.

[9] Igal Ladabaum, Xuecheng Jin, Hyongsok T Soh, Abdullah Atalar, and BT KhuriYakub. Surface micromachined capacitive ultrasonic transducers. IEEE transactions on ultrasonics, ferroelectrics, and frequency control, 45(3):678-690, 1998. 
[10] HG Goovaerts, HP Van Geijn, O Rompelman, R Mantel, and JM Swartjes. Recording fetal breathing movements with a passive transducer based on an inductive principle. Medical and Biological Engineering and Computing, 29(4):358-364, 1991.

[11] Qingshan Yao and Leif Bjorno. Broadband tonpilz underwater acoustic transducers based on multimode optimization. IEEE transactions on ultrasonics, ferroelectrics, and frequency control, 44(5):1060-1066, 1997.

[12] Marco Aurélio Brizzotti Andrade. Análise de materiais piezelétricos compósitos para aplicações em transdutores de ultra-som. Dissertação de mestrado, Escola Politécnica da Universidade de São Paulo, São Paulo, 2006.

[13] Franco Guzmán, Édiguer Enrique, Marco Aurélio Brizzotti Andrade, Jimmy Ernesto San Miguel Medina, Flávio Buiochi, and Júlio Cezar Adamowski. Determination of the acoustic properties of tungsten/epoxy and tungsten/polyurethane composites using ultrasonic transmission technique. COBEM 2005: proceedings, 2005.

[14] TE Gómez Álvarez-Arenas. Acoustic impedance matching of piezoelectric transducers to the air. IEEE transactions on ultrasonics, ferroelectrics, and frequency control, 51(5):624-633, 2004.

[15] W Desmet and D Vandepitte. Finite element modeling for acoustics. Lecture Notes of the ISAAC21 Course. KU Leuven, Leuven, Belgium, 4:22-25, 2010.

[16] Holly Moore. MATLAB for Engineers. Pearson Prentice Hall, 2007.

[17] Qing-Huo Liu and Jianping Tao. The perfectly matched layer for acoustic waves in absorptive media. The Journal of the Acoustical Society of America, 102(4):2072$2082,1997$.

[18] Leonard Meirovitch. Computational methods in structural dynamics, volume 5. Springer Science \& Business Media, 1980.

[19] Timoteo Francisco de Oliveira. Transdutores de ultrassom multielementos lineares flexíveis com sensor de curvatura para superfícies curvas. Tese de doutorado, Escola Politécnica da Universidade de São Paulo, São Paulo, 2015. 
[20] Model 5077PR User's Manual. Panametrics-NTD, 2005.

[21] Singiresu S Rao. The Finite Element Method in Engineering. Elsevier, 2010.

[22] Richard B Lehoucq, Danny C Sorensen, and Chao Yang. ARPACK users' guide: solution of large-scale eigenvalue problems with implicitly restarted Arnoldi methods, volume 6. Siam, 1998.

[23] Gaël Guennebaud, Benoît Jacob, et al. Eigen v3. http:/ / eigen.tuxfamily.org, 2010.

[24] Intel math kernel library. https://software.intel.com/en-us/mkl, 2018. 